\title{
Performance Evaluation of Dialed Number Recorders
}

\author{
Arnold G. Perrey \\ Barry A. Bell
}

U.S. DEPARTMENT OF COMMERCE Natlonal Instltute of standards and Tochnology

Electriclty Division

Caltheraburg, MD 20899

U.S. DEPARTMENT OF COMMERCE Robert A. Mosbacher, Secretary NATIONAL INSTTUTE OF STANDARDS AND TECHNOLOGY

John W. Lyons, Diroctor

100

.056 



\title{
NISTIR 4700 \\ For Official Use Only
}

\section{Performance Evaluation of Dialed Number Recorders}

\author{
Arnold G. Perrey \\ Barry A. Bell
}

U.S. DEPARTMENT OF COMMERCE National Instibute of Standards and Technology Electriclty Division

Calthorburg, MD 20899

October 1991

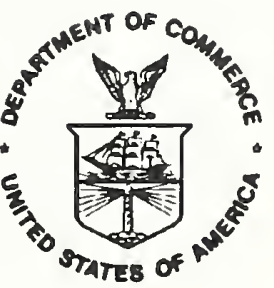

U.S. DEPARTMENT OF COMMERCE Robert A. Mosbacher, Secretary NATONAL INSTITUTE OF STANDARDS AND TECHMOLOGY

John W. Lyone, Director 

List of Figures. . . . . . . . . . . . . . . . . . iii

Abstract . . . . . . . . . . . . . . . . . . . 1

1. Introduction . . . . . . . . . . . . . . . . . . . . . . 1

2. Commonly Used Terms and Acronyms . . . . . . . . . . . . . . . . 3

3. Basic DNR Operational Considerations . . . . . . . . . . . . . . . . 4

4. Dual Tone Multifrequency (DTMF) Signaling . . . . . . . . . . . . 9

5. Brief Decription of the Five DNR Units Tested . . . . . . . . . . . 12

6. Description of the DNR Evaluation Tests . . . . . . . . . . . . . . 15

6.1 Threshold Level Tests . . . . . . . . . . . . . . . 15

6.2 Ring Level and Ring Frequency Tests . . . . . . . . . . . . . 17

6.3 Pulsed Dialing Tests . . . . . . . . . . . . . . . . . . . 19

6.4 DTMF Signal Tests . . . . . . . . . . . . . . . . . . . 22

6.5 Measurement of Input Impedance and Input Resistance . . . . . 25

6.6 Measurement of Audio Circuit Parameters . . . . . . . . . . . 27

6.7 MF Signal Tests . . . . . . . . . . . . . . . . 28

7. Summary . . . . . . . . . . . . . . . . . . . . 31

8. Acknowledgements . . . . . . . . . . . . . . . . . 31

9. References . . . . . . . . . . . . . . . . 32

Appendix A - Tables Comparing DNR Input Parameters and Audio Circuit Test Data . . . . . . . . . . . . 33

Appendix B - Test Data on all Five DNR Units . . . . . . . . . . . . . . 36

Appendix C - Description of Test Equipment . . . . . . . . . . . . . . . 69 



\section{List of Figures}

page

Figure 1. Telephone activity signals . . . . . . . . . . . . . . . . . 4

Figure 2. Basic operating components of a DNR . . . . . . . . . . . . 5

Figure 3. Composite block diagram of the input and detector/decoder circuitry of a DNR . . . . . . . . . . . . . . . . . . . 6

Figure 4. Schematic representation of a DNR and its target line interface 7

Figure 5. Frequency domain representation of the two frequency components specified for the DTMF signal used for the 非 symbol . . . . . 10

Figure 6. Time domain representation of the DTMF signal for the 非 symbol 11

Figure 7. Transition from the On-Hook Voltage $\left(V_{H}\right)$ to the Off-Hook Voltage $\left(\mathrm{V}_{\mathrm{OH}}\right)$ and the Threshold Voltage $\left(\mathrm{V}_{\mathrm{TH}}\right)$ adjusted to the preferred level.................... 15

Figure 8. Valid and invalid off-hook detection regions determined by the adjusted Threshold Voltage $\left(V_{T H}\right)$ settings and the On-Hook Voltage $\left(V_{H}\right)$ at the subscriber's line terminals . . . . . . 16

Figure 9. Test setup for ring level and ring frequency tests . . . . . 18

Figure 10. Block diagram of test setup for dial pulse characterization. 19

Figure 11. Automatic and rotary dial pulses for the digit "2" . . . . 20

Figure 12. Automatic and rotary dial pulses for the digit "0" . . . . 21

Figure 13. Block diagram of test setup for DTMF and MF sensitivity tests 23

Figure 14. Graphic representation of DTMF level and frequency tolerances 24

Figure 15. Block diagram of test setup for input impedance and input resistance measurement . . . . . . . . . . . . . . 26

Figure 16. Block diagram of test circuit for frequency response and automatic gain control measurement . . . . . . . . . . 27

Figure 17. Frequency domain representation of frequency components for the MF signal, Q . . . . . . . . . . . . . . 29

Figure 18. Test fixture used for DTMF and MF signal tests . . . . . . . 74 


\title{
Performance Evaluation of Dialed Number Recorders
}

\author{
Arnold G. Perrey and Barry A. Bell \\ Electricity Division \\ National Institute of Standards and Technology \\ Gaithersburg, MD 20899
}

\section{Abstract}

Dialed number recorders (DNRs) are used by local law enforcement agencies and by various federal agencies in order to prevent communication fraud as well as other violations of federal, state, and regional laws. This report describes methods and procedures used for testing the performance of DNRs with ordinary laboratory-type test equipment, i.e., without using sophisticated telephonetype test equipment. Five such DNRs were tested in order to measure their operational characteristics, which are given in this report.

Key words: communication; detection; dialed number recorder; recording; interception; pen register; signaling; security; monitoring.

\section{Introduction}

Several manufacturers in the United States and Canada make dialed number recorders (DNRs) that are used extensively by law enforcement agencies of both countries. The basic operating function of the DNR is to monitor the activity on a targeted subscriber's telephone. The DNR begins to operate as soon as the handset on a telephone receiver is lifted from its cradle; the monitoring DNR detects an off-hook condition and registers the date and time of the event, and an outgoing dialed number is displayed and recorded. After termination of the connection, the DNR records the duration of the communication and also registers the time the handset was returned to the cradle.

Older DNRs, known as pen registers, were designed and constructed to register dialed numbers that were transmitted using low frequency dc current pulses produced by a rotary dialing mechanism (typically 8 to 12 pulses per second). Generally, pen registers operated over a limited pulse rate, and could not cope with speed dialing. The older pen registers were mainly electromechanical devices that recorded the line activity on a paper tape recorder, and the interpretation of the recording was left to the investigator. However, pen registers have changed in many ways: a modern DNR can intercept virtually all the signaling modes used by various communication carriers, as well as monitor the audio signals that are present on an established line interception. DNRs today can be used to intercept different transmission rates and signals, and are very reliable since their design concept is based on new electronic circuit technology and new signal processing techniques.

Typically, DNR electronics are designed around the use of microprocessors, in 
conjunction with read-only-memory (ROM) and random-access-memory (RAM) circuits that are digitally controlled in order to record and store information retrieved from a targeted telephone subscriber line. DNRs feature a wide range of capabilities such as built-in receivers for detecting Dual Tone Multifrequency (DTMF) signaling, 2100 and $2600 \mathrm{~Hz}$ tone detectors for use with isolation units (loop extenders), and the circuitry needed to provide interception on cellular communication systems. Also, calling number identification or CNI, otherwise known as caller identification (CID), can be added as an option; call progress tone detection circuitry is also available when needed or required.

At the request of the National Institute of Justice (NIJ), the National Institute of Standards and Technology (NIST), through its Office of Law Enforcement Standards (OLES), the Electricity Division has evaluated several differing DNRs in accordance with a generic test plan developed by the Electricity Division. Four manufacturers of DNRs were contacted, and a total of five DNRs were received for testing and evaluation ${ }^{1}$ The basic operational characteristics of the DNRs were tested, e.g., detection of threshold level, detection of rotary dialed pulses and pushbutton ("touch tone") ${ }^{2}$ signals, and the recognition of ring signals. Other parameters were measured, such as ac input impedance, and the amplitude response, signal to noise ratio (S/R), and total harmonic distortion (THD) of the audio circuitry.

1 In order to describe the systems and tests discussed in this report adequately, commercial equipment and instruments are identified by manufacturer's name and/or model number. In no case does such identification imply recommendation or endorsement by the National Institute of Standards and Technology, the National Institute of Justice, or any other government agency.

2 Touch-Tone is a registered trademark of AT\&T 


\section{Commonly Used Terms and Acronyms}

AGC - Automatic gain control; a method of automatically obtaining a substantially constant output signal level from an amplifier circuit over the nominal dynamic range of the input signal.

$\mathrm{dB} \quad$ - Decibel; one tenth of a Bel, the number decibels denoting the ratio of two levels of power being ten times the logarithm to the base of 10 of this ratio, i.e., $d B=10 \log _{10}\left(P_{x} / P_{r e f}\right)$

$\mathrm{dBm}$ - A signal level in decibels referenced to $1 \mathrm{~mW}$, i.e., $P_{r e f}=1 \mathrm{~mW}$.

$\mathrm{dBV} \quad-\mathrm{A} d \mathrm{~B}$ signal level denoting the ratio of two levels of voltage, i.e., $d B V=20 \log _{10}\left(V_{x} / V_{\text {Ief }}\right)$ where $V_{\text {ref }}=1 \mathrm{~V}$.

DTMF - Dual tone multifrequency; commonly known as "touch tone" dialing, each pushbutton, when depressed, activates oscillators that generate two discrete frequencies, e.g., for the digit 5 the frequencies are $770 \mathrm{~Hz}$ and $1330 \mathrm{~Hz}$.

DNR - Dialed number recorder; an electronic apparatus used to monitor the activities (off-hook, dialing, conversation, on-hook) on a targeted subscriber's telephone line. It documents (records and displays) events by registering date, time, and telephone number dialed, and also identifies incoming calls.

FSK - Frequency shift key; the form of frequency modulation in which the modulating wave shifts the output frequency between or among predetermined values, and the wave has no phase discontinuity.

MF - Multifrequency; keypad generated frequency pairs similar to but not compatible with DTMF generated frequencies. For the digit 5 , for instance, the frequencies are $900 \mathrm{~Hz}$ and $1300 \mathrm{~Hz}$. Multifrequency signaling is used for central office (CO) and trunk signaling and communication purposes.

S/N, SNR - Signal-to-noise ratio; a measure of signal range available above the inherent noise level, for example, in an amplifier.

SF - Single frequency; a $2600 \mathrm{~Hz}$ tone used to indicate an idle line condition when there is no activity on an interconnection network.

LE - Loop extender; also called an isolation unit (IU), used to a) provide extra secure isolation between the target line and the monitoring DNR, and b) to connect the monitoring DNR to the target line via long distance telephone lines (leased telephone lines).

ON-HOOK/ - The conditions that mechanically or electrically produce a change OFF-HOOK in the current supplied by the central office dc circuits, thus changing the level of the dc voltage that appears on the line at the subscriber's telephone set. 
The typical signal activity on a telephone line to be monitored by a DNR is illustrated in figure 1 , where the signal voltage is displayed versus time. The starting signal at (1) is the quiescent on-hook dc voltage level of approximately 48 volts that is produced by the dc voltage supply (batteries) used at the central office (CO). The actual on-hook level is dependent on the dc supply level used and, to some extent, the distance from the central office. Signal (2) shows the 40 to 130 volt (rms) low frequency (16 to $67 \mathrm{~Hz}$ ) ac voltage that normally is used to activate the ring circuit in a telephone set. At (3) is shown the dc voltage level that occurs when the telephone receiver (handset) is taken off-hook. The actual off-hook level is dependent. on the central dc supply voltage, the distance from the central office, and the dc resistance of the targeted telephone. The signal at (4) represents the pulsed dc waveform on the line due to a rotary dialing or other type of circuit breaker mechanism prevalent in telephones prior to the late 1970s. With the advent of push-button dialing, the signal at (5) illustrates the various kinds of audio multitone signals that now occur on the line for ringing, dialing, etc. Superimposed on the off-hook level as well, of course, is the complex audio frequency signal that may also need to be recorded.

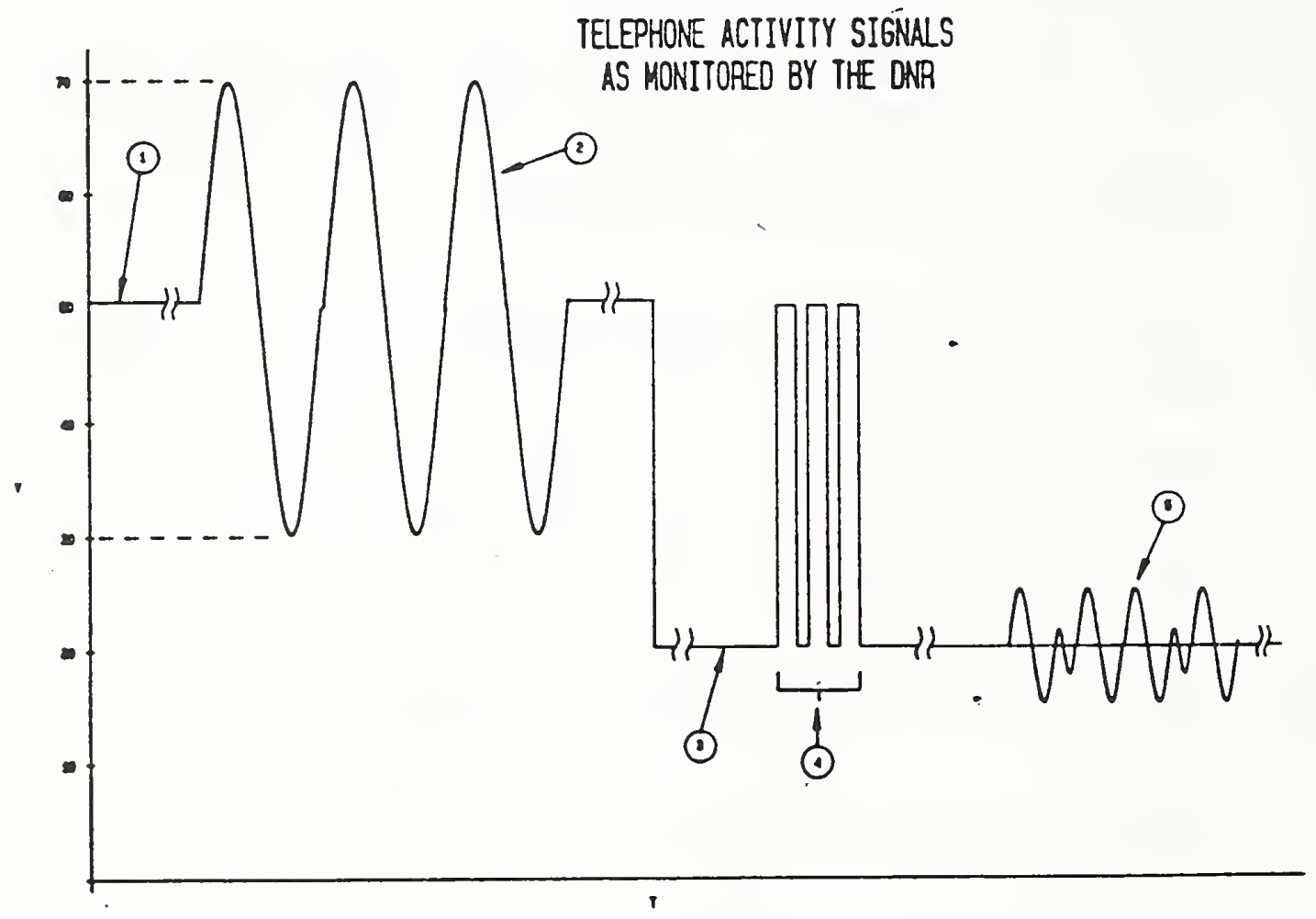

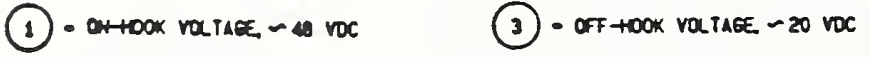

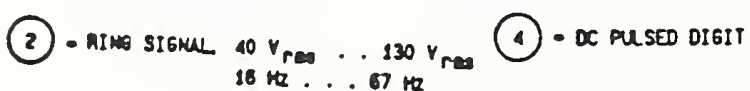

Figure 1. Telephone activity signals 
A simple block diagram, figure 2, shows some of the basic features of a DNR. The various versions of DNRs presently available provide from one to six channels for the incoming target lines. Most DNR units are designed to operate from either external or internal power supplies. Internally, the electronics of DNRs today are generally designed using microprocessors, and contain the required control circuitry such as real-time clocks, RAM, and ROM circuits. A keyboard is used to set the various parameters using menus shown on a display. From the connected target lines the analog input signals are digitized and the information decoded to provide numerical data, e.g., dialed telephone numbers, which are then stored and/or recorded. Calls or "events" are marked for their time and date occurances and added to the called telephone number record. Typically, the DNR can be interfaced with computers, printers, and terminals as required. Also, programable audio circuits are provided for on-line monitoring using headphones and/or for delayed listening using magnetic tape recorders.

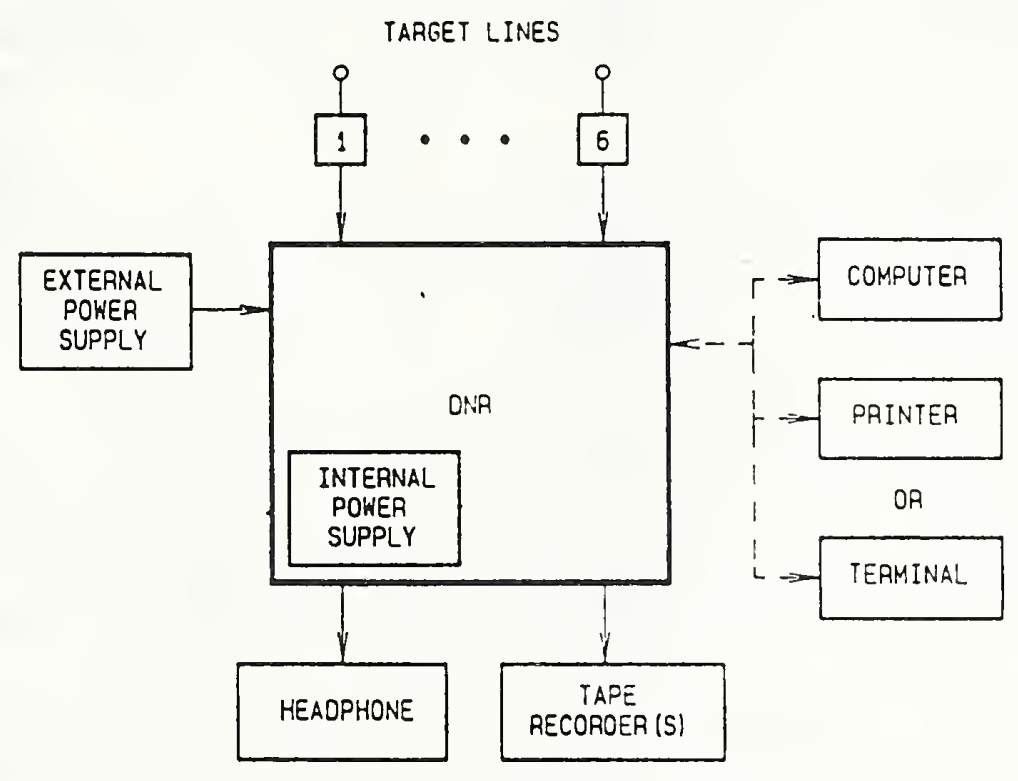

Figure 2. Basic operating components of a DNR

Shown in figure 3 is a block diagram of a typical one channel input circuit for a DNR with its various detector, decoder, and encoder circuits. On the left hand side of the diagram is indicated the isolation circuitry which, by magnetic or optical coupling, separates the voltages and currents of the target telephone line from the electronic circuits of the monitoring DNR. The output from the isolation circuit connects in parallel to various detector circuits and to an audio input amplifier. For communicating the detection information and data to an external display, printer, or computer (for further data processing), the decoded data is collected by a ROM-based code converter and sent through an asynchronous RS-232 transmitter and line driver. Typically, all of these circuits can be activated, or deactivated, through keyboard-selectable menus, which in turn program the DNR for certain modes of operation. 


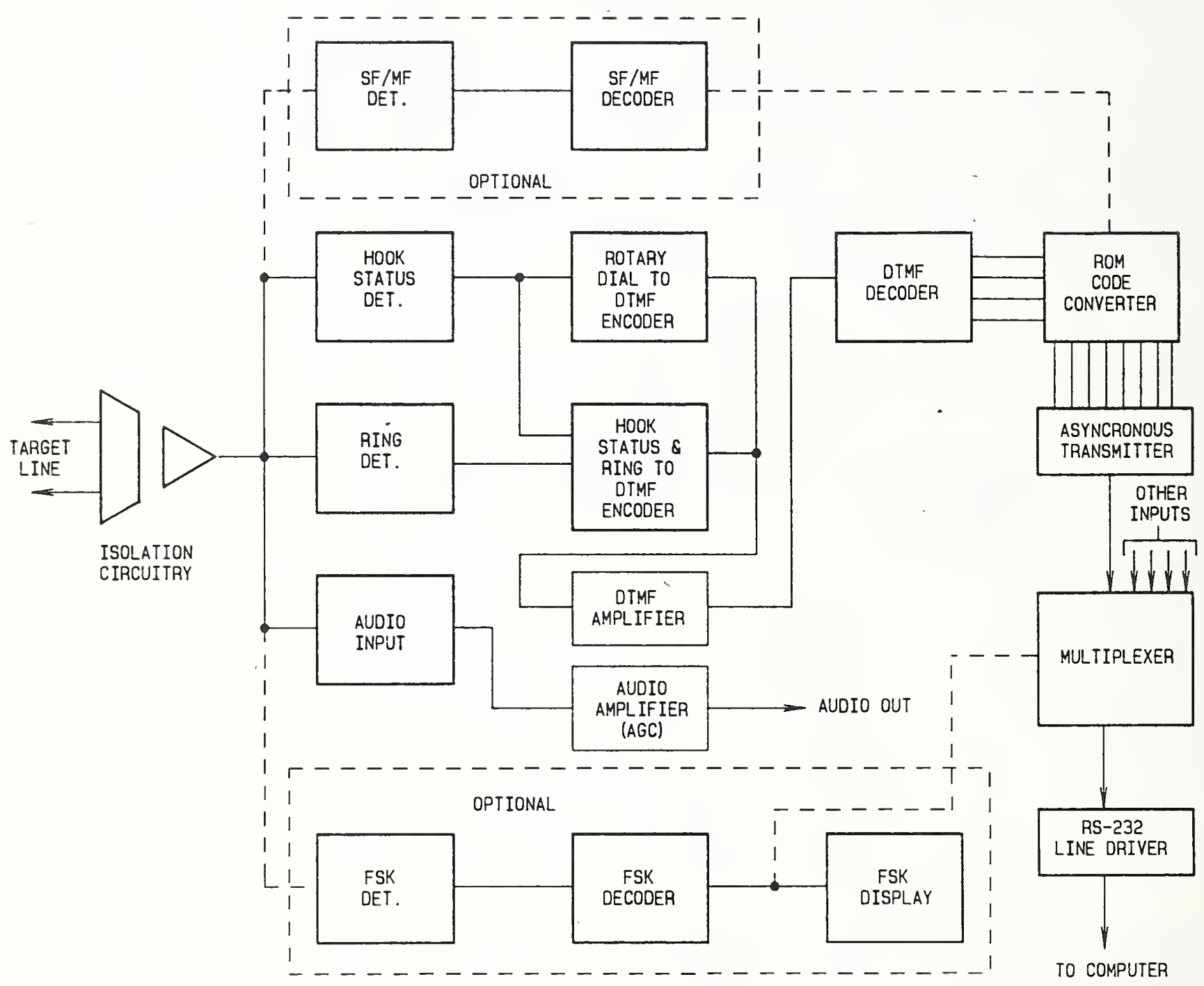

Figure 3. Composite block diagram of the input and detector/decoder circuitry of a DNR 


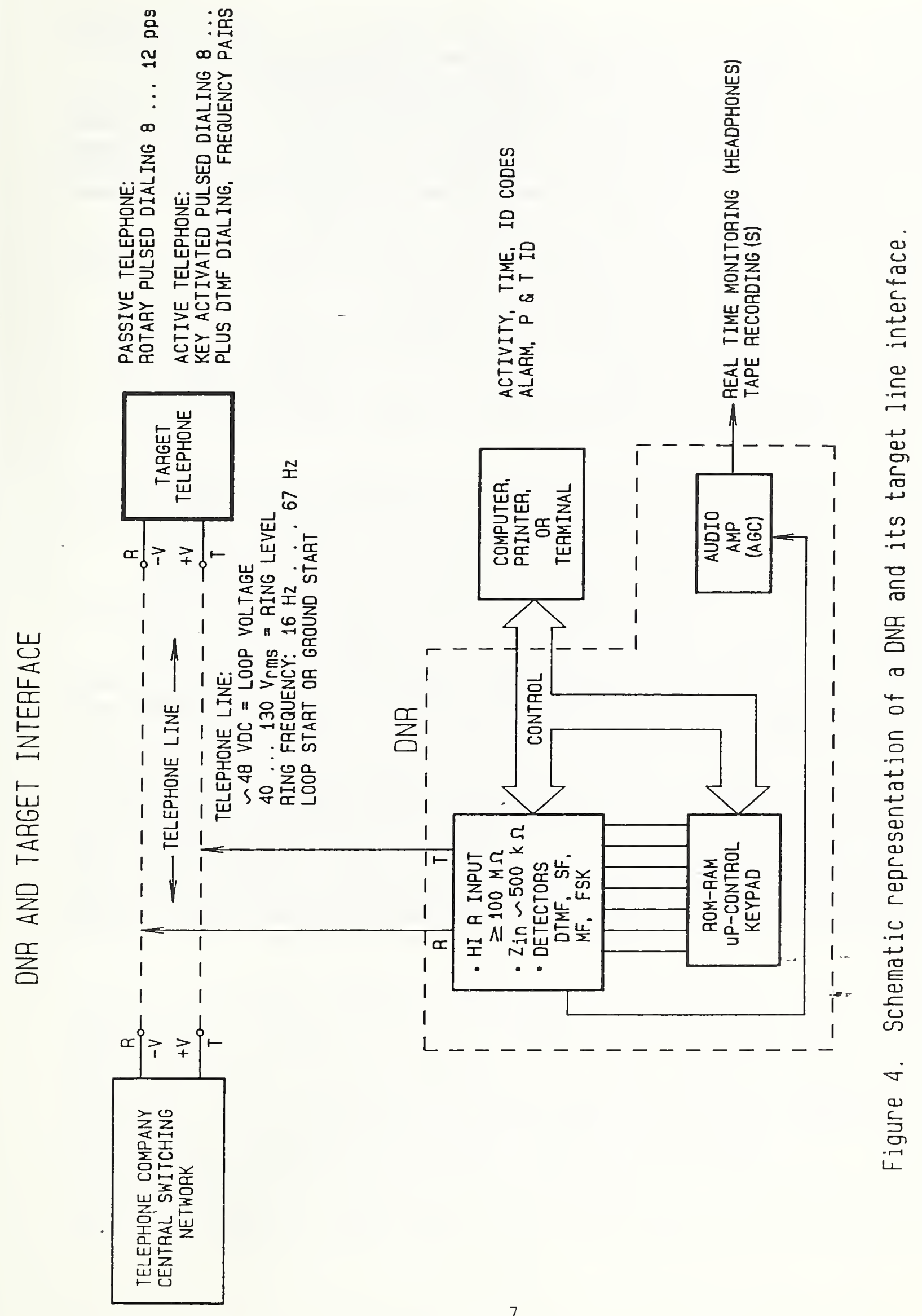


In figure 4 is shown more detail on how a DNR connects to a targeted telephone subscriber. Ordinarily, a telephone line from the telephone company central switching network ( $\mathrm{CO}$ ) connects the subscriber's telephone set to the switching system, as shown. The terminals labeled $\mathrm{R}$ and $\mathrm{T}$ are the "ring" and "tip" connections that supply the $-\mathrm{V}$ and $+\mathrm{V}$ dc loop voltage $(\sim 48 \mathrm{~V})$ from the CO. The telephone itself contains a ringer circuit and the electronics needed for sending out either pulsed dc or DTMF signals. It can be a passive type device ( $L, C, R$ circuitry plus transducers and mechanical components like rotary dial and hook switch) or an active type device (electronic circuitry, amplifiers, DTMF encoders/decoders, and ring converters plus dc pulse generators). The DNR can be connected to the target telephone line at various locations, such as distribution panels, routing panels, or at the central switching network itself. The high input resistance/impedance isolation circuitry that "bridges" across the target telephone line assures the nondetectability of the DNR, since the load currents of the input stage are in the range of 1 to 100 microamperes. Activity on the telephone line is then detected, provided the operator has properly adjusted the DNR for the local operating parameters: threshold level, DTMF detector sensitivity, etc.

Trunk-line signaling, if required, also can be detected using a DNR. This operation requires that the DNR be equipped with multifrequency (MF) decoders, since trunk-line signaling utilizes frequencies different from those used for pulse and DTMF dialing on local telephone lines. In addition, single frequency (SF) signaling can be detected if the DNR is equipped with an appropriate detector; single frequency signaling is used when additional isolation circuits or "loop extenders" are used. Loop extenders are added to the DNR system when the target telephone is at a remote location and long connection lines are required to interface with the DNR. However, many operators of DNRs prefer the general use of loop extenders since they provide protection against inadvertent short circuits between the monitoring DNR and the target telephone subscriber line.

Another important detection parameter is to identify frequency shift keying (FSK) transmission to the target telephone. The FSK operation, otherwise known as caller identification (CID), can be recorded by a DNR when an FSK detection circuit is added to the system, shown as an option in figure 3 . In this case the DNR will record the date, time, and caller telephone number, and add the information to the target line activity record. All of the acquired data are usually stored temporarily by the DNR in its internal memory, and can be displayed on an external computer terminal or on a printer. 


\section{Dual Tone Multifrequency (DTMF) Signaling}

The DTMF dialing signal is composed of two sinusoidal waveforms at different frequencies (or "tones") in the audio frequency range, which are used to represent each character to be transmitted from a telephone pushbutton keypad. The following table gives the pair of nominal frequencies that are used to generate the DTMF digits 1 through 0 plus * and 非 [1]:

\section{Table 1}

Frequency in Hertz

\begin{tabular}{|c|c|c|c|c|c|c|}
\hline Symbol & 697 & 770 & 852 & 941 & 1209 & 1336 \\
\hline 1 & $\mathrm{x}$ & & & & $x$ & \\
\hline 2 & $\mathrm{x}$ & & & & & $\mathrm{x}$ \\
\hline 3 & $\mathrm{x}$ & & & & & \\
\hline 4 & & $\mathrm{x}$ & & & $\mathrm{x}$ & \\
\hline 5 & & $x$ & & & & $\mathrm{x}$ \\
\hline 6 & & $\mathrm{x}$ & & & & \\
\hline 7 & & & $\mathrm{x}$ & & $\mathrm{x}$ & \\
\hline 8 & & & $\mathrm{x}$ & & & $\mathrm{x}$ \\
\hline 9 & & & $\mathrm{x}$ & & & \\
\hline$*$ & & & & $x$ & $\mathrm{x}$ & \\
\hline 0 & & & & $\mathrm{x}$ & & $x$ \\
\hline 非 & & & & $x$ & & \\
\hline
\end{tabular}

The maximum difference in levels between the two frequency components must not exceed $4 \mathrm{~dB}$ and the level of the high frequency component should equal or exceed that of the low frequency component. The two frequency components in the DTMF signal are also specified to have maximum and minimum amplitude levels that depend on how the telephone line is powered. When powered by the Co-supplied loop current, these amplitude levels depend on the loop current used by the telephone and can vary from a maximum of $+4.0 \mathrm{dBm}(1.23 \mathrm{~V})$ to a minimum of $-12.0 \mathrm{dBm}(196 \mathrm{mV})$ for the high frequency component and $-14.0 \mathrm{dBm}$ (155 mV) for the low frequency component. When powered by a local power source, the maximum is $+2.0 \mathrm{dBm}(976 \mathrm{mV})$ and the respective minimums are $-8.0 \mathrm{dBm}(309 \mathrm{mV})$ and $-10.0 \mathrm{dBm}(245 \mathrm{mV})$.

In order to determine a nominal amplitude level to be used for the high and low-frequency components of the DTMF signals, measurements were made on these signals from a standard "touch tone" keypad and on the DTMF signals generated from a commercial electronic telephone set. These levels were found to be in the range of -6.8 to $-8.3 \mathrm{dBm}$ for the low frequency components, and in the range of -4.5 to $-6.2 \mathrm{dBm}$ for the high frequency components. Therefore, settings of $-6 \mathrm{dBm}$ and $-8 \mathrm{dBm}$ were used for the low and high frequency components when generating the nominal levels of DTMF signals.

Besides the frequency and amplitude characteristics for each symbol in a DTMF signal, the composite signal occurs over a finite time or in a "tone burst," 
lasting for a minimum of $50 \mathrm{~ms}$ [2]. Consequently, in testing a DNR for its ability to detect DTMF signals, a maximum digit or symbol recognition time is required by the DNR in order to recognize a minimum DTMF tone burst duration of the dialed DTMF digit or symbol. Typically, the nominal recognition time (valid signal duration) is in the range of $30 \mathrm{~ms} \pm 10 \mathrm{~ms}$.

The photograph given in figure 5 shows the frequency domain representation of

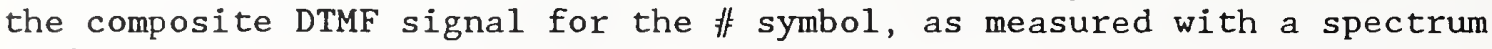
analyzer, consisting of the low frequency component of $941 \mathrm{~Hz}$ and the high frequency component of $1477 \mathrm{~Hz}$. Notice that the vertical amplitude of the high frequency component $(\sim 390 \mathrm{mV}$ or $\sim-6 \mathrm{dBm})$ is larger than the low frequency component $(\sim 300 \mathrm{mV}$ or $\sim-8.2 \mathrm{dBm})$, and their magnitudes differ, therefore, by about $2 \mathrm{~dB}$.

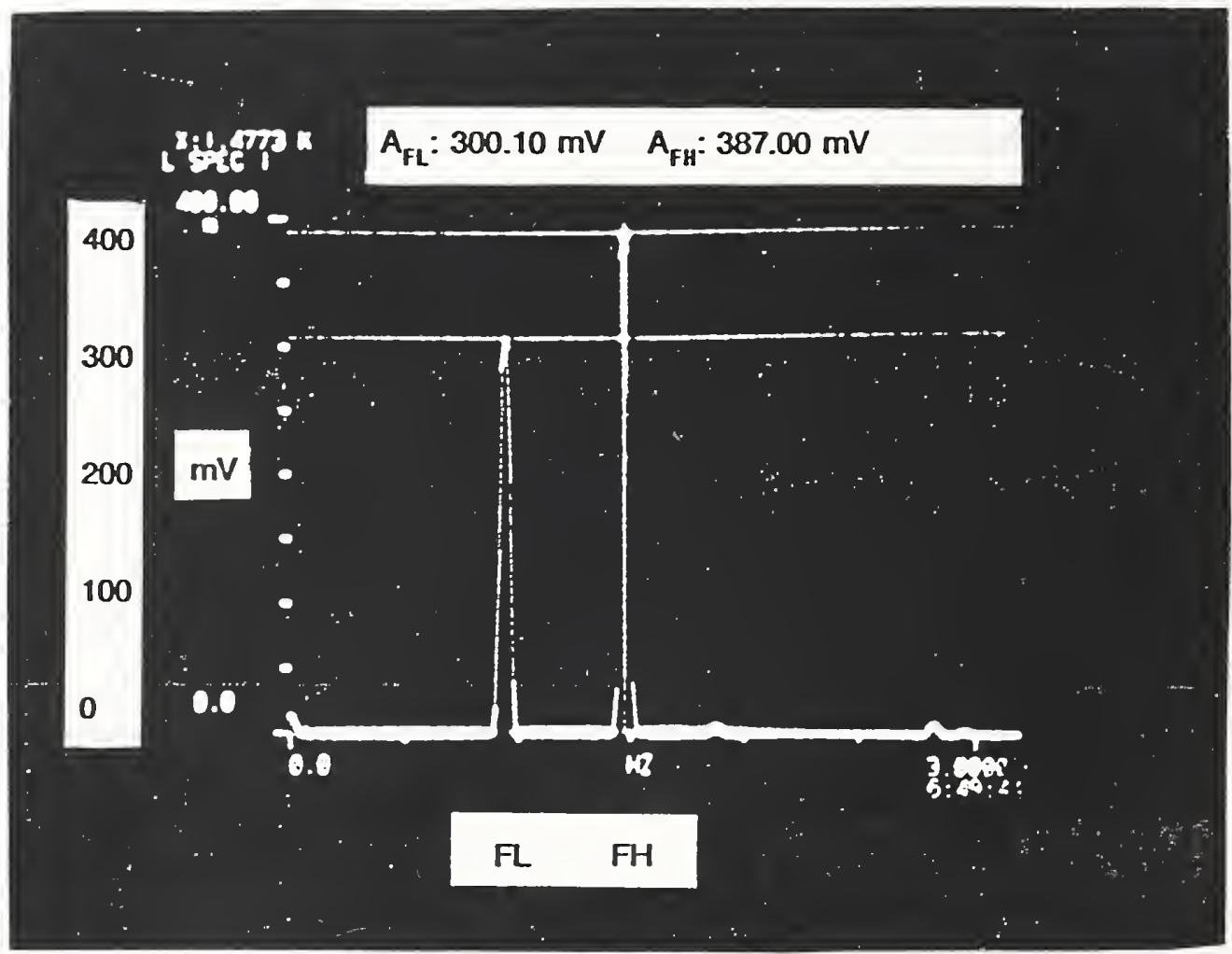

Figure 5. Frequency domain representation of the two frequency components specified for the DTMF signal used for the 非 symbol

The corresponding time domain waveform for the DTMF signal for the 非 symbol, as displayed by an oscilloscope, is shown in figure 6 . Since the two frequency components are not harmonically related, the phase relationship between them is constantly changing. Thus, the composite signal has the nonperiodic-looking waveform characteristic seen in the oscilloscope trace. 


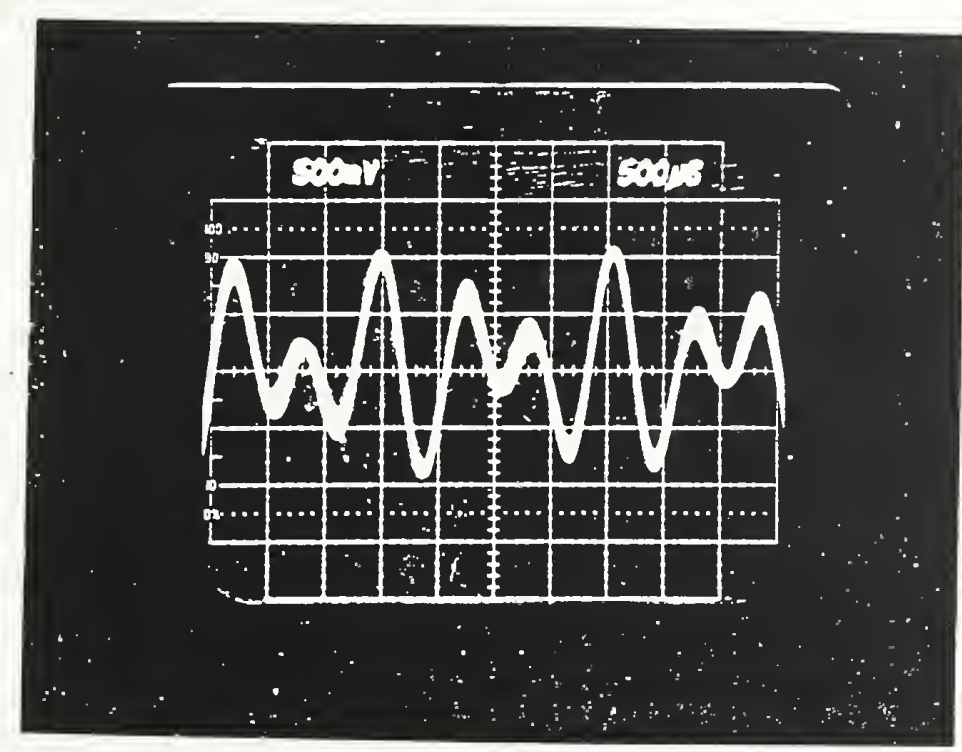

Figure 6. Time domain representation of the DTMF signal for the \#⿰ symbol 
5. Brief Decription of the Five DNR Units Tested

The DNRs received for testing were designated by numbers 1 through 5 and were tested in the order they were received.

\section{Unit 非}

Unit 非 was a single line DNR, capable of monitoring one through five target lines if equipped to do so. This unit can be an effective central office telephone monitoring system, and can provide off-line down loading of the data to a separate computer for analysis. The unit provides for menu-driven programming and operation, and there are no special programming code requirements. All operating parameters like off-hook threshold level, for instance, are keypad adjustable, and no hardware adjustments are required. This DNR provides two RS-232 output ports that allow connection to external printers, computers and/or terminals for remote access of monitoring data. The unit also provides audio outputs for three tape recorders per line as well as the required tape recorder control circuitry. Also, audio monitoring is keypad controlled, and provides for manual or timed minimization of monitoring as well as for password-secured monitoring. The physical dimensions of this DNR are: $21.5 \times 22.8 \times 10.2 \mathrm{~cm}(8.5 \times 9.0 \times 4.0$ inches), and its weight is $2.2 \mathrm{~kg}(4.8 \mathrm{lb})$.

\section{Unit 非}

Unit 非 2 was submitted for testing as a fully equipped six line DNR. Most of the operational features are menu driven and keypad controlled; however, there are a number of switches and potentiometers that have to be set and/or trimmed in order to adjust the off-hook threshold level, dial-pulse rate, and some other modes of operation. All of the line input circuit boards are of identical design and can be interchanged if neccessary; each board provides for an individual audio output and associated tape recorder control circuit. With all six boards installed, this DNR is capable of intercepting the activities on six target lines simultaneously, as well as recording and storing the data for documentation and evaluation. This DNR identifies each telephone line in use and the telephone number dialed; the date and time of an outgoing call and the duration (elapsed time) of the call is recorded as well. The dialing mode, either rotary or DTMF, is also identified. Incoming calls are identified by the number of rings, and as to whether or not the call was answered. The initialization date and time of the call, as well as the elapsed time of the incoming call are identified and recorded. The physical configuration of this unit allows it to be used as either a desk top unit or, if required, as a rack mount unit. The physical dimensions of this unit are $43.8 \times 13.3 \times 32.4 \mathrm{~cm}(17.25 \times 5.25 \times 12.75$ inches $)$, and the weight of this unit is $10.4 \mathrm{~kg}(23 \mathrm{lb})$.

\section{Unit 非}

Unit 非 3 is a DNR of modular design, and consists of three components: a) a laptop type computer, b) a printer module, and c) the main telephone line detector/decoder and audio circuit module. The operational control and mode 
setting is keyboard controlled, and all target line activity is displayed on the computer screen and recorded on a floppy disc for automatic storage of all call data, which then can be uploaded to a fully computerized intelligence network. All outgoing numbers dialed on the monitored target line are printed along with off-hook and on-hook times, date, case number, and call sequence, if desired. Incoming calls, as detected, are identified by date, time, number of rings and answering status, and are recorded by the printer. In addition to being printed, the outgoing dialed number and other call data are displayed on the computer screen. This DNR provides for the interface of three tape rcorders for capturing dialed numbers, as well as appropriate voice communication if warranted by law. Also, $2100 \mathrm{~Hz}$ and "C" tones $(852 \mathrm{~Hz}+$ $1633 \mathrm{~Hz}$ ) detection circuits are provided for operation with isolation units (IUs) or loop extenders (LEs). The physical dimensions of this DNR are $50.8 \times 14.0 \times 22.7 \mathrm{~cm}(20 \times 5.5 \times 9.0$ inches $)$. The weight of this DNR, including carrying case, is $7.7 \mathrm{~kg}$ ( $17 \mathrm{lb})$.

\section{Unit 非}

Unit 非 4 is manufactured by the same company that produced unit 非 . Basically, this DNR is a single telephone line apparatus that can be expanded to five line operation by adding additional circuit boards to the basic master control and operating system. When so expanded, the DNR can simultaneously monitor five individual target telephone lines and record and store all activity data for review and evaluation at a later date. Dial pads are provided for each line in order to operate with LEs or slave units (remotely addressed and monitored by the DNR). Also, each target line input has its own integral $2100 \mathrm{~Hz}$ and "C" tones receiver, for operation with isolation units (IUs) or loop extenders (LEs). Each line connected by a slave unit can operate on a handshake basis if so desired. In the handshake mode, the slave unit signals the DNR on a timed basis regarding the functionality of the connection. In case of an interrupted connection, the DNR will automatically re-dial the slave monitor and reestablish the connection.

This DNR also uses a laptop type computer as its control and operating system, and displays all activity on its screen. A built-in floppy disc system provides for storage of all activity data. Audio documentation is provided by means of individually controlled tape recorder outputs from AGC-type amplifier circuits. The physical dimensions of this unit are $47 \times 20 \times 25 \mathrm{~cm}$ (18.5 $\mathrm{x}$ $8.0 \times 9.75$ inches), and its weight is $9 \mathrm{~kg}(20 \mathrm{lb})$.

\section{Unit 非}

Unit $\left.\right|^{5} 5$ is a microprocessor controlled DNR intended to be used to monitor a single target telephone line. A printed activity record plus an audio output with tape recorder control is provided to the user. Line activity information is documented by an integral printer, which prints the call records at the end of each call. A liquid crystal display is used to show the user the telephone line status and dialed numbers as they occur or as they have occured. Also provided are two serial data ports that output all call records to a computer, modem, or printer when programmed to do so. In general, this DNR is entirely keypad controlled; all operating parameters, such as off-hook threshold level adjustments, DTMF sensitivity levels, audible alarm setting, etc. are menu 
operated and keypad selectable. Headphones can be connected to an output jack located on the front panel for real time monitoring when authorized by law. The unit can be used for direct bridged operation as well as for LE mode applications. The physical dimensions of this DNR are $26.35 \times 15.24 \times 26.7 \mathrm{~cm}$ $(10.25 \times 6.0 \times 10.50$ inches). The weight of the unit is $5.85 \mathrm{~kg}(13.01 \mathrm{~b})$. 


\section{Description of the DNR Evaluation Tests}

The following paragraphs describe the tests performed on the five DNR units that were submitted for evaluation. The test conditions, test parameters, and test procedures conducted on all five systems were essentially identical.

\subsection{Threshold Level Tests}

One of the most important operating parameters tested was the off-hook voltage, its associated threshold voltage level, and the preferred adjustment of the threshold level. The means of adjusting the threshold level varies, depending on the design of the DNR, and the threshold level adjustment can be implemented by either mechanical or electronic control features. In general, a threshold voltage default setting of $40 \mathrm{~V}$ was found to be used by most manufacturers with the assumption that this setting satisfies most operational requirements. It should be noted, however, that the preferred (least sensitive to line level changes) threshold voltage level adjustment depends on the actual on-hook voltage that appears at the subscriber's connection terminals (which is dependent on the line voltage coming from the central office) and on the actual off-hook voltage (which depends orr the distance from the central office and on the type of telephone set used). Therefore, in order to establish a preferred threshold voltage level setting, figure 7 depicts a transition from the on-hook voltage, shown here as approximately $50 \mathrm{~V}$, to the off-hook voltage, shown as about $20 \mathrm{~V}$.

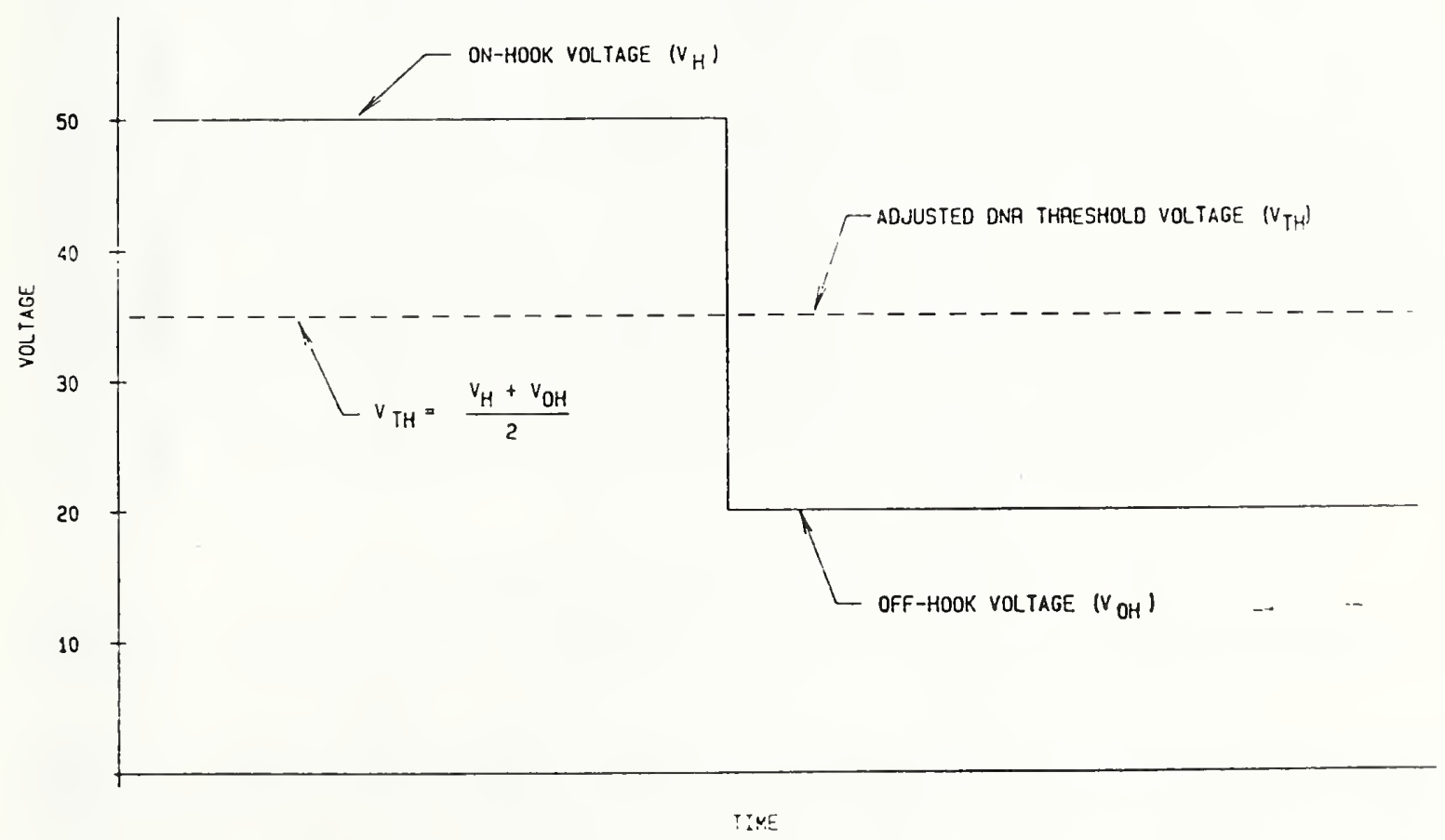

Figure 7. Transition from the On-Hook Voltage $\left(V_{H}\right)$ to the Off-Hook Voltage $\left(\mathrm{V}_{\mathrm{OH}}\right)$ and the Threshold Voltage $\left(\mathrm{V}_{\mathrm{IH}}\right)$ adjusted to the preferred level 


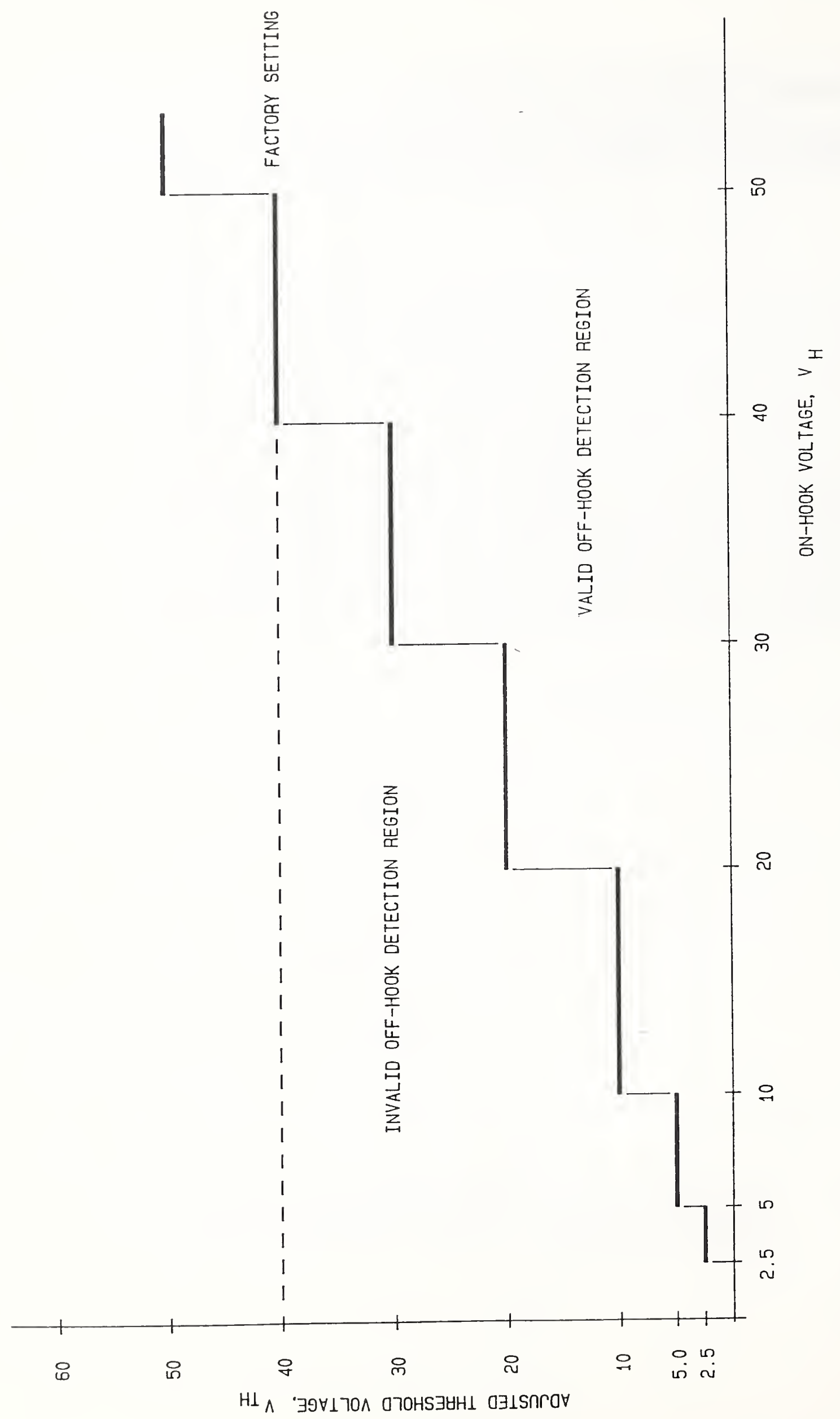


This illustration represents a voltage level change of about $30 \mathrm{~V}$, based on the loop current requirement (input resistance) of the particular telephone set. An accurate adjustment of the preferred setting for the threshold voltage, $V_{T B}$, should be preceeded by a voltage measurement that verifies the actual on-hook and off-hook voltage levels, $\mathrm{V}_{\mathrm{H}}$ and $\mathrm{V}_{\mathrm{OH}}$. By using these measured values, a simple computation of the average value of $\mathrm{V}_{\mathrm{H}}$ and $\mathrm{V}_{\mathrm{OH}}$ will establish the preferred value of the threshold level for the monitoring DNR. In this example it is about $35 \mathrm{~V}$.

The reason that the average value of the on-hook and off-hook voltages is considered to be the preferred or "optimum" level is that it represents a good tradeoff between a setting that is too near the on-hook voltage where noise on the line may cause an indication that the target phone is off-hook, even if it is not. On the other hand if the off-hook threshold level is too low, an actual off-hook condition may not be detected even when the phone is in use. Pulsed dialing detection is also affected by the threshold level: if the level is too high, rotary dialed digits may not be detected; when the threshold level is too low, the same digit may appear for every digit dialed. However, with normal telephone signal levels, there is a fairly wide region of settings for the threshold voltage over which a DNR will be able to perform its proper detection functions.

Figure 8 shows the valid and invalid off-hook detection regions, which depend on the adjusted threshold voltage and the on-hook voltage at the subscriber's line terminals. It can be seen that based on a nominal line (or on-hook) voltage of $50 \mathrm{~V}$, and a default threshold level setting by the factory of $40 \mathrm{~V}$, the valid off-hook detection region lies between 40 and 50 volts. For these evaluation tests, the line voltage was gradually lowered towards the preset threshold level in order to determine the valid detection limit for the $40 \mathrm{~V}$ default setting. Typically, when the lowered line voltage comes to within about $100 \mathrm{mV}$ of the $40 \mathrm{~V}$ setting, the DNR unit indicates, by various means, that a new threshold voltage setting is required. At that point during the testing, the threshold voltage setting was lowered until the invalid off-hook detection indication ceased to exist. The new threshold voltage setting for lower on-hook voltages was then that adjusted value. The remaining part of the characteristic was tested in the same manner, and the complete characteristic documented for each of the five DNRs submitted for testing (shown in Appendix B).

\subsection{Ring Level and Ring Frequency Tests}

In figure 9 is shown the setup used for the ring level and ring frequency tests on a DNR unit under test (UUT).

A loop voltage of about $48 \mathrm{~V}$ originates in the power supply, which acts as a substitute for the central office of a telephone network. Chokes $(\mathrm{L} \approx 2 \mathrm{H})$ are used to isolate the dc supply from the audio frequency signals. During this testing, the on-hook status was maintained and the line voltage used was about $48 \mathrm{~V}$. Capacitively coupled to the dc line was the ac voltage output from an amplifier, which was used to supply the various ring voltages to the telephone set (for detection by the DNR). The amplifier had a fixed gain of $32 \mathrm{~dB}$ (a factor of 40). For ring level adjustment purposes (and to prevent 


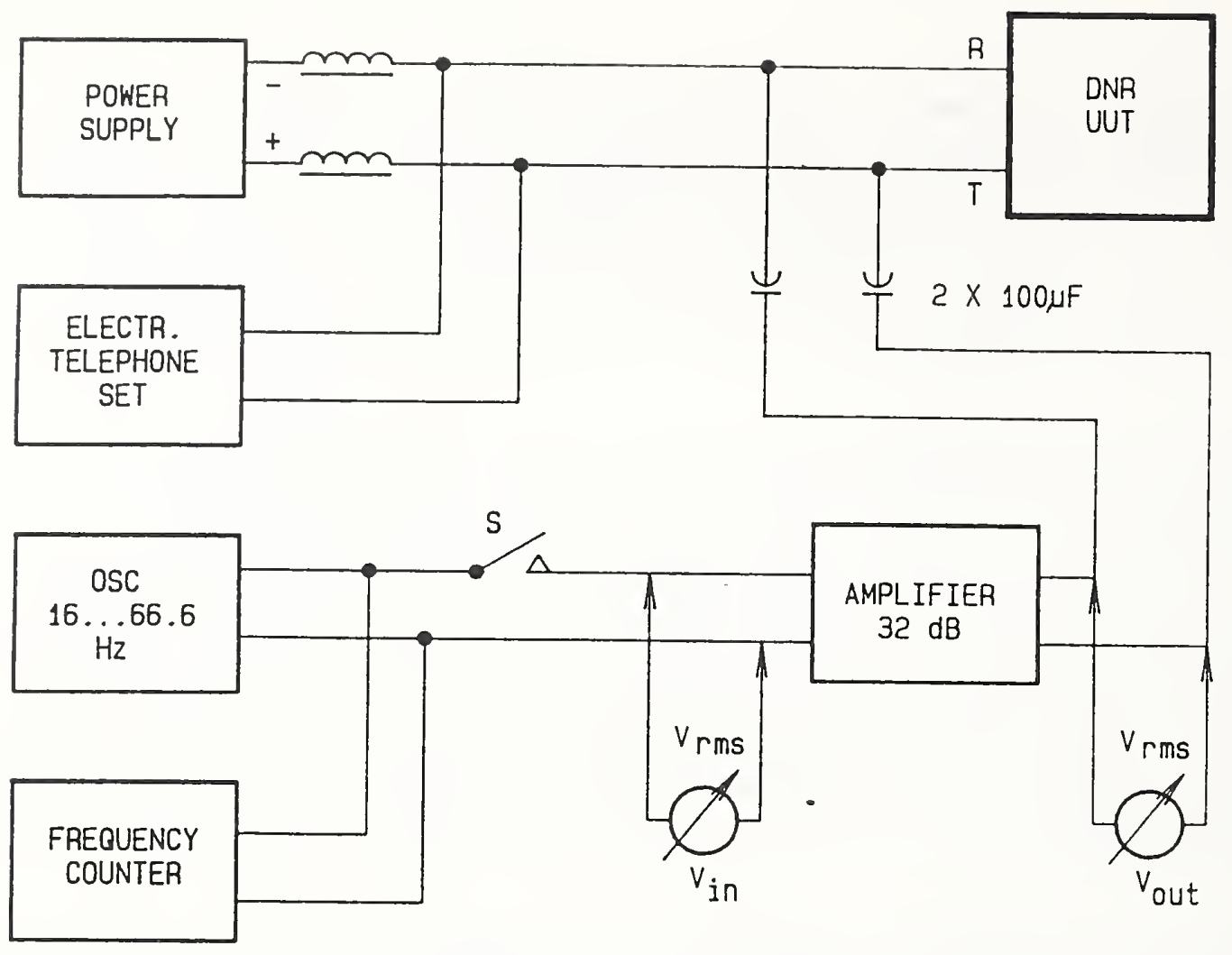

Figure 9. Test setup for ring level and ring frequency tests

inadvertant overloading of the amplifier), both the input and output signals of the amplifier were monitored by means of two rms-reading voltmeters. Ring voltages from $20 \mathrm{~V}$ through $130 \mathrm{~V}$ rms were used, and incremental adjustments within that range were made in $10 \mathrm{~V}$ steps. Also, there were seven discrete ring frequencies of $16.6,20,30,33,40,42$, and $66.6 \mathrm{~Hz}$ applied to the DNRs under test, i.e., each ring voltage level was tested with seven ring frequencies. The test frequencies were adjusted to be within 1 percent of the nominal frequency by means of a monitoring frequency counter. After any needed frequency adjustment, switch $S$ was closed and the audio oscillator output voltage adjusted to provide sufficient input signal to the amplifier to generate the appropriate ring voltage. For example, based on the gain factor of 40 , an input voltage of $3.25 \mathrm{~V}$ rms had to be provided by the audio oscillator for generating a required ring voltage of $130 \mathrm{~V}$ rms.

Following these various adjustments, switch $S$ was toggled in order to generate the ring bursts that activated the telephone ringer (or beeper) circuit. This signal also initiated ring detection by the DNR, which in turn recorded the date and time of the incoming call as well as the number of ringing events. In addition, the DNR identified the on-hook or off-hook condition of the telephone in order to record whether or not the call was answered. For each system tested, a table was made showing the response of the DNR to each frequency and voltage combination of the ring signal. Four of the five DNRs tested responded to all seven of the frequencies given above that were 
utilized for this test. These frequencies were chosen since they are used presently on party lines, where selective ringing alerts the various party line subscribers.

\section{6 . 3 Pulsed Dialing Tests}

The setup shown in figure 10 was used to functionally test a DNR UUT for its ability to detect the dialed pulses generated by rotary dial pulsers and automatic dial pulsers in electronic telephone sets. During the testing the dialed-pulse speed discrimination circuits of the DNR were checked for their ability to detect both the rotary dial pulse repetition ( 8 through 12 pps) and automatic dial pulse repetition ranges ( 8 through 25 pps) [1,3], although an attempt was not made to evaluate the DNR UUT throughout the allowed range of pulse repetition rates. Since the technology for dialing is moving almost exclusively towards pulsed tone methods (DTMF, MF, etc.), the need to thoroughly examine performance for pulsed dc dialing was not felt to be necessary. However, the DNRs were tested for pulse rates of 12.5 pps, rotary dial, and -18 pps, electronic dialing, over a range of on-hook and threshold voltage levels.

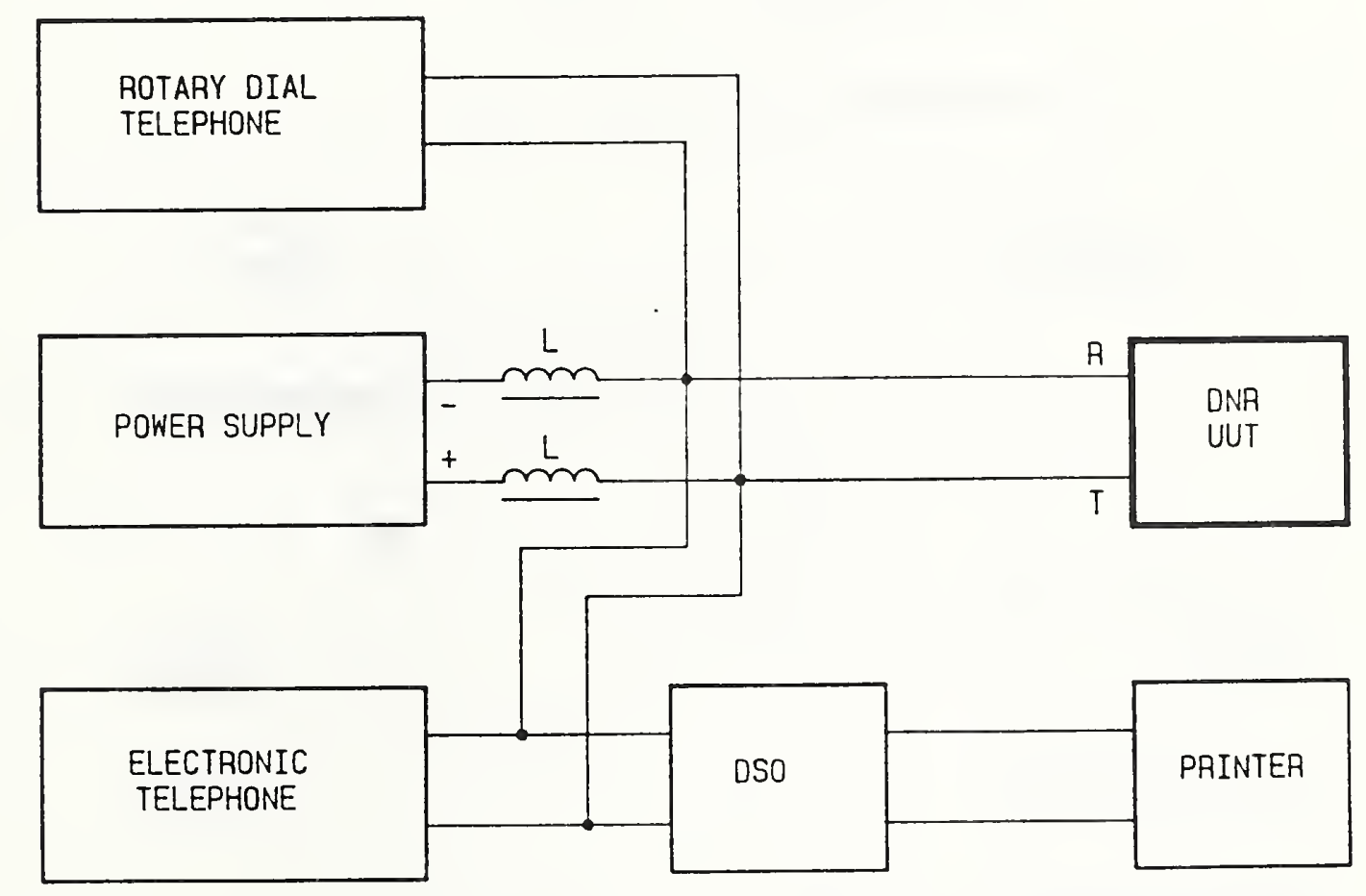

Figure 10. Block diagram of test setup for dialed pulse characterization 
to owaiting triager

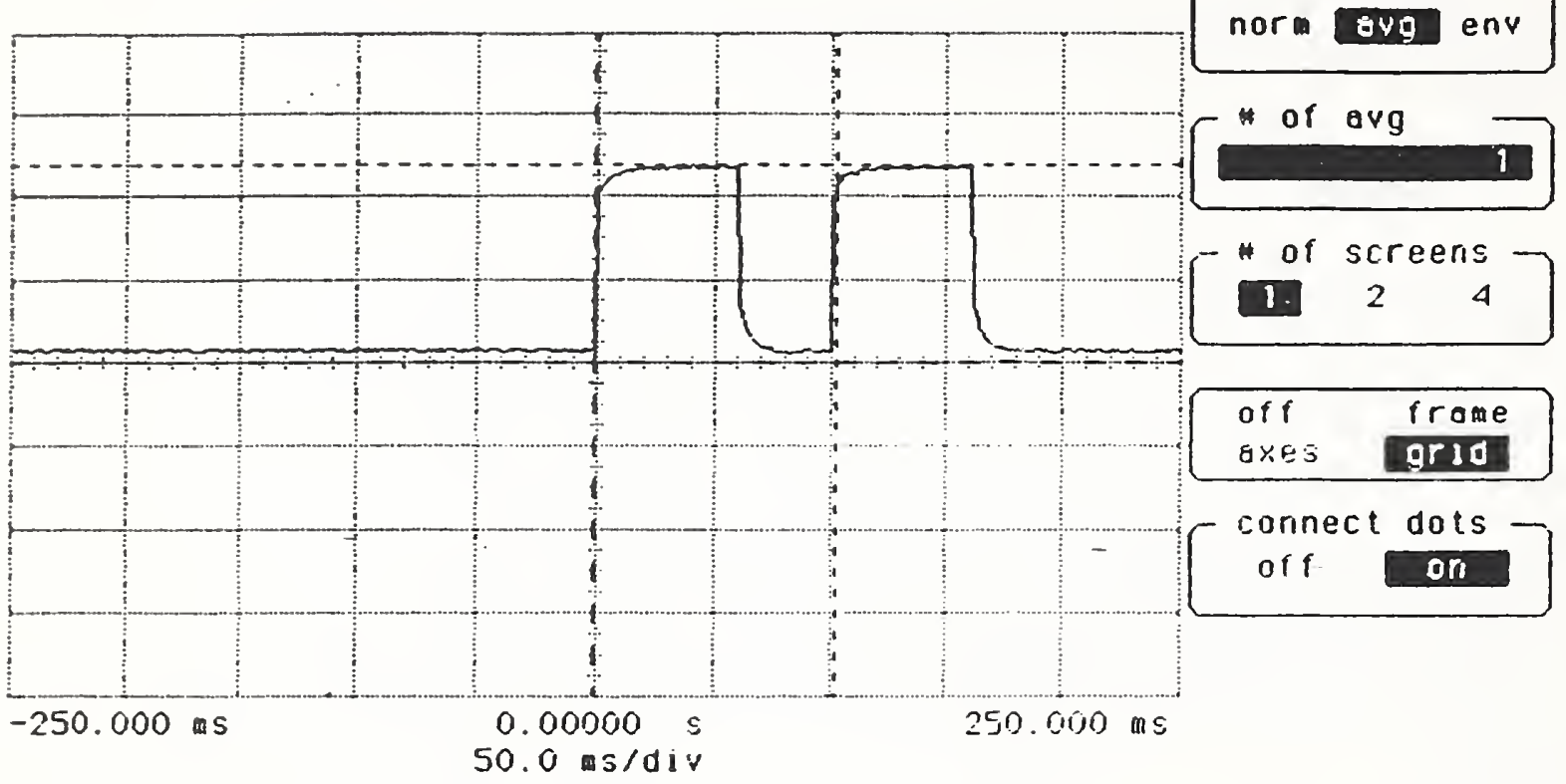

duty cycle( 1$) \quad 60.396 \%$

Rotary pulse Dialer: Digit 2 - Duty Cycle.
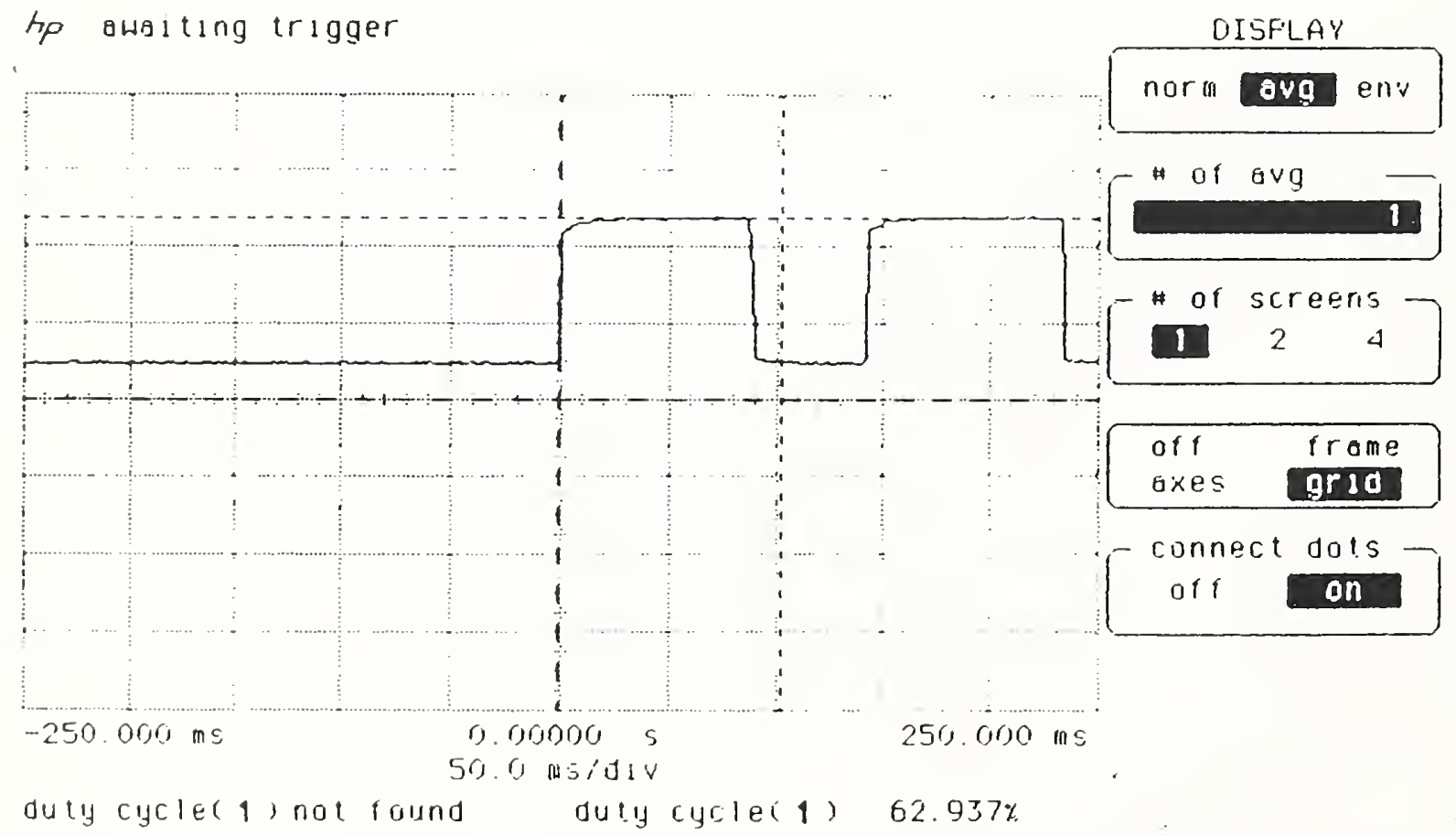

Figure 11. Automatic and rotary dial pulses for the digit " 2 " 
Telephone Auto-Dialer: Digit 0 (ten pulses) Time parameters.

th owaiting trigger

TIMEBASE

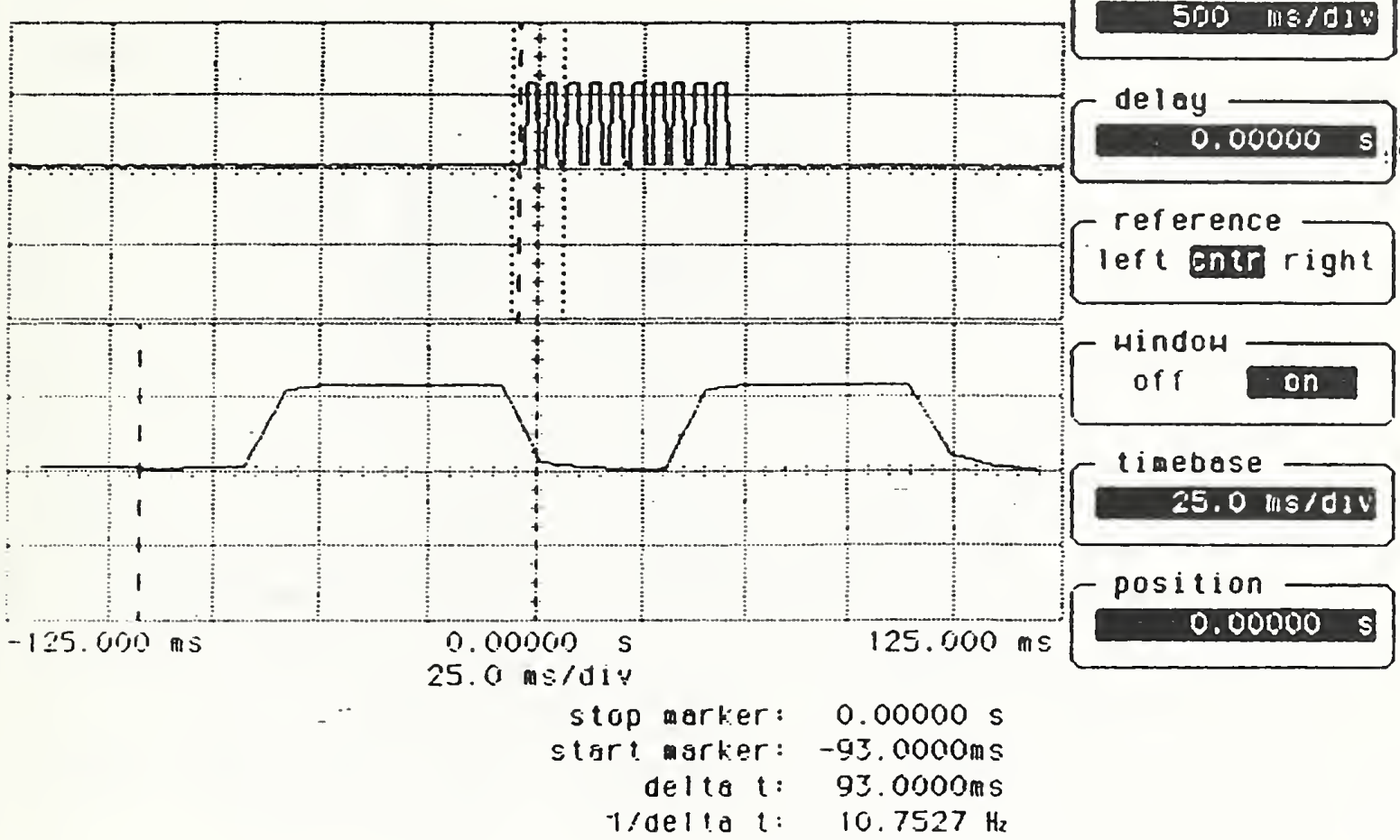

Rotary pulsing Dialer: Digit 0 (ten pulses) Time parameters.

hF GHigltrg trigger

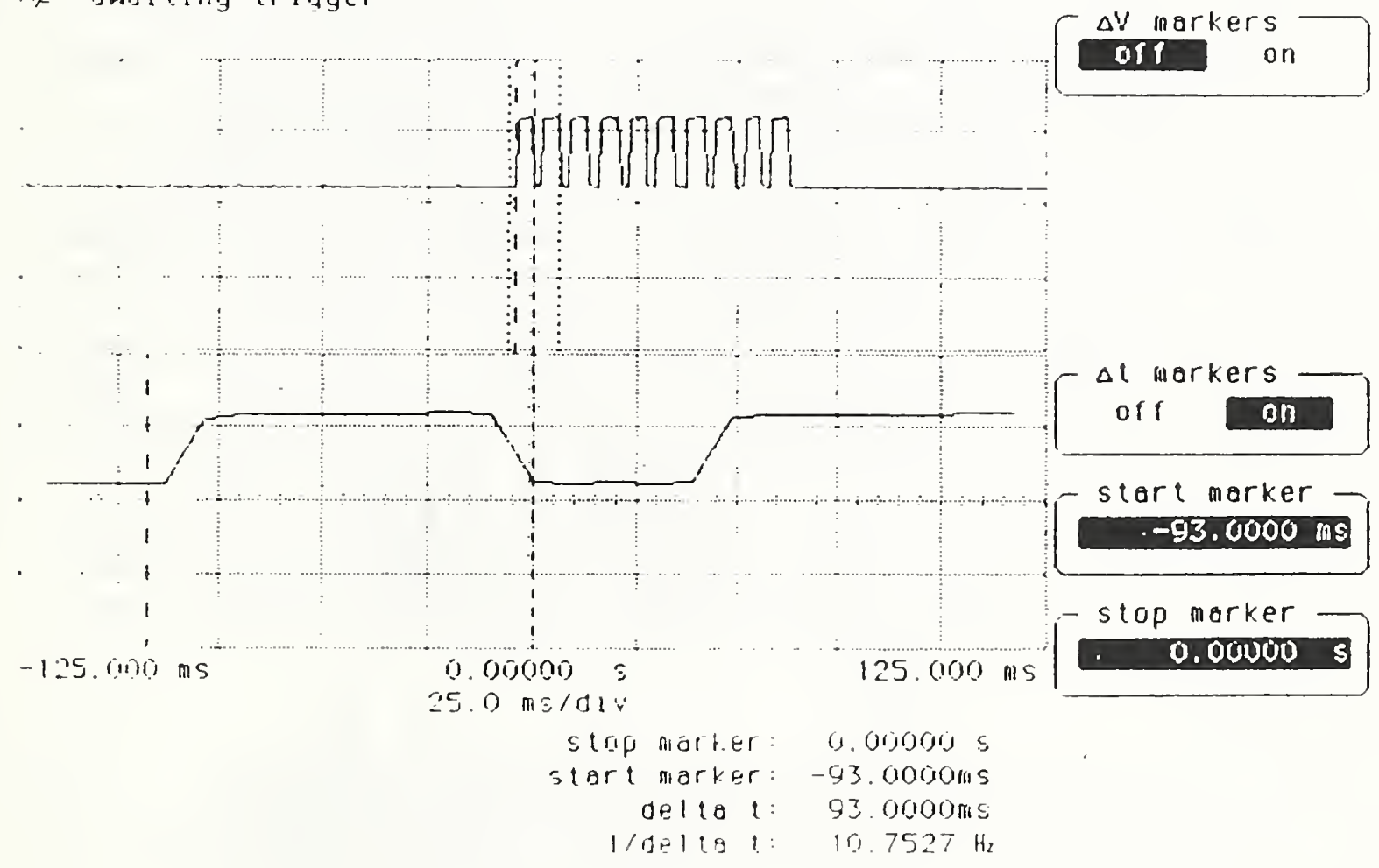

Figure 12. Automatic and rotary dial pulses for the digit "0". 
A rotary dial telephone was used to produce a train of dc pulses (as illustrated in figure 1), and connects to both the DNR and the (line isolated) power supply. A digital sampling oscilloscope (DSO) and an associated hardcopy printer were connected in parallel with these components. The DSO and the printer were used to measure and document the pulses generated by both the rotary dialer and the automatic pulse dialer telephones. Figure 11 is a printout for the digit "2" pulse produced by the rotary dial and by the automatic pulser. On identical scales are shown the differences in pulse shape and duty cycle. For the same digit "2" dialed, the duty cycle of the rotary dialed pulse was about 62.9 percent and the duty cycle of the automatic pulser was about 60.4 percent, well within the specified 60 to 64 percent range [2]. Figure 12 shows the digit "0" (ten pulses) dialed with both the rotary and automatic dialer. The upper trace shows the full complement of ten pulses and the lower trace represents a magnified portion of the pulse train in order to show in more detail the individual pulse widths as well as the pulse rise and fall times. The pulse width of the (mechanically generated) rotary dial pulse was approximately $80 \mathrm{~ms}$, whereas the pulse width of the (electrically generated) automatic dialer was about $56 \mathrm{~ms}$ (specified to be 53 to $80 \mathrm{~ms}$ [2]). The pulse rise time, $t_{r}$, and pulse fall time, $t_{f}$, were $8 \mathrm{~ms}$ and about $10 \mathrm{~ms}$, respectively, for the electronic and mechanical dialers. A table was made showing the response of the DNR under test to the dialed pulses generated by both the rotary and automatic dialers at various line and threshold voltage levels.

\subsection{DTMF Signal Tests}

The DTMF signal test was performed in order to establish the tolerance of the DNR under test to frequency and amplitude deviations in the composite DTMF signal. In figure 13 is shown a block diagram of the test setup that was used to check the DTMF (and MF) signal detection. For generating the signal required for each DTMF digit or symbol, two separately tuneable oscillators were used and bridged together by means of a resistive decoupling network, as shown. The combined signal was connected to a switch module that permits either manual operation, by means of switch $S$, or automatic operation by means of relay $\mathrm{K}$. The output signal from the switch module was capacitively coupled to the target telephone environment seen by the DNR. Directly connected across the line, as needed, was a spectrum analyzer and an oscilloscope, both of which have high input impedance relative to the $600 \Omega$ line impedance. The oscilloscope was used to monitor the composite DTMF (or MF) signal in the time domain. The spectrum analyzer was used to display the composite signal as a function of frequency and to adjust each component in the signal to its nominal frequency and amplitude values. Capacitively coupled to the line was an rms/distortion/noise $(\mathrm{R} / \mathrm{D} / \mathrm{N})$ meter. The $\mathrm{R} / \mathrm{D} / \mathrm{N}$ meter provided a measurement of the rms value, total harmonic distortion (THD), and signal-to-noise ratio of the composite DTMF (or MF) signal.

\section{Nominal Settings}

With switch S closed, the cursor on the display screen of the spectrum analyzer was first adjusted to the nominal value of the low frequency component (see figure 5). In the case of the DTMF signal for the 非 symbol, for instance, this frequency is $941 \mathrm{~Hz}$. With the cursor at the $941 \mathrm{~Hz}$ 


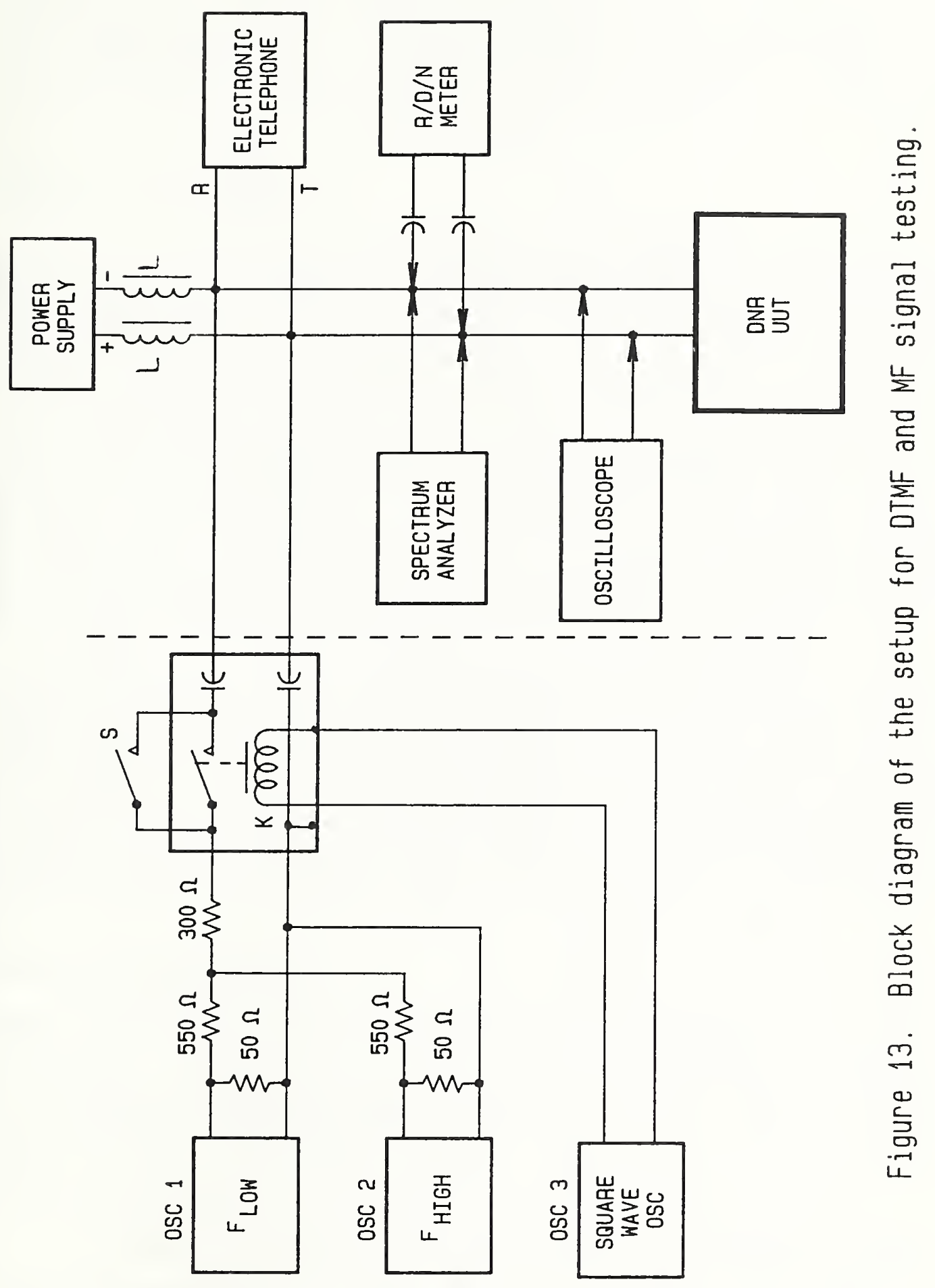




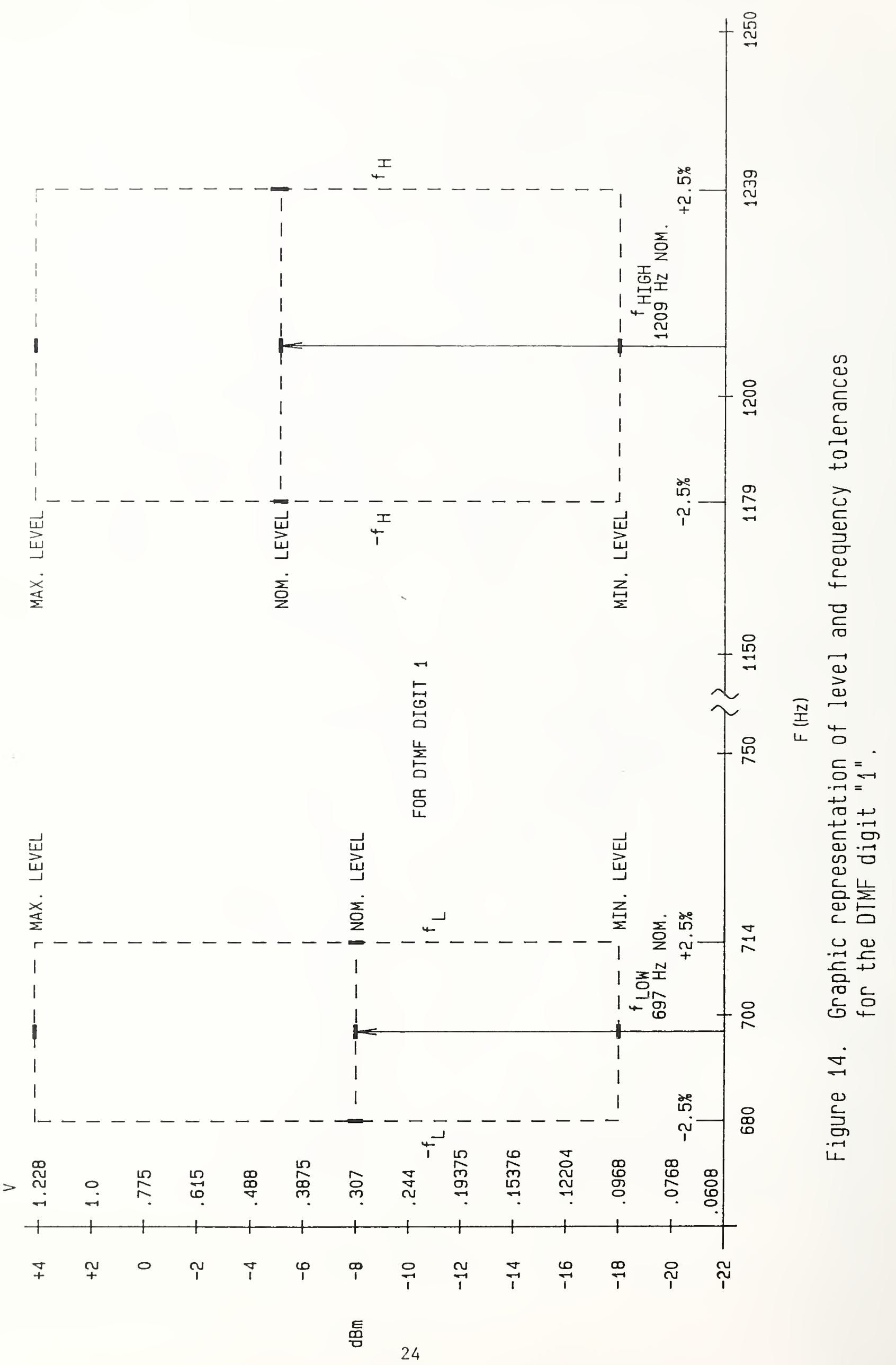


position, oscillator 1 (OSC 1) was adjusted to match its output frequency with the position of the cursor. After the frequency adjustment, the amplitude of the $941 \mathrm{~Hz}$ component was adjusted to the nominal level of $-8 \mathrm{dBm}(\sim 310 \mathrm{mV})$. The cursor of the spectrum analyzer was moved next to where it indicated the high frequency component. Then, oscillator 2 (OSC 2) was adjusted to match its output frequency with the position of the cursor, and the amplitude was set to the nominal level of $-6 \mathrm{dBm}(-390 \mathrm{mV})$. In order to verify the accuracy of the amplitude of each of the two frequency components, the $R / D / N$ meter was used to read the rms levels individually.

\section{Frequency Tolerance Tests}

The procedure for testing the frequency tolerance of the DNR UUT involved adjusting the amplitude of the two frequency components in the composite DTMF signal (for a given symbol) to their nominal levels, and then setting the high and low frequencies to maximum frequency deviation values. Although the maximum deviation from nominal is supposed to be within \pm 1.5 percent for the frequency components of the DTMF signal [2], a maximum deviation of \pm 2.5 percent was used for these tests in order to evaluate the ability of the DNR UUT to perform reliably under wider frequency deviation conditions. For example, as illustrated in figure 14, the nominal value of the low frequency component of the DTMF digit 1 is $697 \mathrm{~Hz}$ and the nominal value of the high frequency component is $1209 \mathrm{~Hz}$. By changing the high frequency component \pm 2.5 percent, it becomes either $1239 \mathrm{~Hz}$ or $1179 \mathrm{~Hz}$. Likewise, the low frequency component of $697 \mathrm{~Hz}$ becomes either $714 \mathrm{~Hz}$ or $680 \mathrm{~Hz}$. To cover the \pm 2.5 percent frequency extremes, each DTMF digit was tested with $f_{L O W}$ at $-f_{L}$ and $f_{B I G H}$ at $f_{B}$, and then with $f_{L O W}$ at $f_{L}$ and $f_{B I G B}$ at $-f_{B}$.

Following the steady-state DTMF signal adjustments using the above procedure, switch $S$ was opened and a square wave oscillator (OSC 3 ) was used to activate relay $K$. Relay control provided convenient adjustment of the repetition rate and duty cycle of the DTMF tone burst signal thus fed into the simulated line environment and into the DNR under test. With this setup, a DTMF signal was generated with a duration of 20,30 , and $40 \mathrm{milliseconds}$ in order to satify the nominal symbol recognition time that was required by the DNR UUT. The resulting response of the DNR under test was noted and recorded in tables shown in Appendix B.

\section{Amplitude Tolerance Tests}

Because of the wide dynamic range allowed for the component amplitudes of the DTMF signal (see section 5.), tests were made to verify the response of the DNR under test to variations in these levels, as illustrated in figure 14. The high and low frequency components were adjusted to their nominal frequency values, and then both components were varied in amplitude from about - $18 \mathrm{dBm}$ $(0.0968 \mathrm{~V})$ up to about $+4 \mathrm{dBm}(1.228 \mathrm{~V})$. The resulting response of the DNR under test was noted and recorded in tables in Appendix B.

\subsection{Measurement of Input Impedance and Input Resistance}

Figure 15 shows the test setups used to measure both the ac impedance and the dc resistance of the DNR line input circuit. 


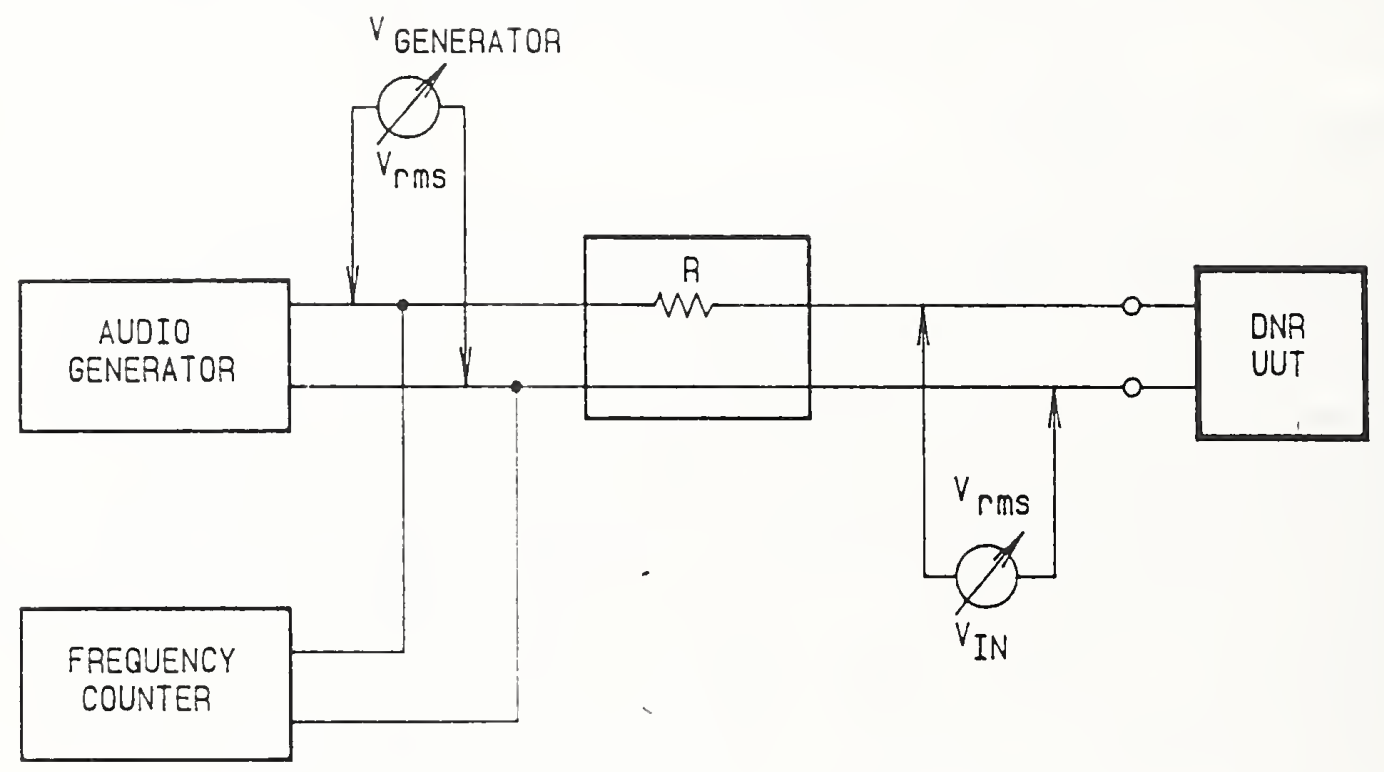

A) TEST SETUP FOR MEASURING INPUT IMPEDANCE

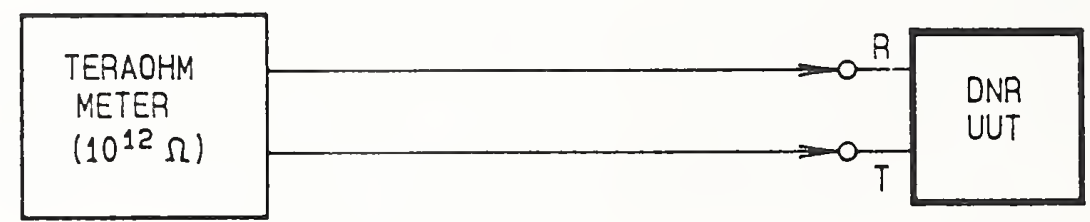

B) MEASUREMENT OF INPUT RESISTANCE

Figure 15. Block diagram of test setup for input impedance and input resistance measurement 
For testing the impedance, the DNR was connected to a component module holding a precision resistor, $R$, of $5 \mathrm{M} \Omega$. This resistance value was chosen since it is about 10 times that of the nominal rated DNR input impedance. By making $R$ large relative to the input impedance, $Z_{I N}$, the DNR input circuit is driven by nearly a constant current source. A signal from the audio generator was

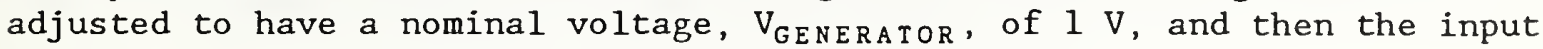
voltage, $V_{I N}$, was measured in order to determine $Z_{I N}$ from:

$$
Z_{I N}=R\left\{V_{I N} /\left(V_{G E N E R A T O R}-V_{I N}\right)\right\} .
$$

Measurements were taken at frequencies of $300 \mathrm{~Hz}, 1000 \mathrm{~Hz}$, and $3500 \mathrm{~Hz}$ and recorded in a table for each DNR unit tested.

Figure $15 \mathrm{~B}$ shows how the input resistance of the DNR UUT was measured. The DNR was connected to its usual source of power and its telephone line input disconnected. Then, a high resistance ohmmeter was used to measure the input resistance directly on the ring (R) and tip ( $T$ ) input terminals and the reading of the ohmmeter recorded. As shown in the table of Appendix $A$, the input resistance between DNR units varies from approximately $400 \mathrm{k} \Omega$ to $>10 \mathrm{M} \Omega$.

\section{$\underline{6.6}$ Measurement of Audio Circuit Parameters}

Figure 16 shows the instrumentation setup used for measuring the parameters of gain, frequency response, automatic gain control, signal to noise ratio, and total harmonic distortion of the audio amplifier and associated circuits in the DNR UUT. An audio oscillator, terminated with a $600 \Omega$ resistor, was capacitively coupled to the dc voltage environment of the DNR line input. The power supply voltage was then lowered in order to set the DNR to the off-hook mode, thereby simulating an activated subscriber telephone set. Upon recognizing this condition, and when programmed to do so, the DNR activates its internal audio circuitry. This feeds the audio input signal to the internal amplifier circuit, which in turn transfers the audio signal to the tape recorder output. The output signal was then connected to the input terminals of the $\mathrm{R} / \mathrm{D} / \mathrm{N}$ meter used for the measurement of the various audio parameters of the DNR audio circuits.

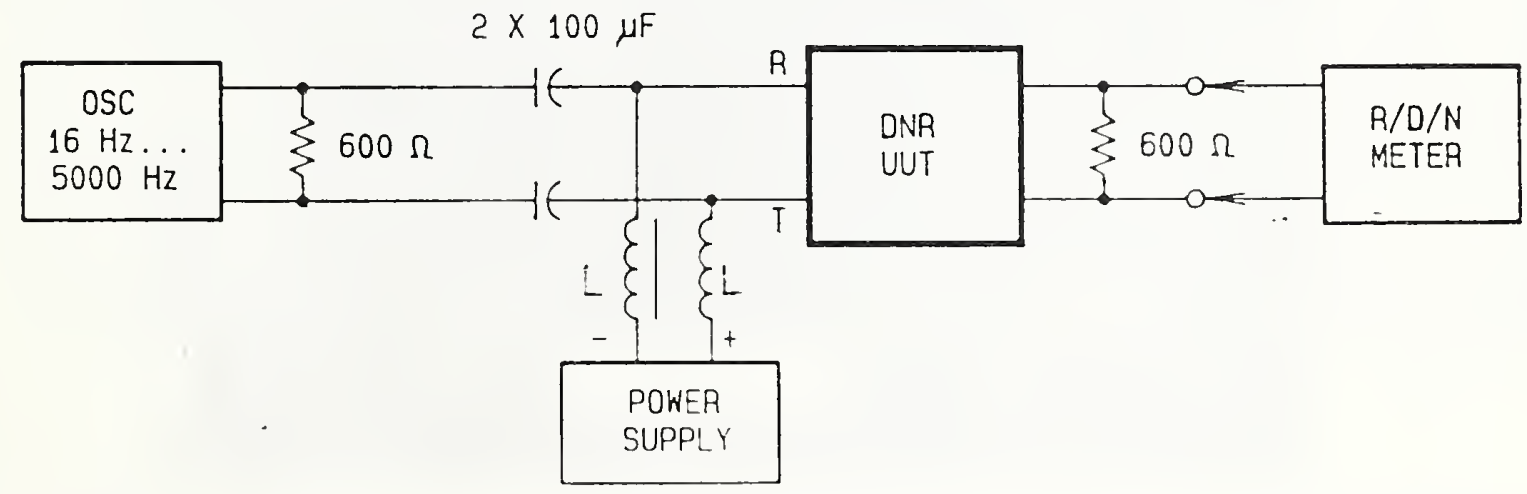

Figure 16. Block diagram of test circuit for frequency response and automatic gain control measurement 
The gain of the DNR audio circuits was determined by feeding a $1000 \mathrm{~Hz}$ signal of $100 \mathrm{mV}(-17 \mathrm{dBm})$ to the telephone line input of the DNR, and measuring the signal level at the tape recorder output terminals of the DNR under test. The difference measured between $V_{i n}$ and $V_{o u t}$ is due to the voltage gain of the DNR audio amplifier (and associated circuits) and can be calculated from

$$
\operatorname{Gain}_{\mathrm{d} B}=20 \log _{10}\left(\mathrm{~V}_{\mathrm{out}} / \mathrm{V}_{\mathrm{in}}\right) \text {. }
$$

In order to determine the gain of the audio circuits as a function of frequency (i.e., the frequency response), the nominal input level was held constant while the frequency settings of the audio oscillator were changed, and readings taken of $\mathrm{V}_{\text {out }}$, as before. The amplitude data were collected from $300 \mathrm{~Hz}$ through about $4000 \mathrm{~Hz}$ in order to cover the frequency response adequately. From the numerical data, amplitude-frequency plots (relative to $1000 \mathrm{~Hz}$ ) were generated for the audio circuits of all five DNR units tested. Also, since the audio circuits of the DNRs incorporate automatic gain control (AGC), various input levels, ranging from $10 \mathrm{mV}(-37.8 \mathrm{dBm})$ through $600 \mathrm{mV}$ $(-2.2 \mathrm{dBm})$ were applied to telephone line input of the DNRs in steps of $10 \mathrm{mV}$ each, and the resulting output levels were measured for each increment. These data were taken in order to establish an AGC gain curve for each DNR.

In order to obtain signal to noise (S/N) data and total harmonic distortion (THD) figures for the DNR audio amplifier circuits, measurements were taken with various input voltage levels, and differing output levels, based on the characteristic of the automatic gain control circuitry for the particular DNR. Typically, the input voltage levels used were $10,100,200,360,400$, and $600 \mathrm{mV}$ (or, $-37.8,-17.7,-11.7,-6.6,-5.7$, and $-2.2 \mathrm{dBm}$, respectively). The test results for each DNR UUT are given in the tables shown in Appendix A.

\subsection{MF Signal Tests}

Similar to the DTMF signaling described above in section 5., MF signaling is used to increase the speed of setting up connections and for the transmission of switching information via trunk lines between central offices. Digital information is transmitted as characters by the combination of two sinusoidal waveforms with the frequencies indicated in table 2. Compared with table 1 , table 2 shows the distinct difference in frequencies used between the common DTMF signaling tones and the MF signaling tones. The transmission level of these signals is customarily at about the $-6 \mathrm{dBm}(\sim 390 \mathrm{mV})$ level [4]. Besides the five frequencies used for the digits 0 through 9 , a sixth frequency of $1700 \mathrm{~Hz}$ is used in combination with $1100 \mathrm{~Hz}$ as a "priming" signal (K), which activates the remote receiver circuitry. Similarly, a "start" signal (S) is generated with a $1700 \mathrm{~Hz}$ tone in combination with a $1500 \mathrm{~Hz}$ tone, which activates the transmission of digital information. The $Q$ signal is used by interoffice operators to establish an operating mode or condition. 


\section{Table 2}

Frequency in Hertz

\begin{tabular}{|c|c|c|c|c|c|}
\hline Symbol & 700 & 900 & 1100 & 1300 & 1500 \\
\hline 1 & $\mathrm{x}$ & $\mathrm{x}$ & & & \\
\hline 2 & $\mathrm{x}$ & & $\mathrm{x}$ & & \\
\hline 3 & & $\mathrm{x}$ & $\mathrm{x}$ & & \\
\hline 4 & $\mathrm{x}$ & & & $\mathrm{x}$ & \\
\hline 5 & & $x$ & & $x$ & \\
\hline 6 & & & $\mathrm{x}$ & $\mathrm{x}$ & \\
\hline 7 & $\mathrm{x}$ & & & & $\mathrm{x}$ \\
\hline 8 & & $\mathrm{x}$ & & & $\mathrm{x}$ \\
\hline 9 & & & $\mathrm{x}$ & & $\mathrm{x}$ \\
\hline 0 & & & & $x$ & $\mathrm{x}$ \\
\hline K & & & $\mathrm{x}$ & & \\
\hline$S$ & & & & & $\mathrm{x}$ \\
\hline$P$ & & $\mathrm{x}$ & & & \\
\hline L & & & & $\mathrm{x}$ & \\
\hline Q & $x$ & & & & \\
\hline
\end{tabular}

The photograph in figure 17 shows a multifrequency (MF) signal (in this case, the special character Q) displayed in the frequency domain with its low frequency component of $700 \mathrm{~Hz}$ and high frequency component of $1700 \mathrm{~Hz}$.

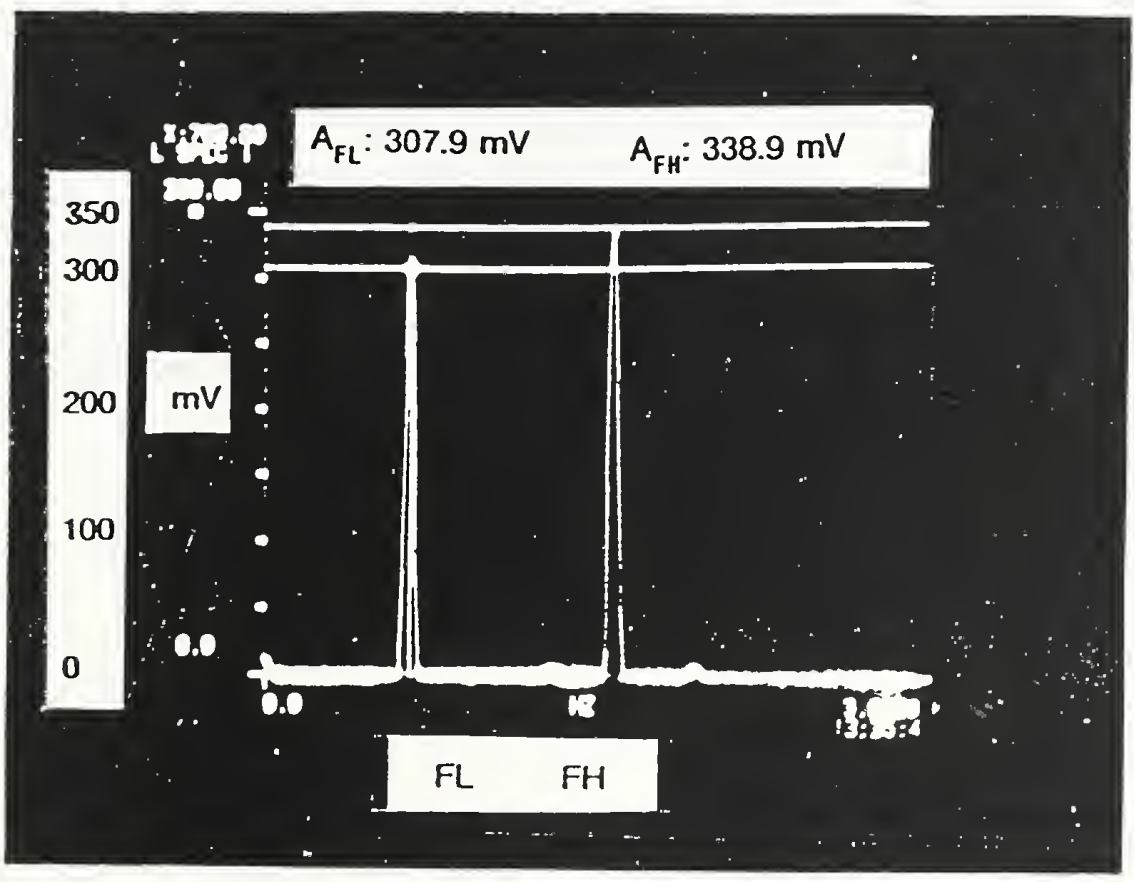

Figure 17. Frequency domain representation of frequency components for the MF signal, Q 
The setup for testing the tolerance of the DNR UUT to frequency deviations in the MF signal is the same as for DTMF signal testing, as shown in figure 13 . Again, the procedure for this testing involved adjusting the amplitude of the two frequency components in the composite MF signal for a given symbol (as shown in table 2) to their nominal levels (switch $S$ closed), and then setting the high and low frequencies to maximum frequency deviation values. Although the maximum deviation is supposed to be within \pm 1.5 percent plus $5 \mathrm{~Hz}$ for the frequency components of the MF signal [4], a maximum deviation of \pm 2.5 percent was used for these tests. For example, the nominal value of the low frequency component of the MF signal for the symbol Q is $700 \mathrm{~Hz}$ and the nominal value of the high frequency component is $1700 \mathrm{~Hz}$. By changing the high frequency component \pm 2.5 percent, it becomes either $1742.5 \mathrm{~Hz}$ or $1657.5 \mathrm{~Hz}$. Likewise, the low frequency component of $700 \mathrm{~Hz}$ becomes either $717.5 \mathrm{~Hz}$ or $682.5 \mathrm{~Hz}$. To cover the \pm 2.5 percent frequency extremes, each MF digit was tested with $f_{L o w}$ at $-f_{\mathrm{L}}$ and $f_{\mathrm{HIGH}}$ at $f_{\mathrm{H}}$, and then with $f_{\mathrm{LOW}}$ at $f_{\mathrm{L}}$ and $\mathrm{f}_{\mathrm{HIGH}}$ at $-f_{\mathrm{H}}$.

Following the steady-state MF signal adjustments using the above procedure, switch $S$ was opened and a square wave oscillator (OSC 3 ) was used to activate relay $K$. Relay control provided convenient adjustment of the repetition rate and duty cycle of the MF tone burst signal thus fed into the simulated line environment and into the DNR under test. With this setup, an MF signal was generated with a duration and repetition rate that was needed to satisfy the nominal symbol recognition time that was required by the DNR UUT.

\section{Amplitude Tolerance Tests}

Because of the wide dynamic range allowed for the component amplitudes of the MF signal [4], tests were made to verify the response of the DNR under test to variations in these levels, as was done for the DTMF signal testing. The high and low frequency components were adjusted to their nominal frequency values, and then both components were varied in amplitude from about $-18 \mathrm{dBm}$ $(0.0968 \mathrm{~V})$ up to about $+4 \mathrm{dBm}(1.228 \mathrm{~V})$.

The resulting responses of the two DNR units that had MF signaling detection capability (Sytems 非 and 非) were recorded, and the results are summarized in tables given in Appendix B. 


\section{Summary}

The dialed number recorders (DNRs) from four manufacturers were submitted to NIST for testing their operational characteristics. The five similar, but not identical, DNRs were evaluated according to a generic test plan developed by the Electricity Division of NIST. The basic operational functions of all the DNRs were the same, but the design features were not. Some of the DNRs were compact and were completely keypad controlled and operated. Others were a hybrid design with keypad operating controls, but with manual adjustments required for certain telephone line and detector/decoder settings. All the DNR units tested were equipped to operate with loop extenders and/or slave monitoring devices (isolation units), which are used in some operational applications. Also, some DNRs were equipped to detect single frequency (SF) as well as multifrequency (MF) signals, which are used for telephone trunkline and cellular telephone signaling purposes. The DNR detector/decoder circuits for dual tone multifrequency (DTMF) and multifrequency (MF) detection were tested by using signals generated by two, low frequency oscillators whose signals were summed and jointly fed to the telephone line input of the DNR under test. This method of dual tone generation allowed the generation of all signaling tones presently in use by communication carriers without the use of sophisticated telephone test equipment.

\section{Acknowledgements}

The authors would like to acknowledge the consulting help received from Mr. Walter Mack, Senior Staff Engineer, Hekimian Labs, who not only provided a background on the development of the DNR from the early days of the pen recorder, but also offered his expert advice concerning telephone line conditions and their effects on testing DNRs. Mr. Mack also was kind enough to critique the contents of this report prior to its publication. The helpful assistance of $\mathrm{Mr}$. Robert $\mathrm{Palm}$ is also acknowledged in the preparation of the figures contained in this report.

The cooperation of the manufacturers who voluntarily sent their DNRs in for test and evaluation is also sincerely appreciated. 


\section{References}

1. Staff of the ITT Corporation, Reference Data for Radio Engineers, Fifth Edition, by Howard W. Sams \& Co., Inc., circa 1965.

2. Electronic Industries Association (EIA) Standard, Telephone Instruments with Loop Signaling, ANSI/EIA-470-A-1987, Approved July 13, 1987.

3. C. Breen and C. A. Dahlbon, "Signaling Systems for Control of Telephone Switching," the Bell System Technical Journal, Vol. 39, No. 6, November, 1960.

4. BellCore Specification TR-TSY000506, Section 6, LSSGR, July, 1987. 
Appendix A - Tables Comparing DNR Input Parameters and Audio Circuit Test Data 
DNR Input Parameters

\begin{tabular}{|c|c|c|c|c|c|}
\hline Parameter & $\begin{array}{c}\text { System } \\
\# 1\end{array}$ & $\begin{array}{c}\text { System } \\
\# 2\end{array}$ & $\begin{array}{c}\text { System } \\
\# 3\end{array}$ & $\begin{array}{c}\text { System } \\
\# 4\end{array}$ & $\begin{array}{c}\text { System } \\
\# 5\end{array}$ \\
\hline $\begin{array}{l}\text { Input Resistance } \\
\left(\mathrm{R}_{\text {in }}\right) \\
\end{array}$ & $10 \mathrm{M} \Omega$ & $22.5 \mathrm{M} \Omega$ & $460 \mathrm{k} \Omega$ & $460 \mathrm{k} \Omega$ & $11.5 \mathrm{M} \Omega$ \\
\hline $\begin{array}{l}\text { Input Impedance } \\
\left(\mathrm{Z}_{i n}\right) \\
\text { at } 1 \mathrm{kHz} \\
\end{array}$ & $682 \mathrm{k} \Omega$ & $102 \mathrm{k} \Omega$ & $13.8 \mathrm{k} \Omega$ & $15.7 \mathrm{k} \Omega$ & $435 \mathrm{k} \Omega$ \\
\hline $\begin{array}{l}\text { Input Impedance } \\
\left(\mathrm{Z}_{\text {in }}\right) \\
\text { at } 3.5 \mathrm{kHz}\end{array}$ & $533 \mathrm{k} \Omega$ & $65.8 \mathrm{k} \Omega$ & $36.5 \mathrm{k} \Omega$ & $16.3 \mathrm{k} \Omega$ & $685 \mathrm{k} \Omega$ \\
\hline $\begin{array}{l}\text { Input Impedance } \\
\left(\mathrm{Z}_{i n}\right) \\
\text { at } 300 \mathrm{~Hz}\end{array}$ & $494 \mathrm{k} \Omega$ & $73.6 \mathrm{k} \Omega$ & $29.8 \mathrm{k} \Omega$ & $17 \mathrm{k} \Omega$ & $505 \mathrm{k} \Omega$ \\
\hline $\begin{array}{l}\text { Load Current } \\
\left(\mathrm{I}_{\text {load }}\right) \\
\text { at } 48 \mathrm{VDC}\end{array}$ & $4.8 \mu \mathrm{A}$ & $2.13 \mu \mathrm{A}$ & $104 \mu \mathrm{A}$ & $104 \mu \mathrm{A}$ & $4.17 \mu \mathrm{A}$ \\
\hline $\begin{array}{l}\text { Load Current } \\
\left(\mathrm{I}_{\text {load }}\right) \\
\text { at } 24 \mathrm{VDC}\end{array}$ & $2.4 \mu \mathrm{A}$ & $1.06 \mu \mathrm{A}$ & $52 \mu \mathrm{A}$ & $52 \mu \mathrm{A}$ & $2.08 \mu \mathrm{A}$ \\
\hline $\begin{array}{l}\text { Load Current } \\
\left(\mathrm{I}_{\text {load }}\right) \\
\text { at } 12 \mathrm{VDC}\end{array}$ & $1.2 \mu \mathrm{A}$ & $0.53 \mu \mathrm{A}$ & $26 \mu \mathrm{A}$ & $26 \mu \mathrm{A}$ & $1.04 \mu \mathrm{A}$ \\
\hline $\begin{array}{l}\text { Load Current } \\
\left(\mathrm{I}_{\text {load }}\right) \\
\text { at } 6 \text { VDC }\end{array}$ & $0.6 \mu \mathrm{A}$ & $0.26 \mu \mathrm{A}$ & $13 \mu \mathrm{A}$ & $13 \mu \mathrm{A}$ & $0.52 \mu \mathrm{A}$ \\
\hline $\begin{array}{l}\text { Ring Voltage } \\
\text { Range }\end{array}$ & $\begin{array}{l}32 \mathrm{~V}_{\text {rms }} \\
\text { through } \\
130 \mathrm{~V}_{\text {rms }}\end{array}$ & $\begin{array}{l}30 \mathrm{~V}_{r m s} \\
\text { through } \\
130 \mathrm{~V}_{r m s}\end{array}$ & $\begin{array}{l}20 \mathrm{~V}_{\text {mms }} \\
\text { through } \\
130 \mathrm{~V}_{\text {rms }}\end{array}$ & $\begin{array}{l}20 \mathrm{~V}_{m s} \\
\text { through } \\
130 \mathrm{~V}_{m s}\end{array}$ & $\begin{array}{l}20 \mathrm{~V}_{\mathrm{rms}} \\
\text { through } \\
130 \mathrm{~V}_{\mathrm{rms}}\end{array}$ \\
\hline $\begin{array}{l}\text { Ring } \\
\text { Frequency } \\
\text { Range }\end{array}$ & $\begin{array}{c}16 \mathrm{~Hz} \\
\text { through } \\
70 \mathrm{~Hz}\end{array}$ & $\begin{array}{c}16 \mathrm{~Hz} \\
\text { through } \\
70 \mathrm{~Hz}\end{array}$ & $\begin{array}{c}16 \mathrm{~Hz} \\
\text { through } \\
70 \mathrm{~Hz}\end{array}$ & $\begin{array}{c}16 \mathrm{~Hz} \\
\text { through } \\
70 \mathrm{~Hz}\end{array}$ & $\begin{array}{c}16 \mathrm{~Hz} \\
\text { through } \\
42 \mathrm{~Hz}\end{array}$ \\
\hline
\end{tabular}




\begin{tabular}{|c|c|c|c|c|c|c|c|c|c|}
\hline 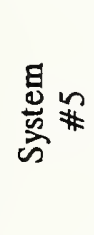 & 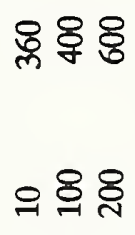 & 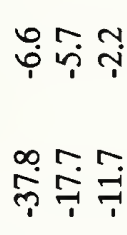 & 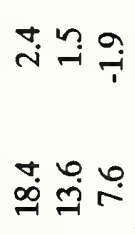 & 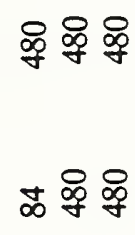 & 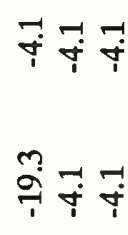 & 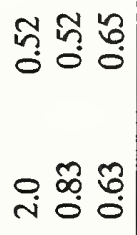 & 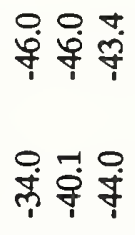 & 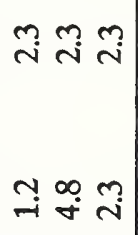 & 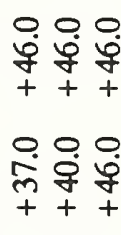 \\
\hline 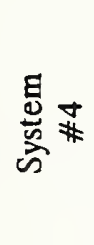 & 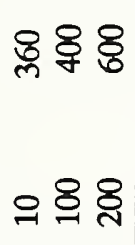 & 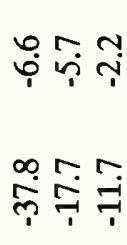 & 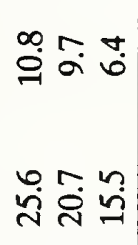 & 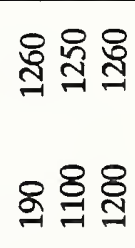 & 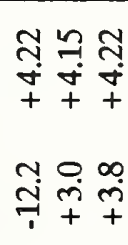 & 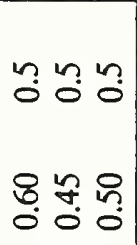 & 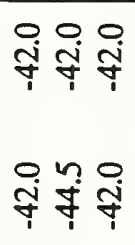 & 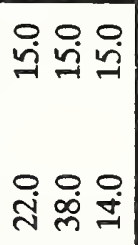 & 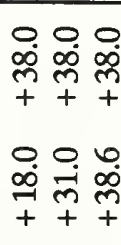 \\
\hline 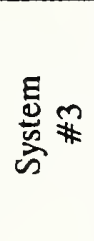 & 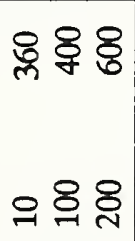 & 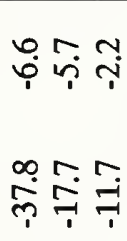 & 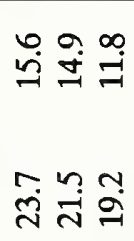 & 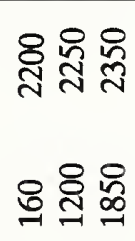 & 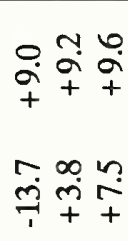 & 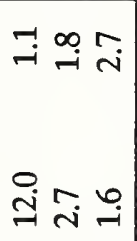 & 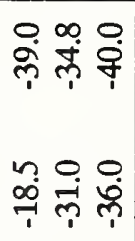 & 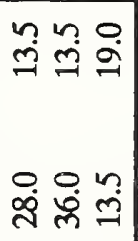 & 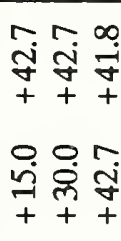 \\
\hline 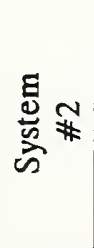 & 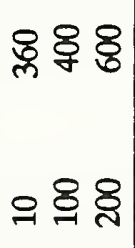 & 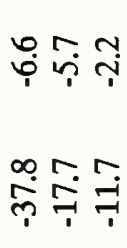 & 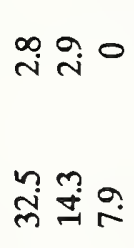 & $\begin{array}{l}\text { ్ㅠㅁ융유 } \\
\text { ్ㅠ윰유 }\end{array}$ & 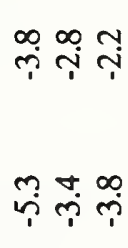 & 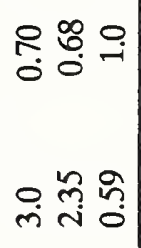 & 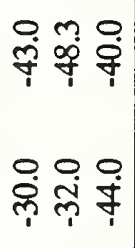 & 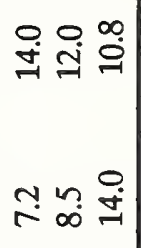 & 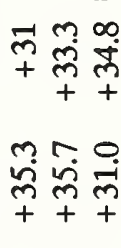 \\
\hline 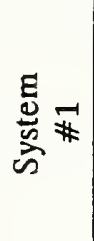 & 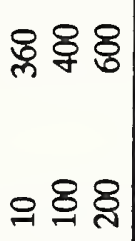 & 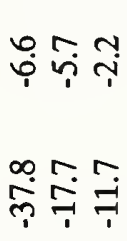 & 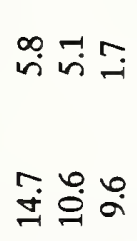 & $\begin{array}{l}\text { 유유ㅇㅠㅠ } \\
\text { 냉용 }\end{array}$ & 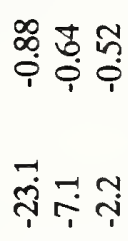 & 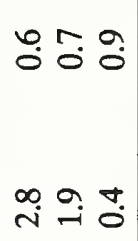 & 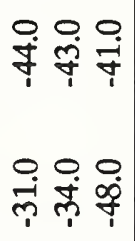 & 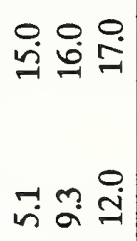 & 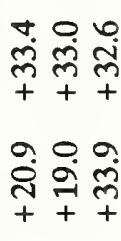 \\
\hline 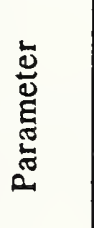 & 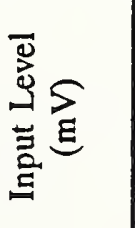 & 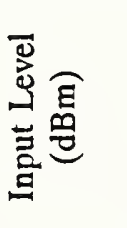 & 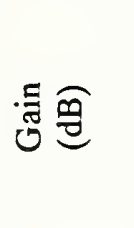 & 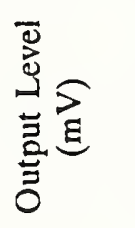 & 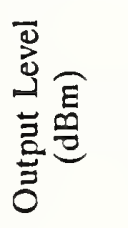 & 옵 & 貝孚 & 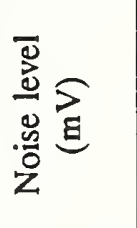 & 文孚 \\
\hline
\end{tabular}


Appendix B - Test Data on all Five DNR Units 
System 1 Test Data 


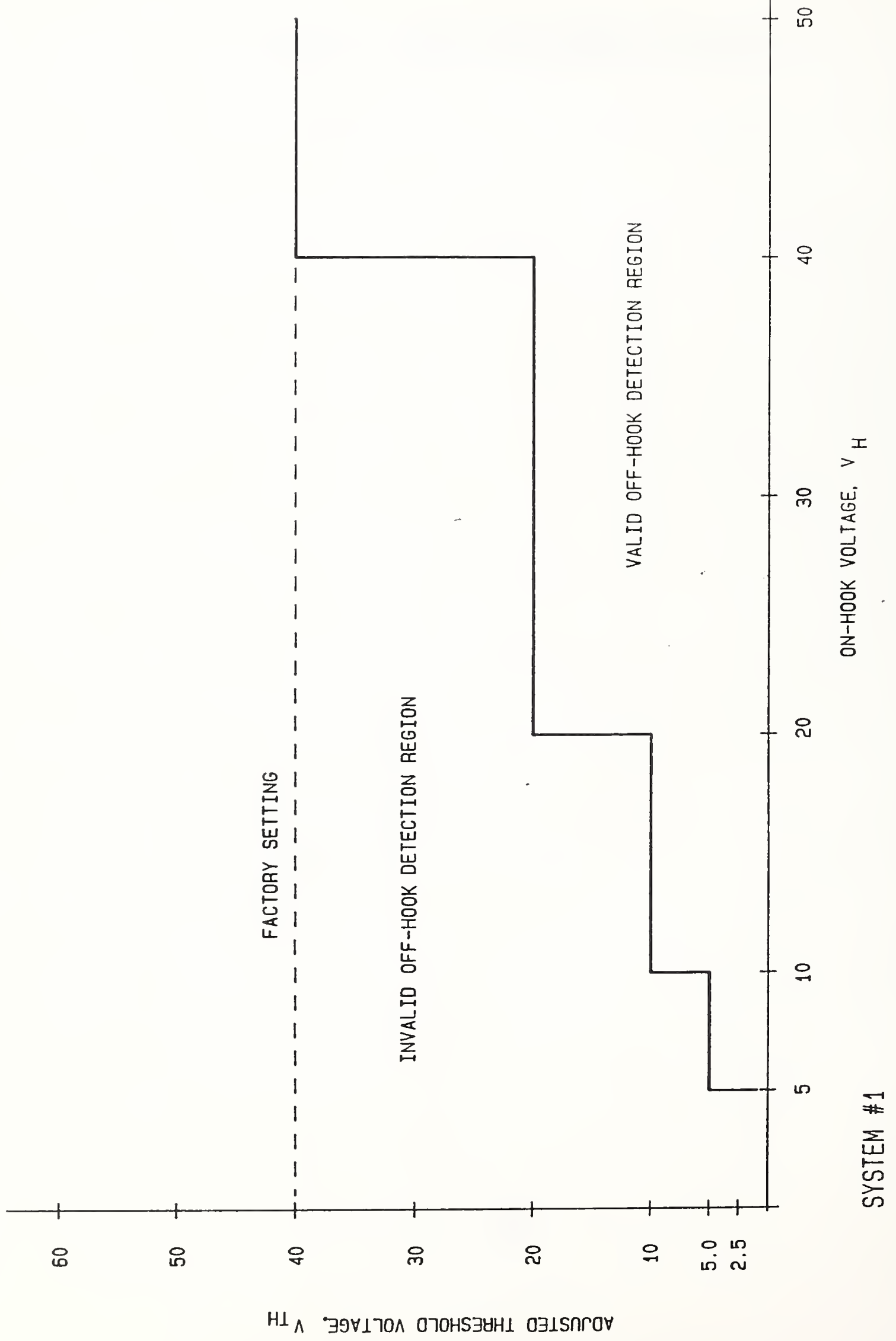




\section{DNR Dialing Response System \#1}

\begin{tabular}{|c|c|c|c|c|c|c||}
\hline $\begin{array}{c}\text { Line } \\
\text { Voltage } \\
(\mathrm{V})\end{array}$ & $\begin{array}{c}\text { Threshold } \\
\text { Voltage } \\
\left(\mathrm{V}_{\mathrm{TH}}\right)\end{array}$ & $\begin{array}{c}\text { Digit } \\
\text { Dialed } \\
2\end{array}$ & $\begin{array}{c}\text { Digit } \\
\text { Dialed } \\
4\end{array}$ & $\begin{array}{c}\text { Digit } \\
\text { Dialed } \\
6\end{array}$ & $\begin{array}{c}\text { Digit } \\
\text { Dialed } \\
8\end{array}$ & $\begin{array}{c}\text { Digit } \\
\text { Dialed } \\
0\end{array}$ \\
\hline 50 & 40 & Yes & Yes & Yes & Yes & Yes \\
\hline 40 & 40 & Yes & Yes & Yes & Yes & Yes \\
\hline 40 & 20 & Yes & Yes & Yes & Yes & Yes \\
\hline 20 & 10 & Yes & Yes & Yes & Yes & Yes \\
\hline 10 & 5 & Yes & Yes & Yes & Yes & Yes \\
\hline
\end{tabular}

Pulse Source: Rotary Dial Telephone

\begin{tabular}{||c|c|c|c|c|c|c||}
\hline $\begin{array}{c}\text { Line } \\
\text { Voltage } \\
(\mathrm{V})\end{array}$ & $\begin{array}{c}\text { Threshold } \\
\text { Voltage } \\
\left(\mathrm{V}_{\mathrm{TH}}\right)\end{array}$ & $\begin{array}{c}\text { Digit } \\
\text { Dialed } \\
2\end{array}$ & $\begin{array}{c}\text { Digit } \\
\text { Dialed } \\
4\end{array}$ & $\begin{array}{c}\text { Digit } \\
\text { Dialed } \\
6\end{array}$ & $\begin{array}{c}\text { Digit } \\
\text { Dialed } \\
8\end{array}$ & $\begin{array}{c}\text { Digit } \\
\text { Dialed } \\
0\end{array}$ \\
\hline 50 & 40 & Yes & Yes & Yes & Yes & Yes \\
\hline 40 & 30 & Yes & Yes & Yes & Yes & Yes \\
\hline 30 & 20 & Yes & Yes & Yes & Yes & Yes \\
\hline 20 & 10 & Yes & Yes & Yes & Yes & Yes \\
\hline 10 & 5 & Yes & Yes & Yes & Yes & Yes \\
\hline
\end{tabular}

Pulse Source: Electronic Dial Telephone 
DTMF Detection Test

System \#1

\begin{tabular}{|c|c|c|c|c|c|c|c|c|c|c|}
\hline Digit & $\begin{array}{c}\mathrm{f}_{l o w} \\
-2.5 \% \\
(\mathrm{~Hz})\end{array}$ & $\begin{array}{c}\mathrm{f}_{l o w} \\
+2.5 \% \\
(\mathrm{~Hz}) \\
\end{array}$ & $\begin{array}{c}\mathrm{f}_{h i g h} \\
-2.5 \% \\
(\mathrm{~Hz})\end{array}$ & $\begin{array}{c}\mathrm{f}_{\text {high }} \\
+2.5 \% \\
(\mathrm{~Hz}) \\
\end{array}$ & $\begin{array}{c}\text { 2-Freq. } \\
\text { Burst } \\
20 \mathrm{~ms} \\
\text { (min.) }\end{array}$ & $\begin{array}{c}\text { 2-Freq. } \\
\text { Burst } \\
30 \mathrm{~ms} \\
\text { (nom.) }\end{array}$ & $\begin{array}{l}\text { 2-Freq. } \\
\text { Burst } \\
40 \mathrm{~ms} \\
\text { (max.) }\end{array}$ & $\begin{array}{c}\text { Low } \\
\text { Level } \\
\mathrm{mV} / \mathrm{dBm} \\
90 /-18\end{array}$ & $\begin{array}{c}\text { Nom } \\
\text { Level } \\
\mathrm{mV} / \mathrm{dBm} \\
390 /-6\end{array}$ & $\begin{array}{c}\text { High } \\
\text { Level } \\
\mathrm{mV} / \mathrm{dBm} \\
1228 /+4\end{array}$ \\
\hline * & 680 & & & 1239 & Yes & Yes & Yes & Yes & Yes & Yes \\
\hline 1 & & 714 & 1179 & & Yes & Yes & Yes & Yes & Yes & Yes \\
\hline 2 & 680 & & & 1369 & Yes & Yes & Yes & Yes & Yes & Yes \\
\hline 2 & & 714 & 1303 & & Yes & Yes & Yes & Yes & Yes & Yes \\
\hline 3 & 680 & & & 1515 & Yes & Yes & Yes & Yes & Yes & Yes \\
\hline 3 & & 714 & 1442 & & Yes & Yes & Yes & Yes & Yes & Yes \\
\hline 9 & 751 & & & 1239 & Yes & Yes & Yes & Yes & Yes & Yes \\
\hline 1 & & 789 & 1179 & & Yes & Yes & Yes & Yes & Yes & Yes \\
\hline 5 & 751 & & & 1369 & Yes & Yes & Yes & Yes & Yes & Yes \\
\hline 5 & & 789 & 1303 & & Ýes & Yes & Yes & Yes & Yes & Yes \\
\hline 6 & 751 & & & 1515 & Yes & Yes & Yes & Yes & Yes & Yes \\
\hline 6 & & 789 & 1442 & & Yes & Yes & Yes & Yes & Yes & Yes \\
\hline 7 & 831 & & & 1239 & Yes & Yes & Yes & Yes & Yes & Yes \\
\hline 7 & & 873 & 1179 & & Yes & Yes & Yes & Yes & Yes & Yes \\
\hline 8 & 831 & & & 1369 & Yes & Yes & Yes & Yes & Yes & Yes \\
\hline 8 & & 873 & 1303 & & Yes & Yes & Yes & Yes & Yes & Yes \\
\hline 9 & 831 & & & 1515 & Yes & Yes & Yes & Yes & Yes & Yes \\
\hline 9 & & 873 & 1442 & & Yes & Yes & Yes & Yes & Yes & Yes \\
\hline 9 & 918 & & & 1369 & Yes & Yes & Yes & Yes & Yes & Yes \\
\hline 0 & & 964 & 1303 & & Yes & Yes & Yes & Yes & Yes & Yes \\
\hline * & 918 & & & 1239 & Yes & Yes & Yes & Yes & Yes & Yes \\
\hline * & & 964 & 1179 & & Yes & Yes & Yes & Yes & Yes & Yes \\
\hline$\#$ & 918 & & & 1515 & Yes & Yes & Yes & Yes & Yes & Yes \\
\hline \# & & 964 & 1442 & & Yes & Yes & Yes & Yes & Yes & Yes \\
\hline
\end{tabular}




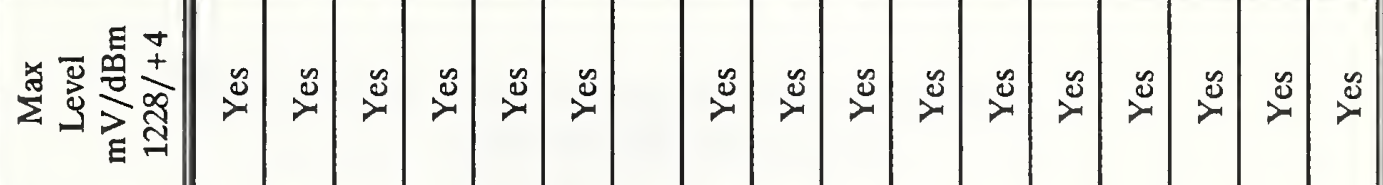

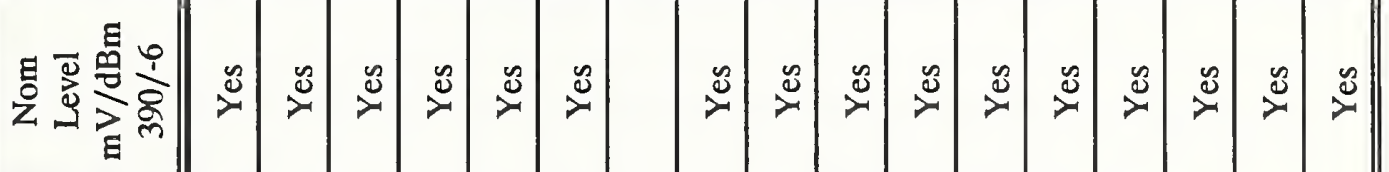

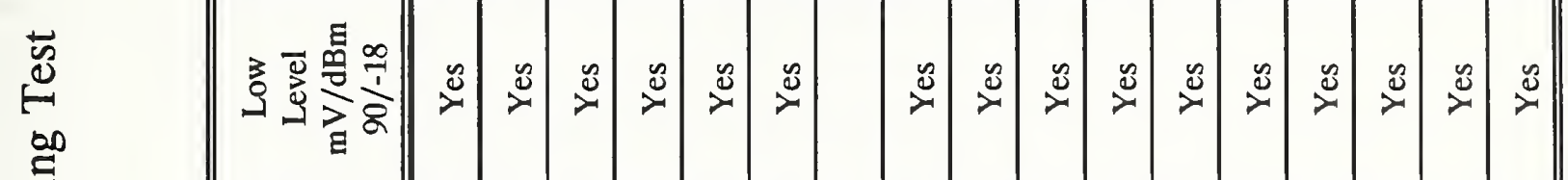

量

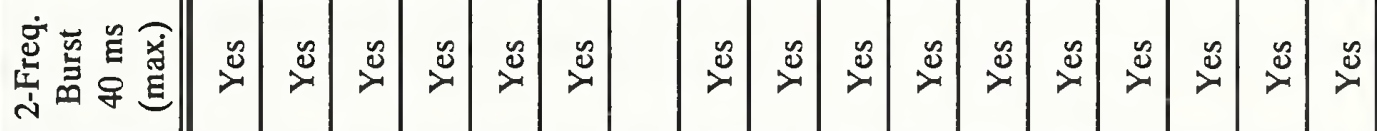

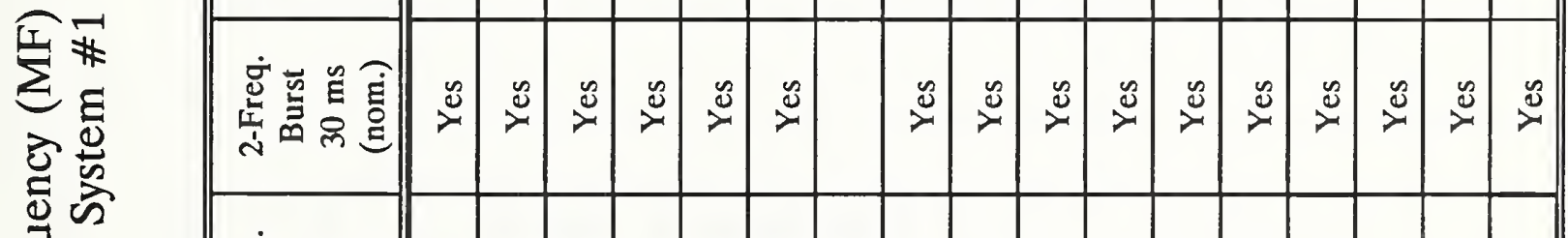

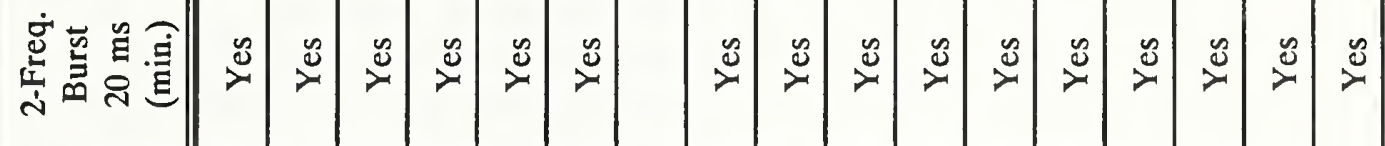

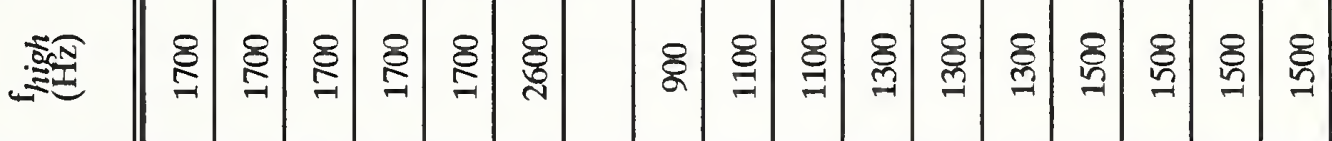

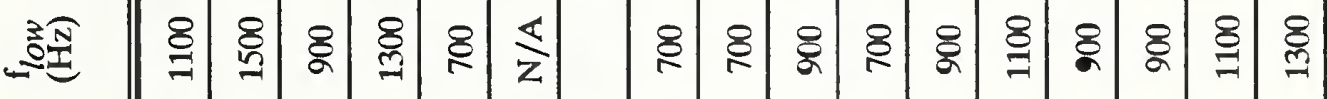

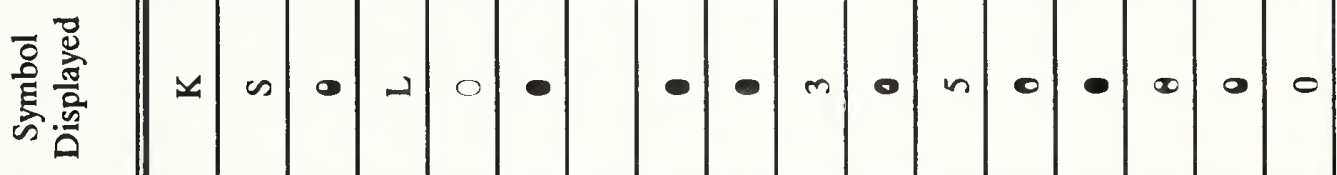

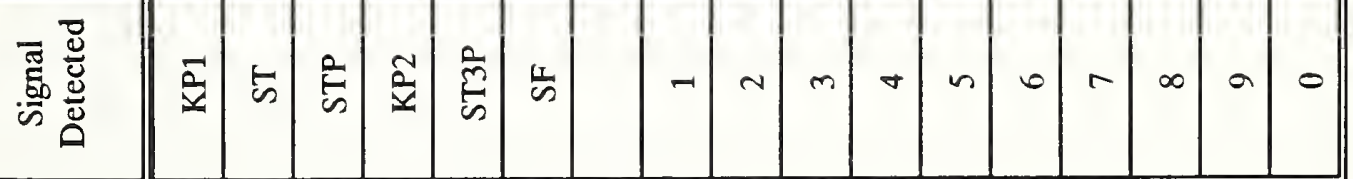




\section{AUDIO TEST - FREQUENCY RESPONSE SYSTEM \#1}

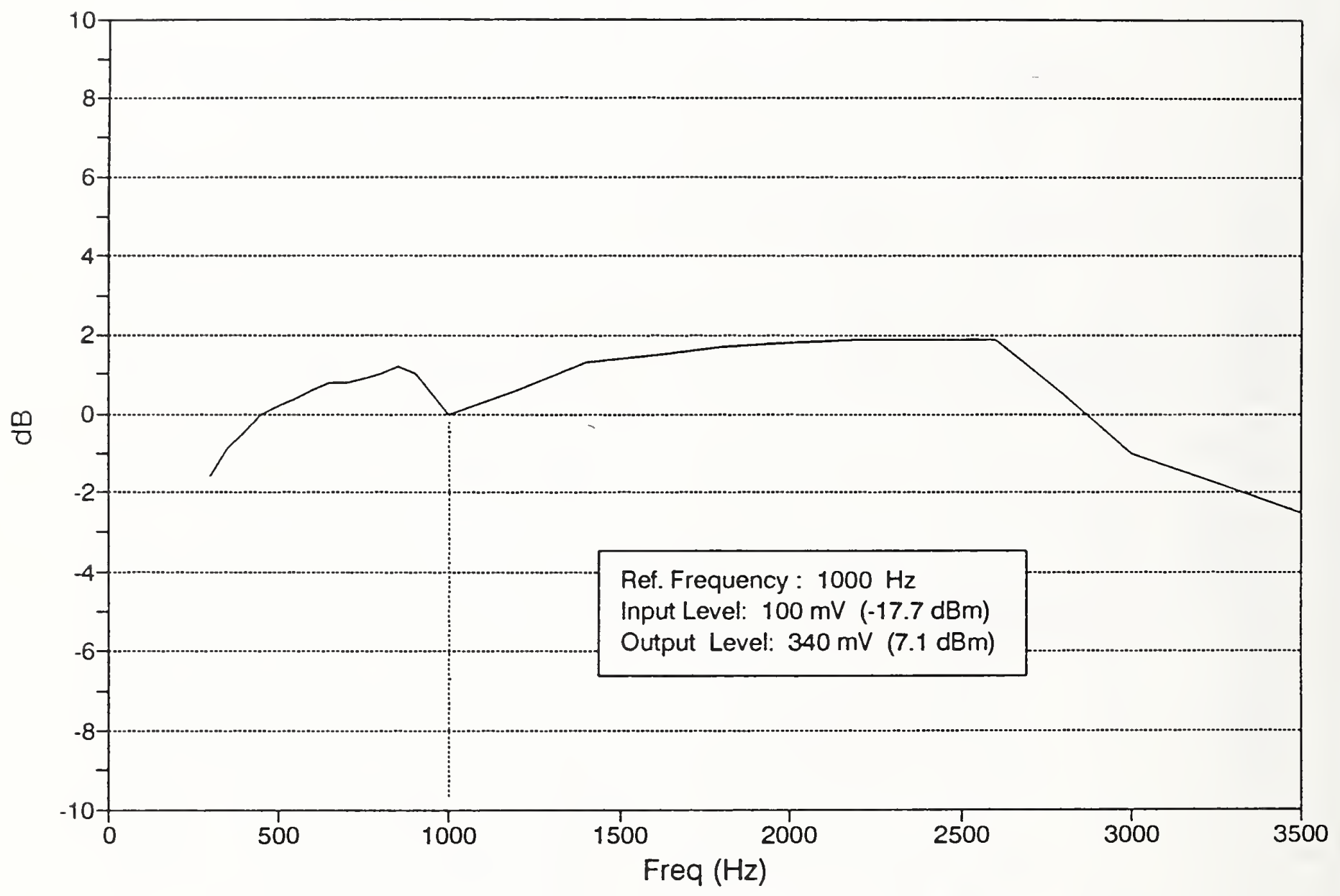




\section{AUDIO TEST - AGC $(1000 \mathrm{~Hz})$ SYSTEM \#1}

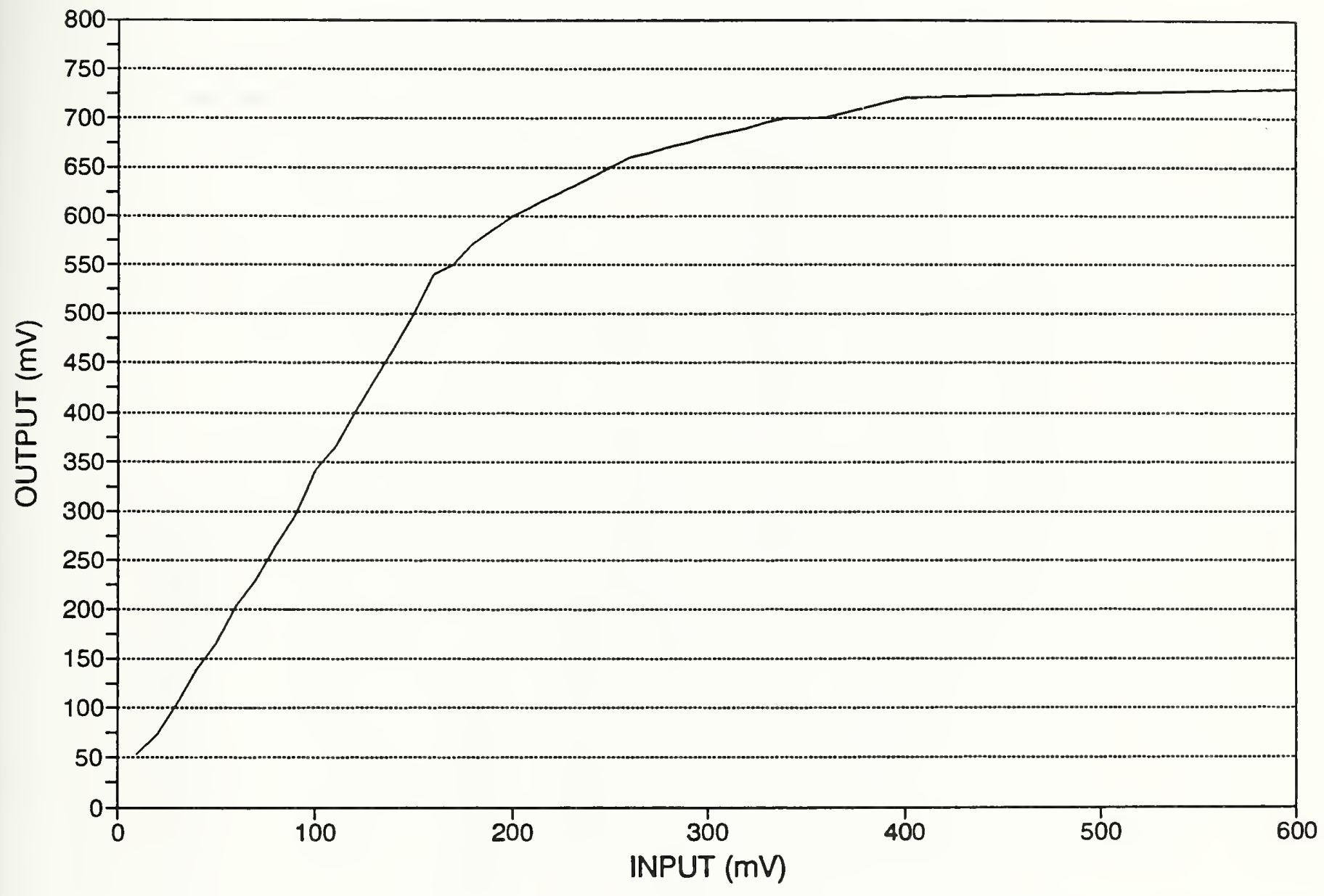


System 2 Test Data 


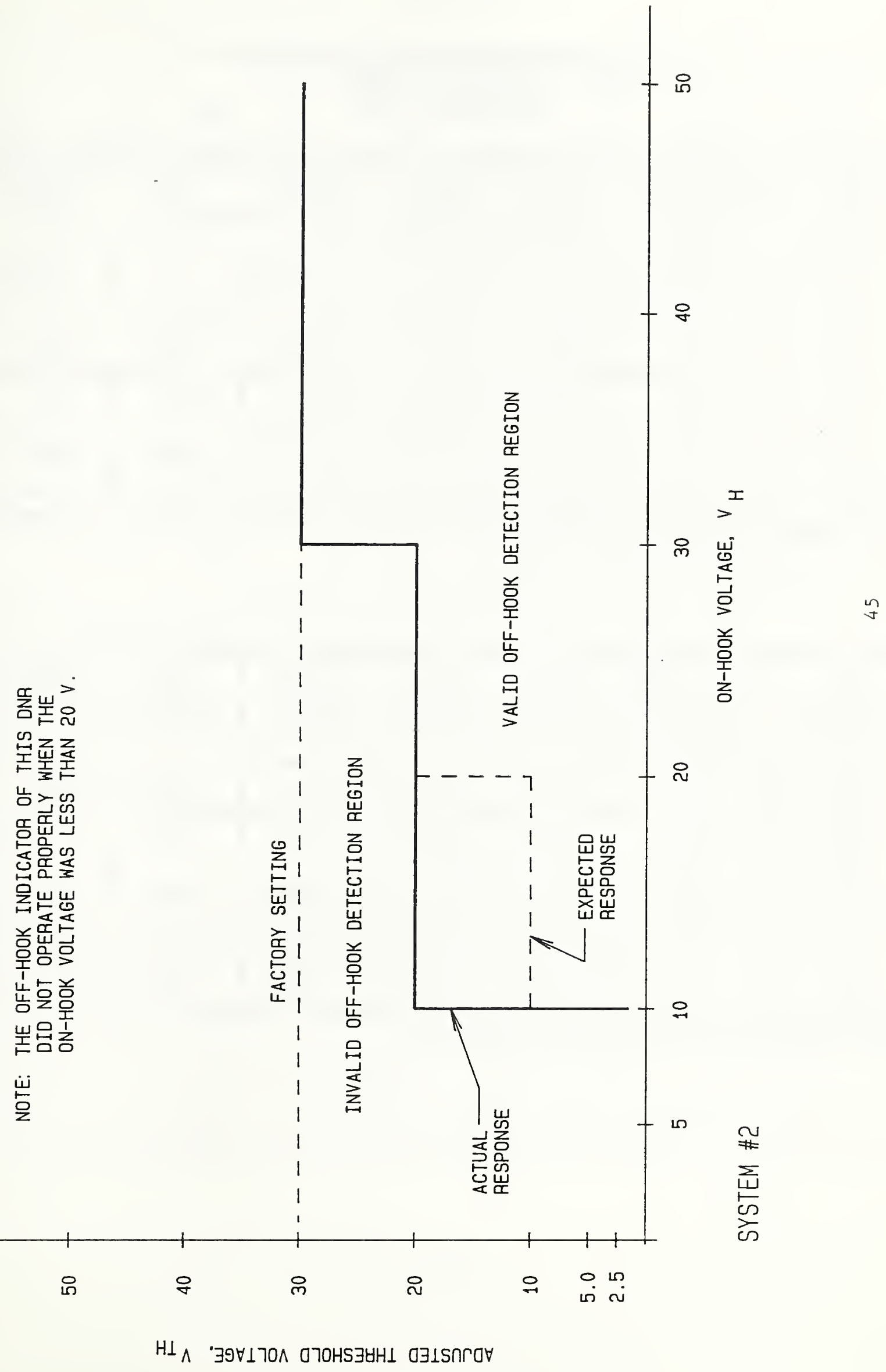




\section{DNR Dialing Response System \#2}

\begin{tabular}{|c|c|c|c|c|c|c||}
\hline $\begin{array}{c}\text { Line } \\
\text { Voltage } \\
(\mathrm{V})\end{array}$ & $\begin{array}{c}\text { Threshold } \\
\text { Voltage } \\
\left(\mathrm{V}_{\text {TH }}\right)\end{array}$ & $\begin{array}{c}\text { Digit } \\
\text { Dialed } \\
2\end{array}$ & $\begin{array}{c}\text { Digit } \\
\text { Dialed } \\
4\end{array}$ & $\begin{array}{c}\text { Digit } \\
\text { Dialed } \\
8\end{array}$ & $\begin{array}{c}\text { Digit } \\
\text { Dialed } \\
8\end{array}$ & $\begin{array}{c}\text { Digit } \\
\text { Dialed } \\
0\end{array}$ \\
\hline 50 & 30 & Yes & Yes & Yes & Yes & Yes \\
\hline 30 & 30 & Yes & Yes & Yes & Yes & Yes \\
\hline 30 & 20 & Yes & Yes & Yes & Yes & Yes \\
\hline 20 & 10 & Yes & Yes & Yes & Yes & Yes \\
\hline 10 & 5 & Yes & Yes & Yes & Yes & Yes \\
\hline
\end{tabular}

Pulse Source: Rotary Dial Telephone

\begin{tabular}{||c|c|c|c|c|c|c|}
\hline $\begin{array}{c}\text { Line } \\
\text { Voltage } \\
(\mathrm{V})\end{array}$ & $\begin{array}{c}\text { Threshold } \\
\text { Voltage } \\
\left(\mathrm{V}_{\mathrm{TH}}\right)\end{array}$ & $\begin{array}{c}\text { Digit } \\
\text { Dialed } \\
2\end{array}$ & $\begin{array}{c}\text { Digit } \\
\text { Dialed } \\
4\end{array}$ & $\begin{array}{c}\text { Digit } \\
\text { Dialed } \\
6\end{array}$ & $\begin{array}{c}\text { Digit } \\
\text { Dialed } \\
8\end{array}$ & $\begin{array}{c}\text { Digit } \\
\text { Dialed } \\
0\end{array}$ \\
\hline 50 & 40 & Yes & Yes & Yes & Yes & Yes \\
\hline 40 & 30 & Yes & Yes & Yes & Yes & Yes \\
\hline 30 & 20 & Yes & Yes & Yes & Yes & Yes \\
\hline 20 & 10 & Yes & Yes & Yes & Yes & Yes \\
\hline 10 & 5 & Yes & Yes & Yes & Yes & Yes \\
\hline
\end{tabular}

Pulse Source: Electronic Dial Telephone 
DTMF Detection Test

System \#2

\begin{tabular}{|c|c|c|c|c|c|c|c|c|c|c|}
\hline Digit & $\begin{array}{c}\mathrm{f}_{l o w} \\
-2.5 \% \\
(\mathrm{~Hz})\end{array}$ & $\begin{array}{c}\mathrm{f}_{l o w} \\
+2.5 \% \\
(\mathrm{~Hz})\end{array}$ & $\begin{array}{l}\mathrm{f}_{h i g h} \\
-2.5 \% \\
(\mathrm{~Hz})\end{array}$ & $\begin{array}{c}\mathrm{f}_{h i g h} \\
+2.5 \% \\
(\mathrm{~Hz})\end{array}$ & $\begin{array}{l}\text { 2-Freq. } \\
\text { Burst } \\
20 \mathrm{~ms} \\
\text { (min.) }\end{array}$ & $\begin{array}{l}\text { 2-Freq. } \\
\text { Burst } \\
30 \mathrm{~ms} \\
\text { (nom.) }\end{array}$ & $\begin{array}{l}\text { 2-Freq. } \\
\text { Burst } \\
40 \mathrm{~ms} \\
(\max .)\end{array}$ & $\begin{array}{c}\text { Low } \\
\text { Level } \\
\mathrm{mV} / \mathrm{dBm} \\
90 /-18\end{array}$ & $\begin{array}{c}\text { Nom } \\
\text { Level } \\
\mathrm{mV} / \mathrm{dBm} \\
390 /-6\end{array}$ & $\begin{array}{c}\text { High } \\
\text { Level } \\
\mathrm{mV} / \mathrm{dBm} \\
1228 /+4\end{array}$ \\
\hline 1 & 680 & & & 1239 & Yes & Yes & Yes & Yes & Yes & Yes \\
\hline 1 & & 714 & 1179 & & Yes & Yes & Yes & Yes & Yes & Yes \\
\hline 2 & 680 & & & 1369 & Yes & Yes & Yes & Yes & Yes & Yes \\
\hline 2 & & 714 & 1303 & & Yes & Yes & Yes & Yes & Yes & Yes \\
\hline 3 & 680 & & & 1515 & Yes & Yes & Yes & Yes & Yes & Yes \\
\hline 3 & & 714 & 1442 & & Yes & Yes & Yes & Yes & Yes & Yes \\
\hline 3 & 751 & & & 1239 & Yes & Yes & Yes & Yes & Yes & Yes \\
\hline 3 & & 789 & 1179 & & Yes & Yes & Yes & Yes & Yes & Yes \\
\hline 5 & 751 & & & 1369 & Yes & Yes & Yes & Yes & Yes & Yes \\
\hline 5 & & 789 & 1303 & & Yes & Yes & Yes & Yes & Yes & Yes \\
\hline 5 & 751 & & & 1515 & Yes & Yes & Yes & Yes & Yes & Ycs \\
\hline 5 & & 789 & 1442 & & Yes & Yes & Yes & Yes & Yes & Yes \\
\hline 7 & 831 & & & 1239 & Yes & Yes & Yes & Yes & Yes & Yes \\
\hline 7 & & 873 & 1179 & & Yes & Yes & Yes & Yes & Yes & Yes \\
\hline 5 & 831 & & & 1369 & Yes & Yes & Yes & Yes & Yes & Yes \\
\hline 8 & & 873 & 1303 & & Yes & Yes & Yes & Yes & Yes & Yes \\
\hline i & 831 & & & 1515 & Yes & Yes & Yes & Yes & Yes & Yes \\
\hline 9 & & 873 & 1442 & & Yes & Yes & Yes & Yes & Yes & Yes \\
\hline 0 & 918 & & & 1369 & Yes & Yes & Yes & Yes & Yes & Yes \\
\hline 0 & & 964 & 1303 & & Yes & Yes & Yes & Yes & Yes & Yes \\
\hline 3 & 918 & & & 1239 & Yes & Yes & Yes & Yes & Yes & Yes \\
\hline * & & 964 & 1179 & & Yes & Yes & Yes & Yes & Yes & Yes \\
\hline$\#$ & 918 & & & 1515 & Yes & Yes & Yes & Yes & Yes & Yes \\
\hline \# & & 964 & 1442 & & Yes & Yes & Yes & Yes & Yes & Yes \\
\hline
\end{tabular}




\section{AUDIO TEST - FREQUENCY RESPONSE SYSTEM \#2}

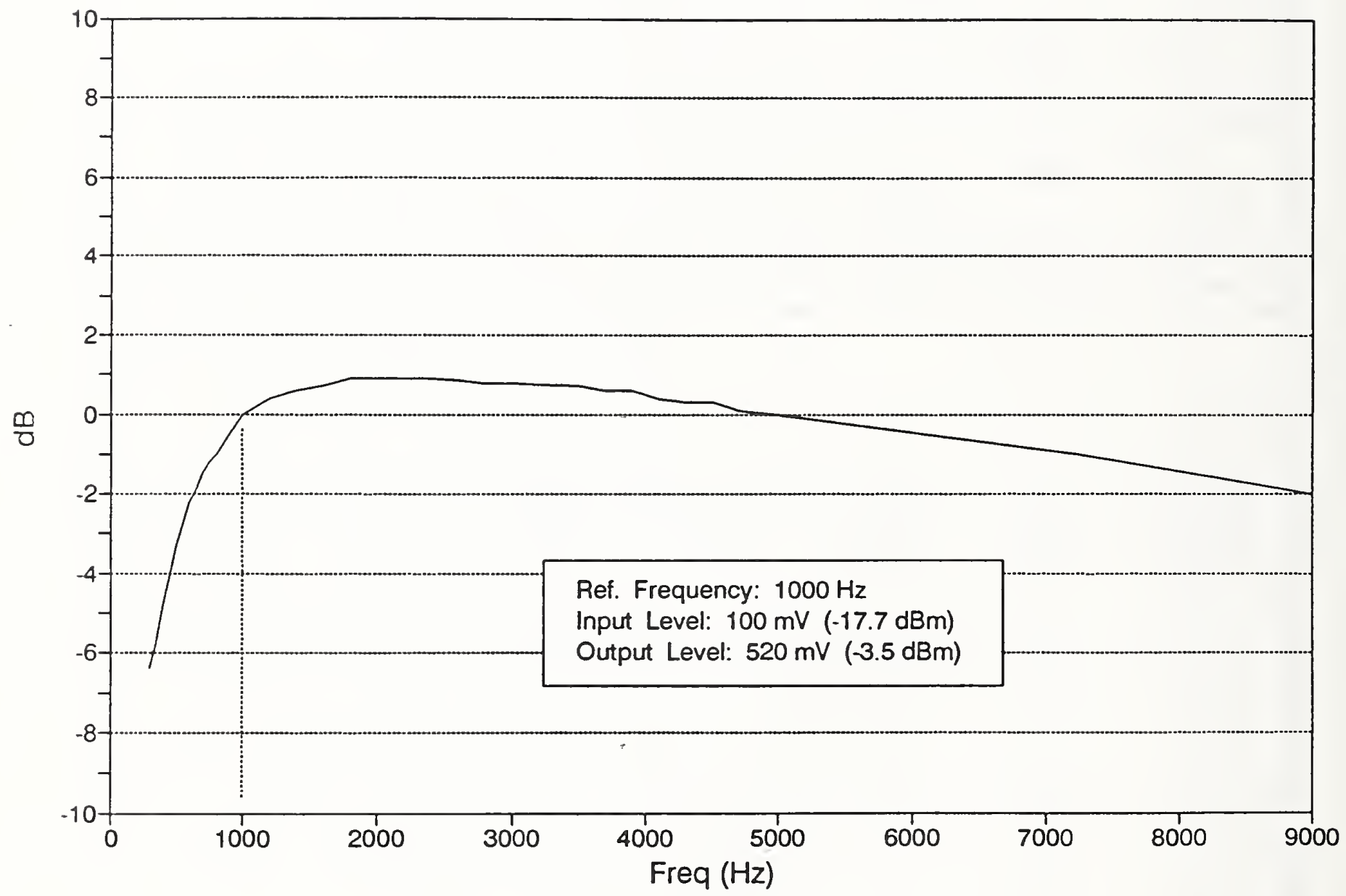


AUDIO TEST - AGC $(1000 \mathrm{~Hz})$

SYSTEM \#2

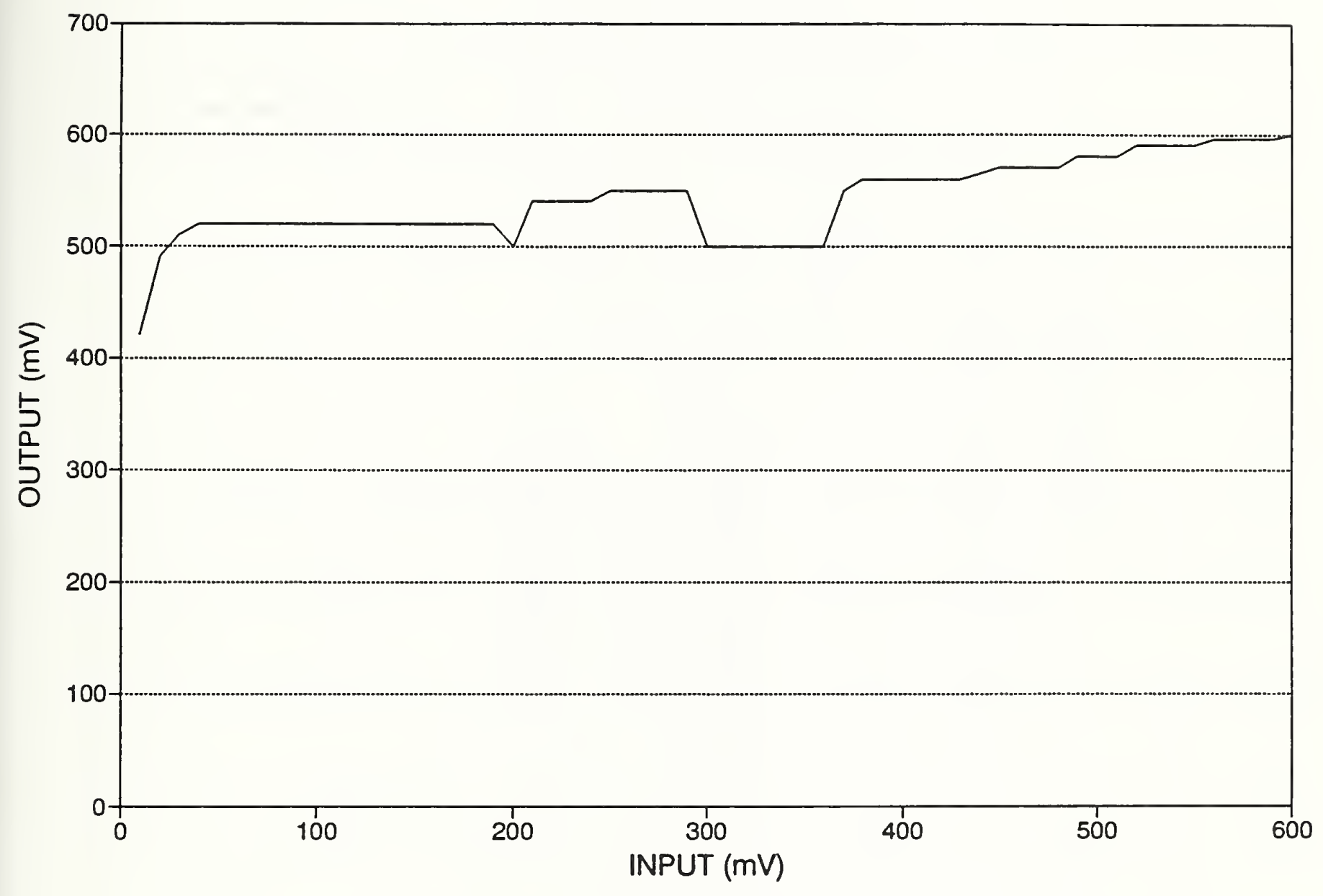


System 3 Test Data 


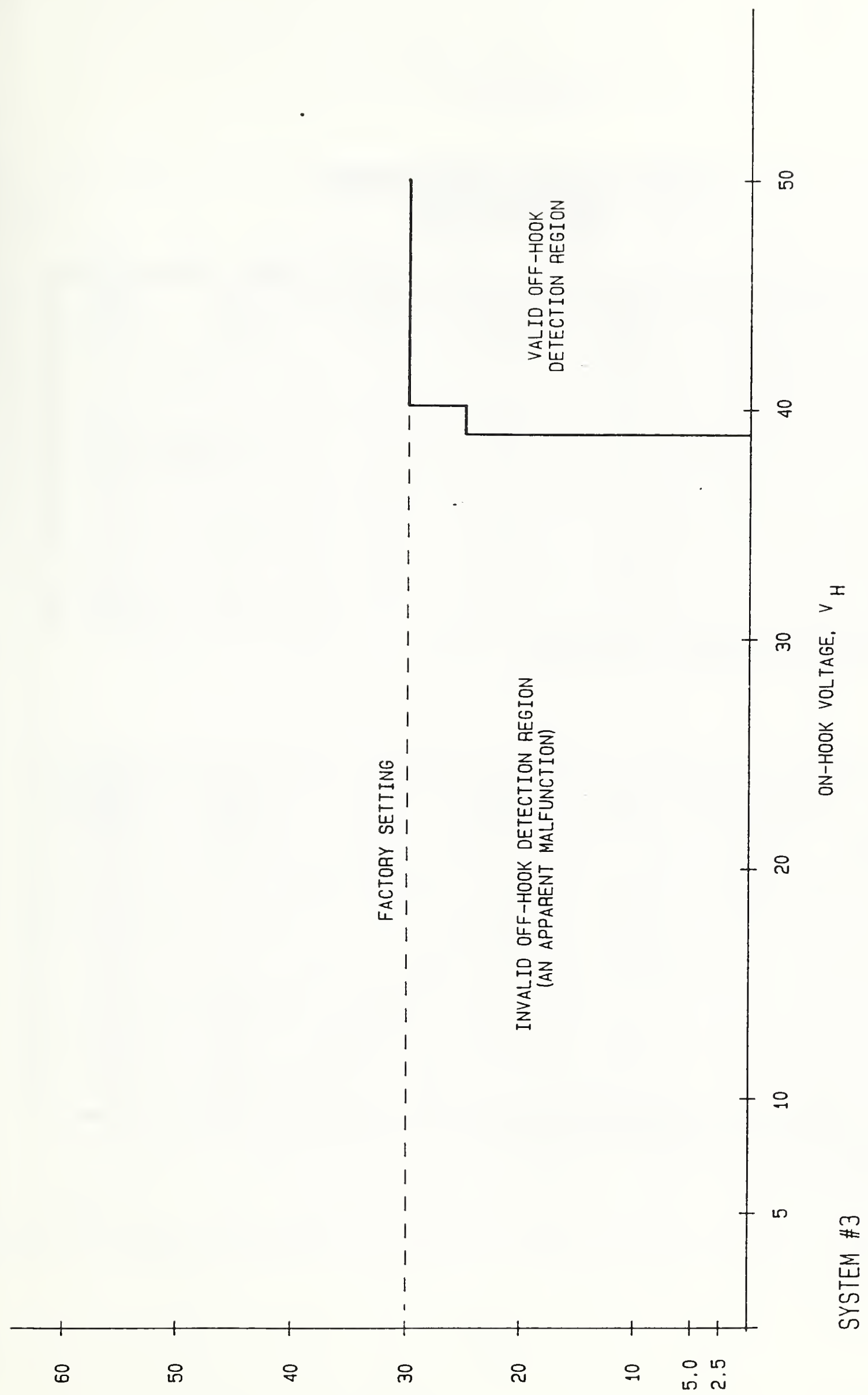

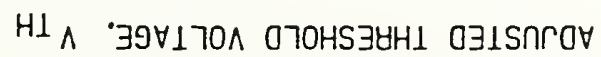




\section{DNR Dialing Response System \#3}

\begin{tabular}{||c|c|c|c|c|c|c||}
\hline $\begin{array}{c}\text { Line } \\
\text { Voltage } \\
(\mathrm{V})\end{array}$ & $\begin{array}{c}\text { Threshold } \\
\text { Voltage } \\
\left(\mathrm{V}_{\mathrm{TH}}\right)\end{array}$ & $\begin{array}{c}\text { Digit } \\
\text { Dialed } \\
2\end{array}$ & $\begin{array}{c}\text { Digit } \\
\text { Dialed } \\
4\end{array}$ & $\begin{array}{c}\text { Digit } \\
\text { Dialed } \\
6\end{array}$ & $\begin{array}{c}\text { Digit } \\
\text { Dialed } \\
8\end{array}$ & $\begin{array}{c}\text { Digit } \\
\text { Dialed } \\
0\end{array}$ \\
\hline 50 & 40 & Yes & Yes & Yes & Yes & Yes \\
\hline 30 & 30 & No & No & No & No & No \\
\hline 30 & 20 & No & No & No & No & No \\
\hline 20 & 10 & No & No & No & No & No \\
\hline 10 & 5 & No & No & No & No & No \\
\hline
\end{tabular}

Pulse Source: Rotary Dial Telephone

\begin{tabular}{|c|c|c|c|c|c|c|}
\hline $\begin{array}{c}\text { Line } \\
\text { Voltage } \\
(\mathrm{V})\end{array}$ & $\begin{array}{c}\text { Threshold } \\
\text { Voltage } \\
\left(\mathrm{V}_{\mathrm{TH}}\right)\end{array}$ & $\begin{array}{c}\text { Digit } \\
\text { Dialed } \\
2\end{array}$ & $\begin{array}{c}\text { Digit } \\
\text { Dialed } \\
4\end{array}$ & $\begin{array}{c}\text { Digit } \\
\text { Dialed } \\
6\end{array}$ & $\begin{array}{c}\text { Digit } \\
\text { Dialed } \\
6\end{array}$ & $\begin{array}{c}\text { Digit } \\
\text { Dialed } \\
0\end{array}$ \\
\hline 50 & 40 & No & Yes & Yes & Yes & Yes \\
\hline 30 & 30 & No & No & No & No & No \\
\hline 30 & 20 & No & No & No & No & No \\
\hline 20 & 10 & No & No & No & No & No \\
\hline 10 & 5 & No & No & No & No & No \\
\hline
\end{tabular}

Pulse Source: Electronic Dial Telephone 
DTMF Detection Test

System \#3

\begin{tabular}{|c|c|c|c|c|c|c|c|c|c|c|}
\hline Digit & $\begin{array}{c}\mathrm{f}_{\text {low }} \\
-2.5 \% \\
(\mathrm{~Hz}) \\
\end{array}$ & $\begin{array}{c}\mathrm{f}_{l o w} \\
+2.5 \% \\
(\mathrm{~Hz})\end{array}$ & $\begin{array}{c}\mathrm{f}_{h i g h} \\
-2.5 \% \\
(\mathrm{~Hz})\end{array}$ & $\begin{array}{l}\mathrm{f}_{\text {high }} \\
+2.5 \% \\
(\mathrm{~Hz})\end{array}$ & $\begin{array}{c}\text { 2-Freq. } \\
\text { Burst } \\
20 \mathrm{~ms} \\
\text { (min.) }\end{array}$ & $\begin{array}{c}\text { 2-Freq. } \\
\text { Burst } \\
30 \mathrm{~ms} \\
\text { (nom.) }\end{array}$ & $\begin{array}{c}\text { 2-Freq. } \\
\text { Burst } \\
40 \mathrm{~ms} \\
\text { (max.) }\end{array}$ & $\begin{array}{c}\text { Low } \\
\text { Level } \\
\mathrm{mV} / \mathrm{dBm} \\
90 /-18\end{array}$ & $\begin{array}{c}\text { Nom } \\
\text { Level } \\
\mathrm{mV} / \mathrm{dBm} \\
390 /-6\end{array}$ & $\begin{array}{c}\text { High } \\
\text { Level } \\
\mathrm{mV} / \mathrm{dBm} \\
1228 /+4\end{array}$ \\
\hline 1 & 680 & & & 1239 & Yes & Yes & Yes & No & Yes & Yes \\
\hline 1 & & 714 & 1179 & & Yes & Yes & Yes & No & Yes & Yes \\
\hline 2 & 680 & & & 1369 & Yes & Yes & Yes & No & Yes & Yes \\
\hline 2 & & 714 & 1303 & & Yes & Yes & Yes & No & Yes & Yes \\
\hline 3 & 680 & & & 1515 & Yes & Yes & Yes & No & Yes & Yes \\
\hline 3 & & 714 & 1442 & & Yes & Yes & Yes & No & Yes & Yes \\
\hline 3 & 751 & & & 1239 & Yes & Yes & Yes & No & Yes & Yes \\
\hline 3 & & 789 & 1179 & & Yes & Yes & Yes & No & Yes & Yes \\
\hline 5 & 751 & & & 1369 & Yes & Yes & Yes & No & Yes & Yes \\
\hline 5 & & 789 & 1303 & & Yes & Yes & Yes & No & Yes & Yes \\
\hline 6 & 751 & & & 1515 & Yes & Yes & Yes & No & Yes & Yes \\
\hline 6 & & 789 & 1442 & & Yes & Yes & Yes & No & Yes & Yes \\
\hline 7 & 831 & & & 1239 & Yes & Yes & Yes & No & Yes & Yes \\
\hline 7 & & 873 & 1179 & & Yes & Yes & Yes & No & Yes & Yes \\
\hline 6 & 831 & & & 1369 & Yes & Yes & Yes & No & Yes & Yes \\
\hline 8 & & 873 & 1303 & & Yes & Yes & Yes & No & Yes & Yes \\
\hline 9 & 831 & & & 1515 & Yes & Yes & Yes & No & Yes & Yes \\
\hline 9 & & 873 & 1442 & & Yes & Yes & Yes & No & Yes & Yes \\
\hline 0 & 918 & & & 1369 & Yes & Yes & Yes & No & Yes & Yes \\
\hline 9 & & 964 & 1303 & & Yes & Yes & Yes & No & Yes & Yes \\
\hline 3 & 918 & & & 1239 & Yes & Yes & Yes & No & Yes & Yes \\
\hline * & & 964 & 1179 & & Yes & Yes & Yes & No & Yes & Yes \\
\hline$\#$ & 918 & & & 1515 & Yes & Yes & Yes & No & Yes & Yes \\
\hline$\#$ & & 964 & 1442 & & Yes & Yes & Yes & No & Yes & Yes \\
\hline
\end{tabular}




\section{AUDIO TEST - FREQUENCY RESPONSE SYSTEM \#3}

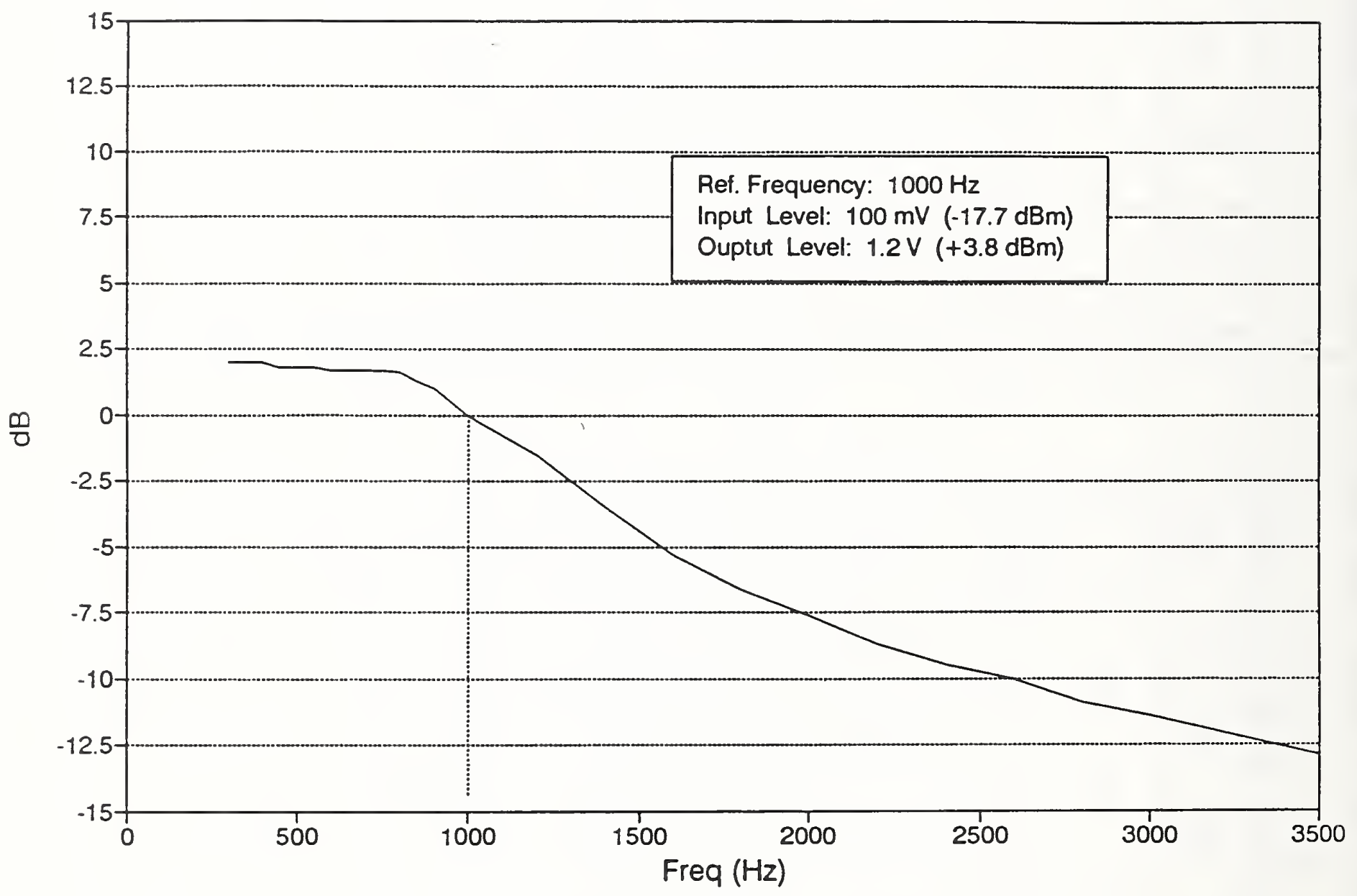




\section{AUDIO TEST - AGC $(1000 \mathrm{~Hz})$ SYSTEM \#3}

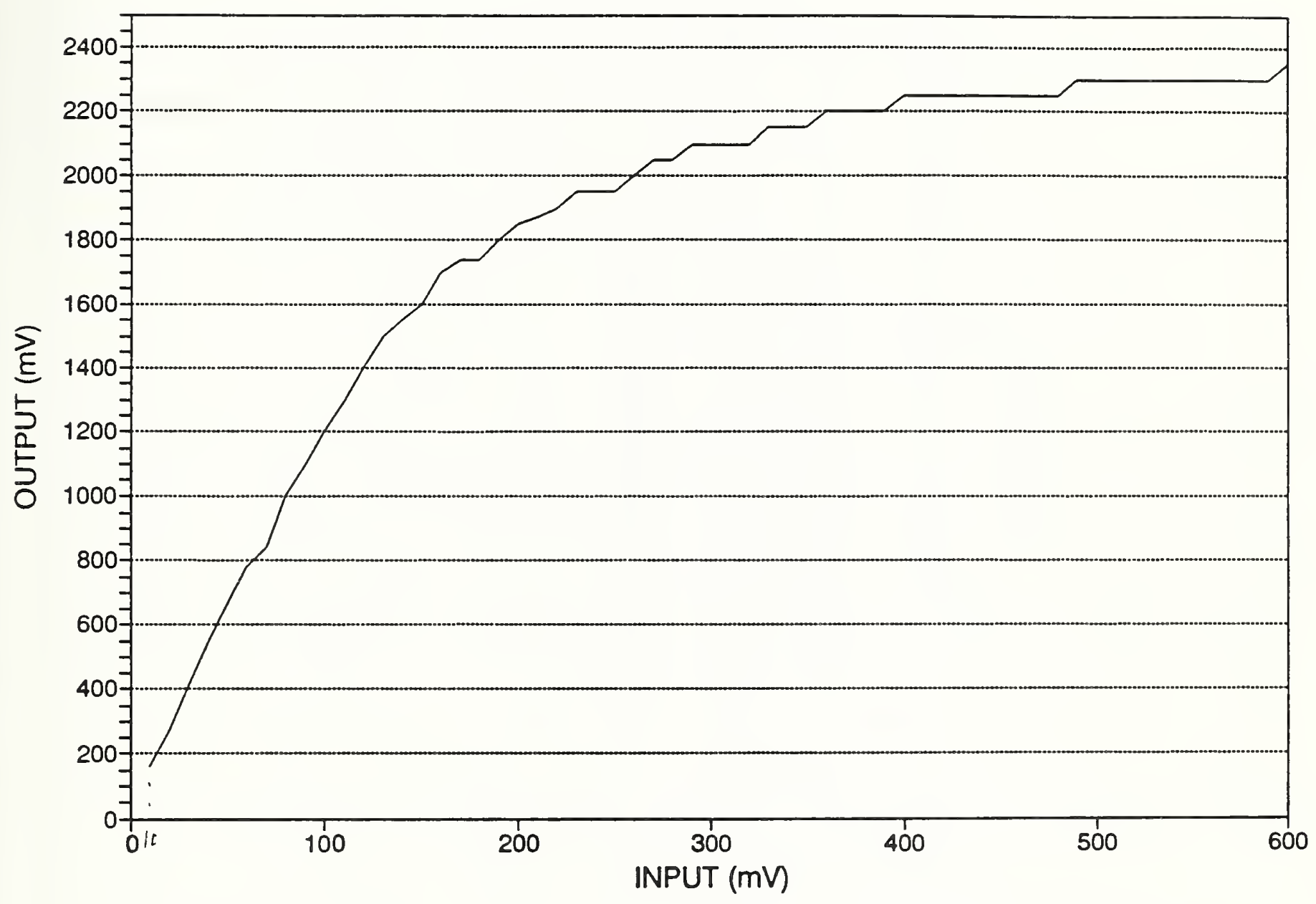


System 4 Test Data 


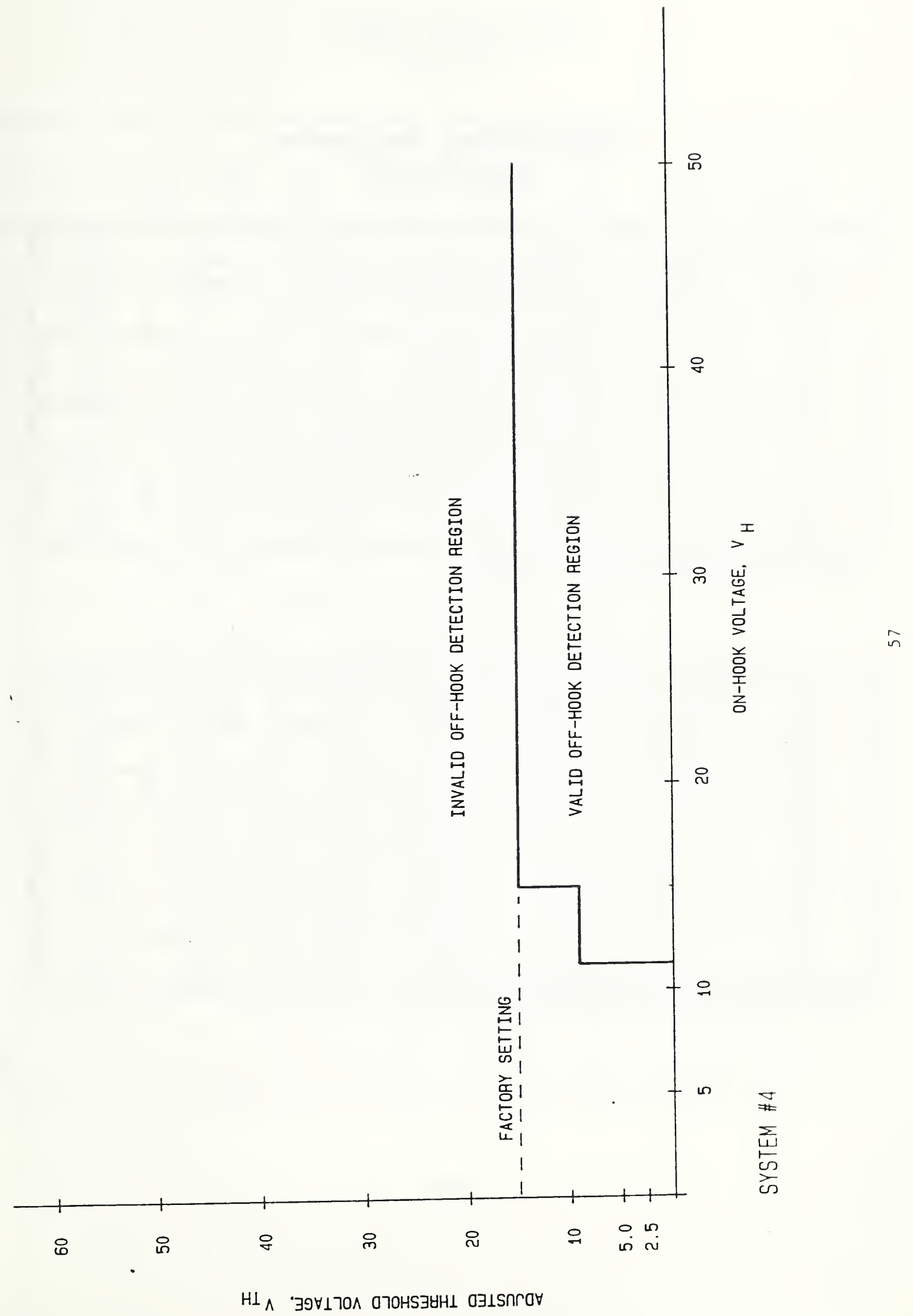




\section{DNR Dialing Response System \#4}

\begin{tabular}{|c|c|c|c|c|c|c|}
\hline $\begin{array}{c}\text { Line } \\
\text { Voltage } \\
(\mathrm{V})\end{array}$ & $\begin{array}{c}\text { Threshold } \\
\text { Voltage } \\
\left(\mathrm{V}_{\mathrm{TH}}\right)\end{array}$ & $\begin{array}{c}\text { Digit } \\
\text { Dialed } \\
2\end{array}$ & $\begin{array}{c}\text { Digit } \\
\text { Dialed } \\
4\end{array}$ & $\begin{array}{c}\text { Digit } \\
\text { Dialed } \\
6\end{array}$ & $\begin{array}{c}\text { Digit } \\
\text { Dialed } \\
8\end{array}$ & $\begin{array}{c}\text { Digit } \\
\text { Dialed } \\
0\end{array}$ \\
\hline 50 & 10 & Yes & Yes & Yes & Yes & Yes \\
\hline 30 & 30 & Yes & Yes & Yes & Yes & Yes \\
\hline 30 & 20 & Yes & Yes & Yes & Yes & Yes \\
\hline 20 & 10 & Yes & Yes & Yes & Yes & Yes \\
\hline 10 & 5 & Yes & Yes & Yes & Yes & Yes \\
\hline
\end{tabular}

Pulse Source: Rotary Dial Telephone

\begin{tabular}{|c|c|c|c|c|c|c||}
\hline $\begin{array}{c}\text { Line } \\
(\mathrm{V})\end{array}$ & $\begin{array}{c}\text { Threshold } \\
\text { Voltage } \\
\left(\mathrm{V}_{\mathrm{TH}}\right)\end{array}$ & $\begin{array}{c}\text { Digit } \\
\text { Dialed } \\
2\end{array}$ & $\begin{array}{c}\text { Digit } \\
\text { Dialed } \\
4\end{array}$ & $\begin{array}{c}\text { Digit } \\
\text { Dialed } \\
\mathbf{8}\end{array}$ & $\begin{array}{c}\text { Digit } \\
\text { Dialed } \\
8\end{array}$ & $\begin{array}{c}\text { Digit } \\
\text { Dialed } \\
0\end{array}$ \\
\hline 50 & 10 & Yes & Yes & Yes & Yes & Yes \\
\hline 40 & 30 & Yes & Yes & Yes & Yes & Yes \\
\hline 30 & 20 & Yes & Yes & Yes & Yes & Yes \\
\hline 20 & 10 & Yes & Yes & Yes & Yes & Yes \\
\hline 10 & 5 & Yes & Yes & Yes & Yes & Yes \\
\hline
\end{tabular}

Pulse Source: Electronic Dial Telephone 


\begin{tabular}{|c|c|c|c|c|c|c|c|c|c|c|}
\hline Digit & $\begin{array}{c}\mathrm{f}_{\text {low }} \\
-2.5 \% \\
(\mathrm{~Hz})\end{array}$ & $\begin{array}{c}\mathrm{f}_{l o w} \\
+2.5 \% \\
(\mathrm{~Hz})\end{array}$ & $\begin{array}{c}\mathbf{f}_{h i g h} \\
-2.5 \% \\
(\mathrm{~Hz})\end{array}$ & $\begin{array}{c}\mathrm{f}_{h i g h} \\
+2.5 \% \\
(\mathrm{~Hz})\end{array}$ & $\begin{array}{c}\text { 2-Freq. } \\
\text { Burst } \\
20 \mathrm{~ms} \\
\text { (min.) }\end{array}$ & $\begin{array}{c}\text { 2-Freq. } \\
\text { Burst } \\
30 \mathrm{~ms} \\
\text { (nom.) } \\
\end{array}$ & $\begin{array}{c}\text { 2-Freq. } \\
\text { Burst } \\
40 \mathrm{~ms} \\
\text { (max.) }\end{array}$ & $\begin{array}{c}\text { Low } \\
\text { Level } \\
\mathrm{mV} / \mathrm{dBm} \\
90 /-18\end{array}$ & $\begin{array}{c}\text { Nom } \\
\text { Level } \\
\mathrm{mV} / \mathrm{dBm} \\
390 /-6\end{array}$ & $\begin{array}{c}\text { High } \\
\text { Level } \\
\mathrm{mV} / \mathrm{dBm} \\
1228 /+4\end{array}$ \\
\hline 1 & 680 & & & 1239 & Yes & Yes & Yes & Yes & Yes & Yes \\
\hline 1 & & 714 & 1179 & & Yes & Yes & Yes & Yes & Yes & Yes \\
\hline 2 & 680 & & & 1369 & Yes & Yes & Yes & Yes & Yes & Yes \\
\hline 7 & & 714 & 1303 & & Yes & Yes & Yes & Yes & Yes & Yes \\
\hline 3 & 680 & & & 1515 & Yes & Yes & Yes & Yes & Yes & Yes \\
\hline$*$ & & 714 & 1442 & & Yes & Yes & Yes & Yes & Yes & Yes \\
\hline * & 751 & & & 1239 & Yes & Yes & Yes & Yes & Yes & Yes \\
\hline * & & 789 & 1179 & & Yes & Yes & Yes & Yes & Yes & Yes \\
\hline$*$ & 751 & & & 1369 & Yes & Yes & Yes & Yes & Yes & Yes \\
\hline 9 & & 789 & 1303 & & Yes & Yes & Yes & Yes & Yes & Yes \\
\hline 6 & 751 & & & 1515 & Yes & Yes & Yes & Yes & Yes & Yes \\
\hline 6 & & 789 & 1442 & & Yes & Yes & Yes & Yes & Yes & Yes \\
\hline 7 & 831 & & & 1239 & Yes & Yes & Yes & Yes & Yes & Yes \\
\hline 7 & & 873 & 1179 & & Yes & Yes & Yes & Yes & Yes & Yes \\
\hline 8 & 831 & & & 1369 & Yes & Yes & Yes & Yes & Yes & Yes \\
\hline 8 & & 873 & 1303 & & Yes & Yes & Yes & Yes & Yes & Yes \\
\hline 9 & 831 & & & 1515 & Yes & Yes & Yes & Yes & Yes & Yes \\
\hline 9 & & 873 & 1442 & & Yes & Yes & Yes & Yes & Yes & Yes \\
\hline 0 & 918 & & & 1369 & Yes & Yes & Yes & Yes & Yes & Yes \\
\hline 0 & & 964 & 1303 & & Yes & Yes & Yes & Yes & Yes & Yes \\
\hline * & 918 & & & 1239 & Yes & Yes & Yes & Yes & Yes & Yes \\
\hline * & & 964 & 1179 & & Yes & Yes & Yes & Yes & Yes & Yes \\
\hline \# & 918 & & & 1515 & Yes & Yes & Yes & Yes & Yes & Yes \\
\hline$\#$ & & 964 & 1442 & & Yes & Yes & Yes & Yes & Yes & Yes \\
\hline
\end{tabular}




\section{AUDIO TEST - FREQUENCY RESPONSE SYSTEM \#4}

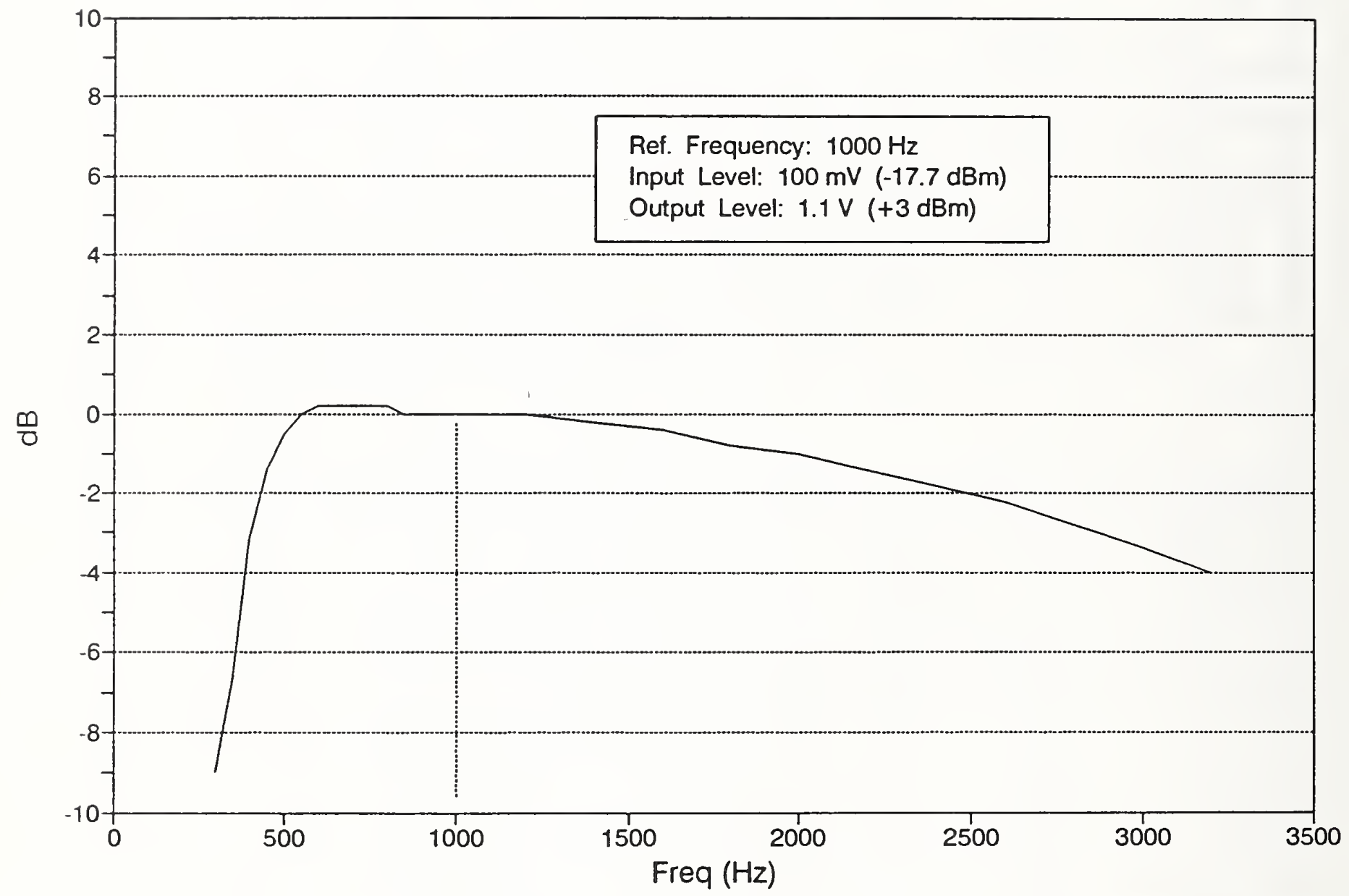


System 5 Test Data 


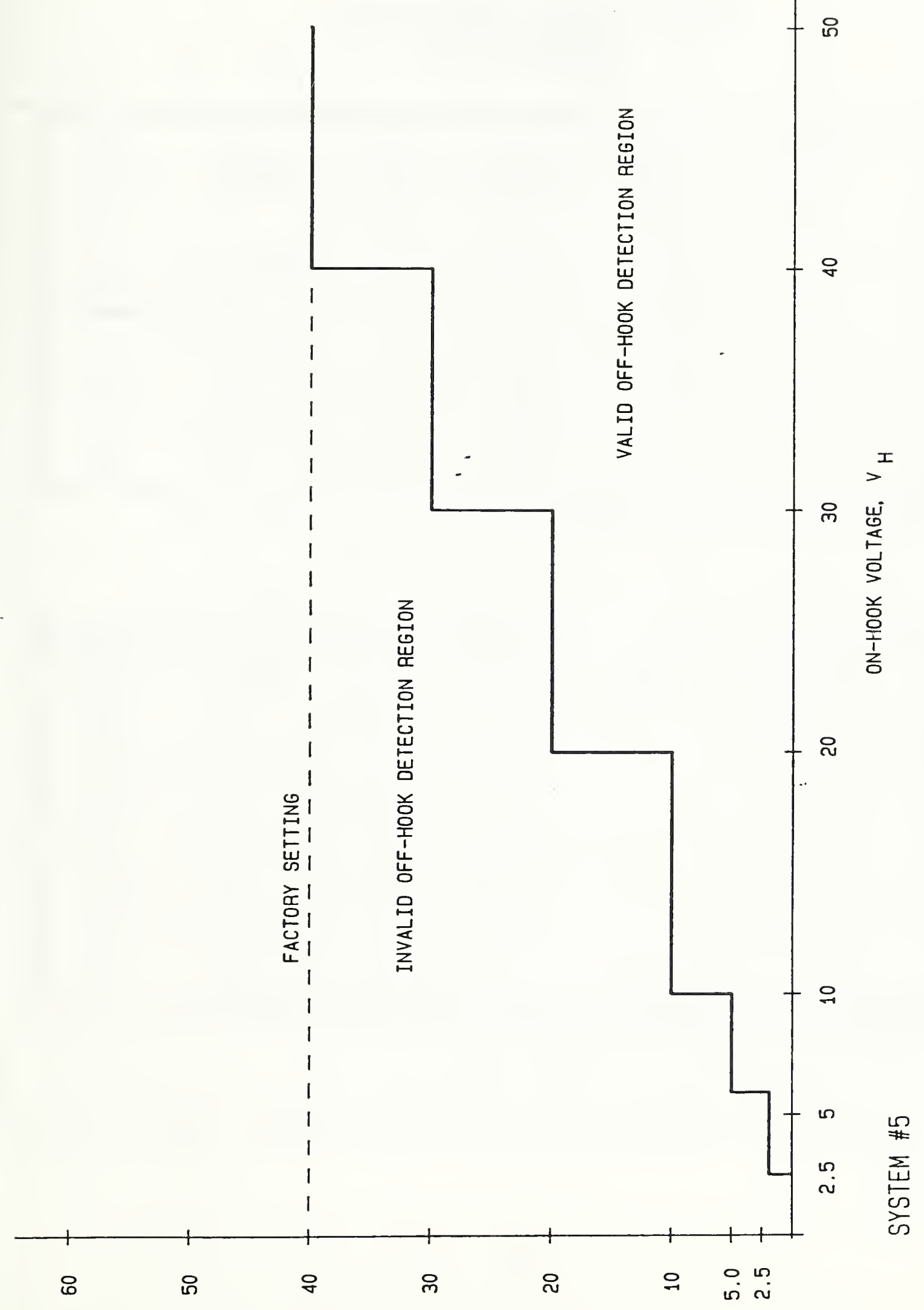

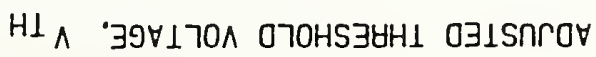




\section{DNR Dialing Response System \#5}

\begin{tabular}{||c|c|c|c|c|c|c||}
\hline $\begin{array}{c}\text { Line } \\
\text { Voltage } \\
(\mathrm{V})\end{array}$ & $\begin{array}{c}\text { Threshold } \\
\text { Voltage } \\
\left(\mathrm{V}_{\mathrm{TH}}\right)\end{array}$ & $\begin{array}{c}\text { Digit } \\
\text { Dialed } \\
2\end{array}$ & $\begin{array}{c}\text { Digit } \\
\text { Dialed } \\
4\end{array}$ & $\begin{array}{c}\text { Digit } \\
\text { Dialed } \\
6\end{array}$ & $\begin{array}{c}\text { Digit } \\
\text { Dialed } \\
8\end{array}$ & $\begin{array}{c}\text { Digit } \\
\text { Dialed } \\
0\end{array}$ \\
\hline 50 & 40 & Yes & Yes & Yes & Yes & Yes \\
\hline 10 & 30 & Yes & Yes & Yes & Yes & Yes \\
\hline 30 & 20 & Yes & Yes & Yes & Yes & Yes \\
\hline 20 & 10 & Yes & Yes & Yes & Yes & Yes \\
\hline 10 & 5 & Yes & Yes & Yes & Yes & Yes \\
\hline
\end{tabular}

Pulse Source: Rotary Dial Telephone

\begin{tabular}{|c|c|c|c|c|c|c||}
\hline $\begin{array}{c}\text { Line } \\
\text { Voltage } \\
(\mathrm{V})\end{array}$ & $\begin{array}{c}\text { Threshold } \\
\text { Voltage } \\
\left(\mathrm{V}_{\mathrm{TH}}\right)\end{array}$ & $\begin{array}{c}\text { Digit } \\
\text { Dialed } \\
2\end{array}$ & $\begin{array}{c}\text { Digit } \\
\text { Dialed } \\
4\end{array}$ & $\begin{array}{c}\text { Digit } \\
\text { Dialed } \\
6\end{array}$ & $\begin{array}{c}\text { Digit } \\
\text { Dialed } \\
8\end{array}$ & $\begin{array}{c}\text { Digit } \\
\text { Dialed } \\
0\end{array}$ \\
\hline 50 & 40 & Yes & Yes & Yes & Yes & Yes \\
\hline 40 & 30 & Yes & Yes & Yes & Yes & Yes \\
\hline 30 & 20 & Yes & Yes & Yes & Yes & Yes \\
\hline 20 & 10 & Yes & Yes & Yes & Yes & Yes \\
\hline 10 & 5 & Yes & Yes & Yes & Yes & Yes \\
\hline
\end{tabular}

Pulse Source: Electronic Dial Telephone 


\section{DTMF Detection Test System \#5}

\begin{tabular}{|c|c|c|c|c|c|c|c|c|c|c|}
\hline Digit & $\begin{array}{c}\mathrm{f}_{\text {low }} \\
-2.5 \% \\
(\mathrm{~Hz})\end{array}$ & $\begin{array}{c}\mathrm{f}_{\text {low }} \\
+2.5 \% \\
(\mathrm{~Hz})\end{array}$ & $\begin{array}{c}\mathbf{f}_{h i g h} \\
-2.5 \% \\
(\mathrm{~Hz})\end{array}$ & $\begin{array}{l}\mathrm{f}_{h i g h} \\
+2.5 \% \\
(\mathrm{~Hz})\end{array}$ & $\begin{array}{l}\text { 2-Freq. } \\
\text { Burst } \\
20 \mathrm{~ms} \\
\text { (min.) }\end{array}$ & $\begin{array}{c}\text { 2-Freq. } \\
\text { Burst } \\
30 \mathrm{~ms} \\
\text { (nom.) }\end{array}$ & $\begin{array}{l}\text { 2-Freq. } \\
\text { Burst } \\
40 \mathrm{~ms} \\
\text { (max.) }\end{array}$ & $\begin{array}{c}\text { Low } \\
\text { Level } \\
\mathrm{mV} / \mathrm{dBm} \\
90 /-18\end{array}$ & $\begin{array}{c}\text { Nom } \\
\text { Level } \\
\mathrm{mV} / \mathrm{dBm} \\
390 /-6\end{array}$ & $\begin{array}{c}\text { High } \\
\text { Level } \\
\mathrm{mV} / \mathrm{dBm} \\
1228 /+4\end{array}$ \\
\hline 1 & 680 & & & 1239 & Yes & Yes & Yes & Yes & Yes & Yes \\
\hline 1 & & 714 & 1179 & & Yes & Yes & Yes & Yes & Yes & Yes \\
\hline 2 & 680 & & & 1369 & Yes & Yes & Yes & Yes & Yes & Yes \\
\hline 2 & & 714 & 1303 & & Yes & Yes & Yes & Yes & Yes & Yes \\
\hline 3 & 680 & & & 1515 & Yes & Yes & Yes & Yes & Yes & Yes \\
\hline 4 & & 714 & 1442 & & Yes & Yes & Yes & Yes & Yes & Yes \\
\hline 4 & 751 & & & 1239 & Yes & Yes & Yes & Yes & Yes & Yes \\
\hline 4 & & 789 & 1179 & & Yes & Yes & Yes & Yes & Yes & Yes \\
\hline 5 & 751 & & & 1369 & Yes & Yes & Yes & Yes & Yes & Yes \\
\hline 5 & & 789 & 1303 & & Yes & Yes & Yes & Yes & Yes & Yes \\
\hline 5 & 751 & & & 1515 & Yes & Yes & Yes & Yes & Yes & Yes \\
\hline 6 & & 789 & 1442 & & Yes & Yes & Yes & Yes & Yes & Yes \\
\hline 7 & 831 & & & 1239 & Yes & Yes & Yes & Yes & Yes & Yes \\
\hline 4 & & 873 & 1179 & & Yes & Yes & Yes & Yes & Yes & Yes \\
\hline $\mathfrak{s}$ & 831 & & & 1369 & Yes & Yes & Yes & Yes & Yes & Yes \\
\hline$\theta$ & & 873 & 1303 & & Yes & Yes & Yes & Yes & Yes & Yes \\
\hline 0 & 831 & & & 1515 & Yes & Yes & Yes & Yes & Yes & Yes \\
\hline 9 & & 873 & 1442 & & Yes & Yes & Yes & Yes & Yes & Yes \\
\hline 0 & 918 & & & 1369 & Yes & Yes & Yes & Yes & Yes & Yes \\
\hline 0 & & 964 & 1303 & & Yes & Yes & Yes & Yes & Yes & Yes \\
\hline 4 & 918 & & & 1239 & Yes & Yes & Yes & Yes & Yes & Yes \\
\hline$*$ & & 964 & 1179 & & Yes & Yes & Yes & Yes & Yes & Yes \\
\hline \# & 918 & & & 1515 & Yes & Yes & Yes & Yes & Yes & Yes \\
\hline \# & & 964 & 1442 & & Yes & Yes & Yes & Yes & Yes & Yes \\
\hline
\end{tabular}




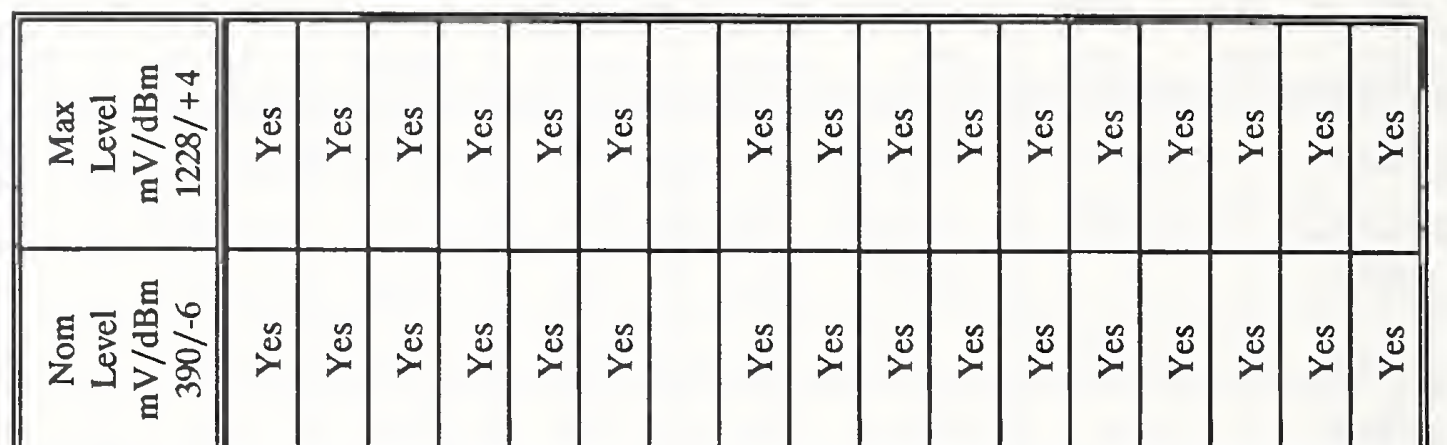

总

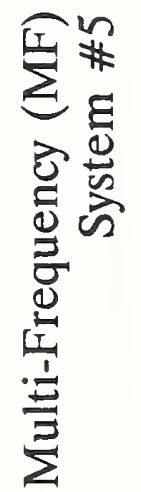

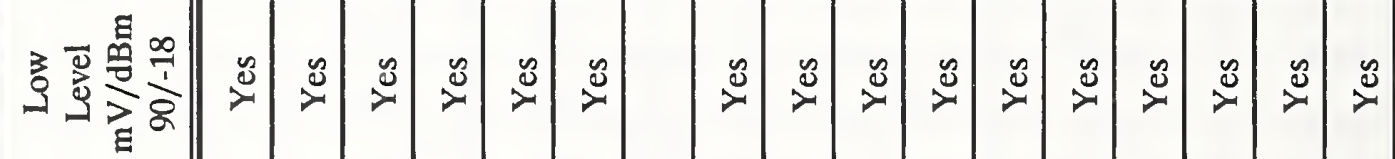

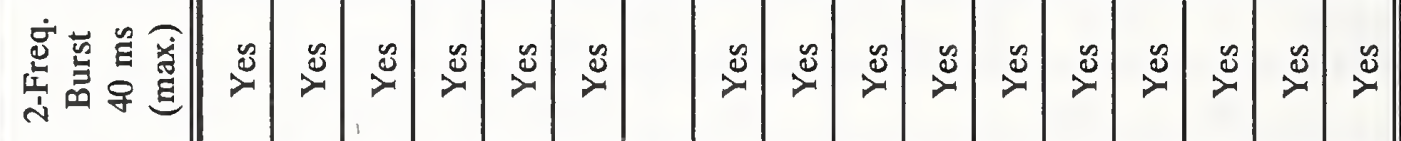

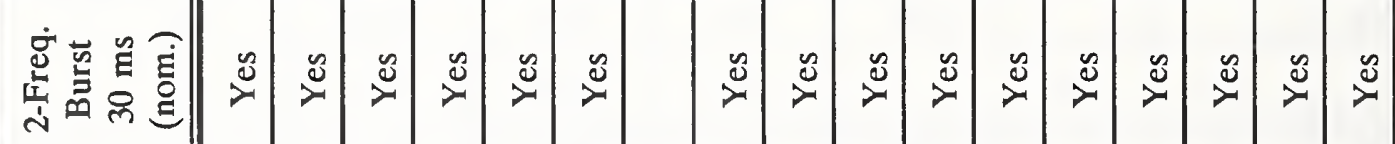

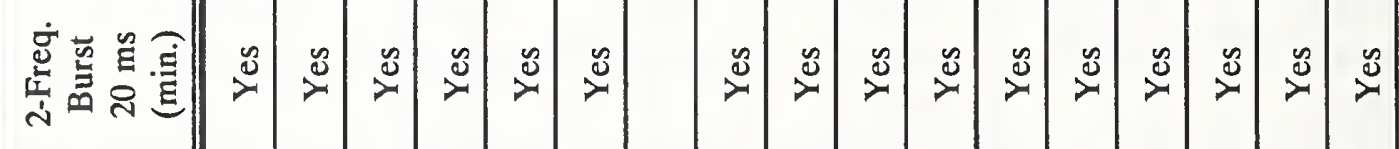

䇺要

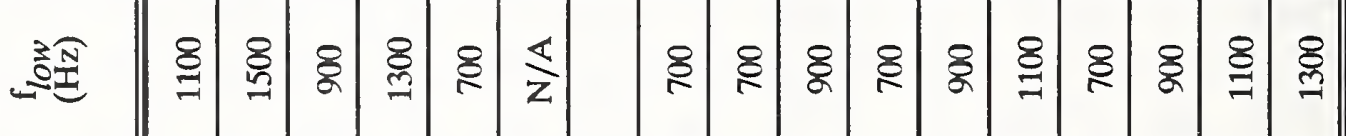

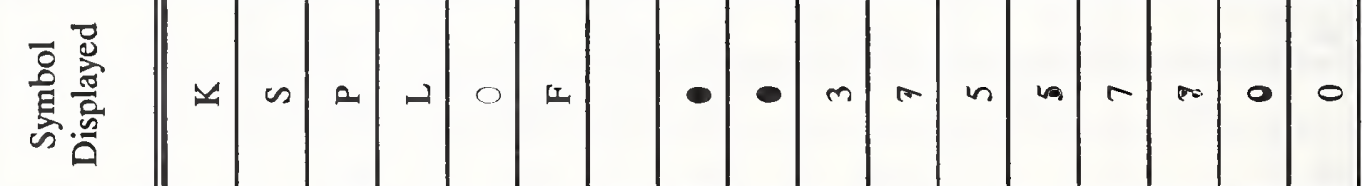

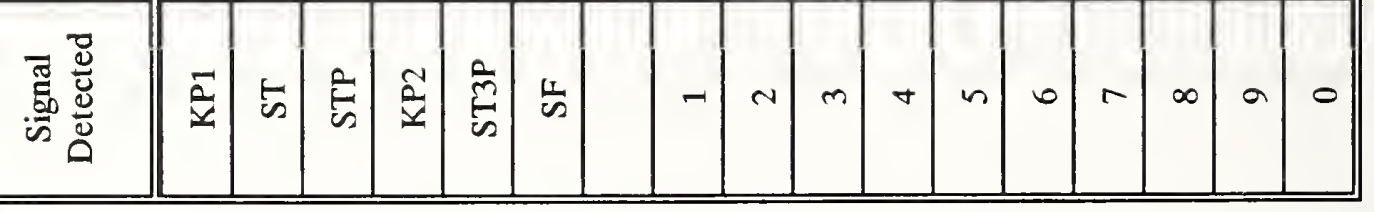




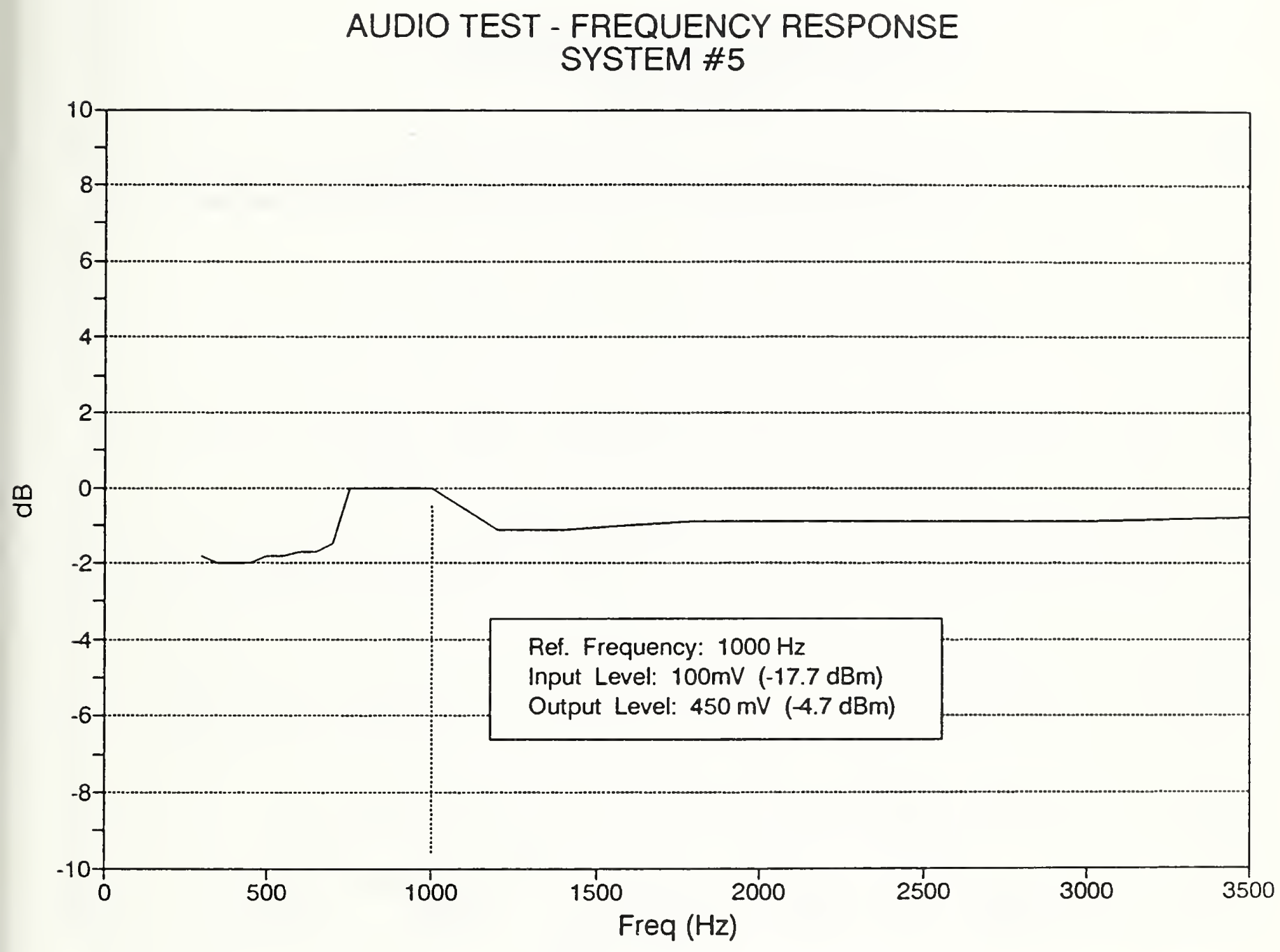




\section{AUDIO TEST - AGC $(1000 \mathrm{~Hz})$ SYSTEM \#5}

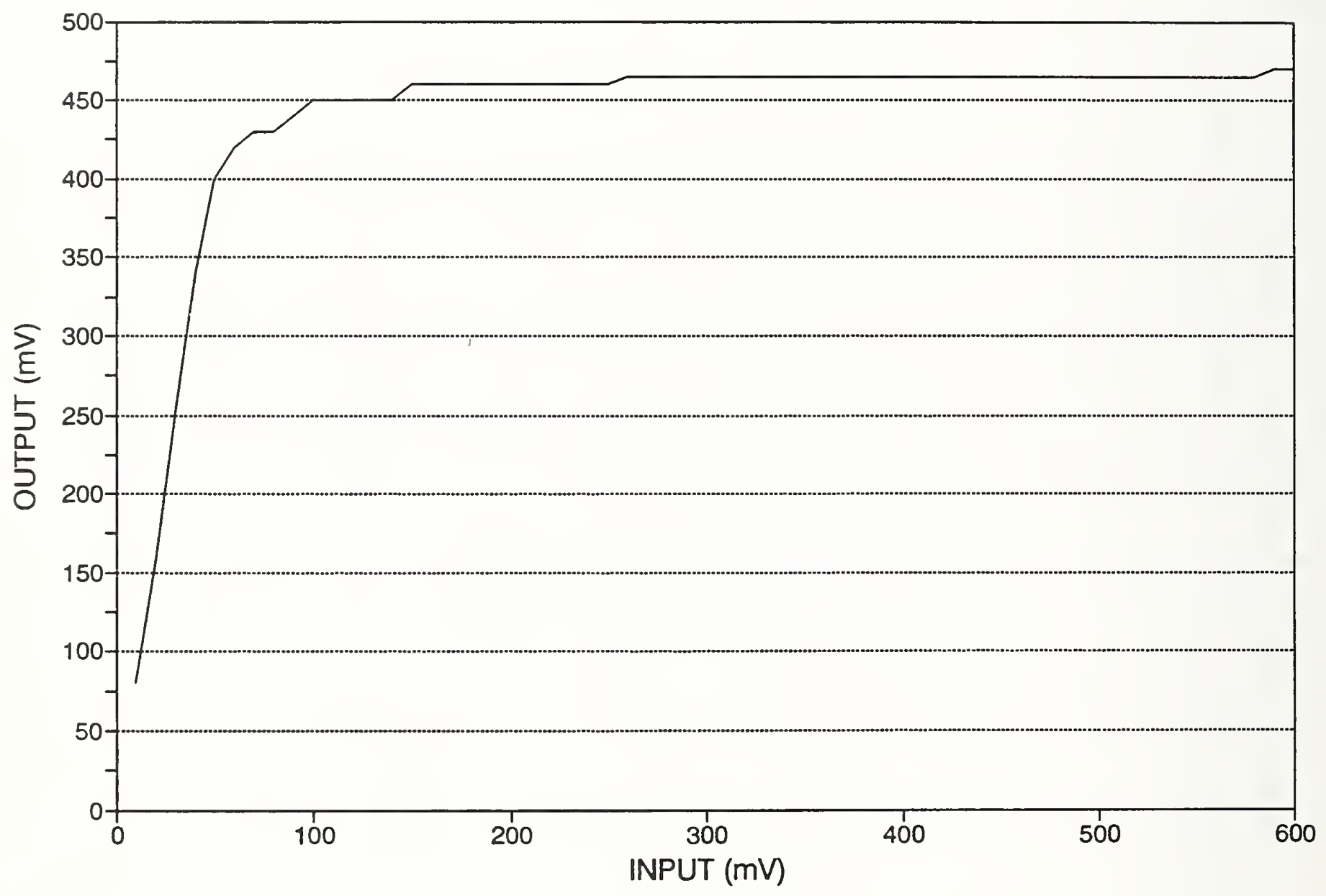


Appendix C - Equipment used for the DNR Evaluation Tests 
Appendix C - Equipment used for the DNR Evaluation Tests

The test equipment used for the evaluation of the five DNRs consisted of the items described below: ${ }^{3}$

- Function Generator, Tektronix FG 503

Although a good audio generator would suffice, this function generator provided a convenient source of low frequency test signals in its sine mode of operation. The following set of specifications are applicable for the tests described herein:

Frequency Range: $1.0 \mathrm{~Hz}$ to $3 \mathrm{MHz}$ ( 0.01 to $5 \mathrm{MHz}$ usable)

Frequency Stability: $\leq 0.5 \%$ of full scale for 24 hrs. (const. temp.)

Output Amplitude: $\geq 20 \mathrm{~V}$ p-p open circuit; $\geq 10 \mathrm{~V}$ p-p into 50 Ohms

Amplitude Flatness: $\pm 0.5 \mathrm{~dB}(20 \mathrm{~Hz}$ to $20 \mathrm{kHz})$

Another FG 503 unit operating in the square wave mode of operation, was used to activate relay $\mathrm{K}$ (see fig. 13), and to control the repetition rate as well as the duty cycle of the generated two-tone signal, by adjusting the square wave duration and period. The applicable specifications are:

Square Wave Rise Time: $\leq 60$ ns

Aberrations: $\leq 3 \%$

- Frequency Counter, Tektronix DC 504

This counter/timer used was to monitor and adjust the test frequencies that were used for the measurement of the DNR input impedance. The unit displays the audio frequency in convenient digital form. It has the basic specification of:

Frequency Resolution: $0.1 \mathrm{~Hz}$ (10 Hz to $1 \mathrm{MHz}, \mathrm{AC}$ coupled)

3 In order to describe the systems and tests described in this report adequately, commercial equipment and instruments are identified by manufacturer's name and/or model number. In no case does such identification imply recommendation or endorsement by the National Institute of Standards and Technology, the National Institute of Justice, or any other government agency, nor does it imply that the material or equipment identified is necessarily the best available for the purpose. 
- Distortion and Noise Meter, Amber 3501

This meter was used to measure the audio circuit parameters of the DNR unit under test, as described in this report. The instrument has three measurement modes: 1) rms voltage, 2) total harmonic distortion (THD), and 3) noise (SNR). In the rms (level) mode, the meter employs a precision rms detector that can accomodate signals with crest factors as as high as 10 , assuring accurate rms indication with signals having distortion and noise. Three types of internal filters provide a high pass $(400 \mathrm{~Hz}, 3 \mathrm{~dB}$ point,) and two low pass ( $30 \mathrm{kHz}$ and $80 \mathrm{kHz}, 3 \mathrm{~dB}$ point) functions that have $18 \mathrm{~dB} /$ octave $(60 \mathrm{~dB} /$ decade) slopes. The following specifications are pertinent for the evaluation tests:

\author{
Maximum/minimum Input Levels: $100 \mathrm{~V}$ rms $/ 0.3 \mu \mathrm{V}$ rms \\ RMS level accuracy: $\pm 2 \%(\sim \pm 0.17 \mathrm{~dB}), 20 \mathrm{~Hz}$ to $20 \mathrm{kHz}$ \\ $60 \mathrm{~Hz}$ power frequency rejection: $>40 \mathrm{~dB}$ (high pass filter) \\ Common Mode Rejection: $\geq 40 \mathrm{~dB}(50 / 60 \mathrm{~Hz})$ \\ THD/SNR accuracy: $\pm 1 \mathrm{~dB}(\sim \pm 12 \%), 20 \mathrm{~Hz}$ to $20 \mathrm{kHz}$ \\ THD/SNR range: 0 to $-70 \mathrm{~dB}$
}

- Oscilloscope, Tektronix 465

This instrument was used to monitor and observe the various test signals in the time domain in conjunction with the Amber $3501 \mathrm{R} / \mathrm{D} / \mathrm{N}$ meter. The basic specifications of this dual channel unit are:

Frequency range: dc to $100 \mathrm{MHz}$

Deflection accuracy: $\pm 3 \%$

Input impedance: $1 \mathrm{M} \Omega$ in paralle1 with $20 \mathrm{pF}$

- Digitizing Oscilloscope, Hewlett-Packard HP 54501A

This oscilloscope was used for the pulsed dialing tests in order to determine the duty cycles, pulse widths, and rise and fall times generated by the pulse trains from both the rotary dial and electronic type telephones. The basic applicable specifications of this four channel unit are:

Frequency range: dc to $100 \mathrm{MHz}$

Input impedance: $1 \mathrm{M} \Omega$ in parallel with $7 \mathrm{pF}$ (nominal) 


$$
\text { - Power supply, HP } 6205 \text { C }
$$

This power supply was used to provide the required dc loop voltage of about $48 \mathrm{~V}$ to both the rotary dial and electronic telephone sets and to the DNR unit under test. The basic specifications of this dual output supply are:

$$
\begin{aligned}
& \text { Output voltage range: } 0 \text { to } 20 \mathrm{~V} \text {, or } 0 \text { to } 40 \mathrm{~V} \\
& \text { Output current range: } 0 \text { to } 0.6 \mathrm{~A} \text {, or } 0 \text { to } 0.3 \mathrm{~A} \\
& \text { Load regulation: } 0.01 \%+4 \mathrm{mV} \\
& \text { Inductor(s), WECO } 1101
\end{aligned}
$$

These devices were used to decouple the power supply circuitry from the audio and pulse signals generated for testing the DNR. The specifications are:

Inductance: $\geq 2 \mathrm{H}$

Resistance: $\leq 400 \Omega$

- RMS voltmeter, Beckman RMS 3030

This rms voltmeter was used during ring level and ring frequency testing where measurements were made at the input and output of an amplifier with a fixed gain of $32 \mathrm{~dB}$ (a factor of 40). The pertinent specifications are:

Normal mode rejection: $>60 \mathrm{~dB}$

Common mode rejection: $>160 \mathrm{~dB}$ up to $1500 \mathrm{~V}$

AC voltage resolution: $200 \mathrm{~V}$ range, $0.1 \mathrm{~V}$

Accuracy: $45 \mathrm{~Hz}$ to $2 \mathrm{kHz}, 0.75 \%+3$ digits

- Teraohm meter, ELTEC 602

This particular meter was used to directly measure the input resistance of the DNRs under test. The unit is battery powered and provides eight measurement ranges that go from $100 \mathrm{k} \Omega$ to $1 \mathrm{~T} \Omega$ by 1 decade per range step. The basic specifications of this meter are:

Accuracy: for full scale $10, \pm 5 \%$

Accuracy: for full scale $3, \pm 2.5 \%$ 


\section{- Test fixtures, NIST made}

Two test fixtures were made up in order to provide for easy and convenient connection of the audio oscillators to the test setup as well as to the control circuitry. Figure 18 on the next page shows how the fixtures were constructed, and figure 13 shows how the components (isolation resistors, relay $K$, and switch $S$ ) interconnect.

\section{- Spectrum analyzer, Hewlett-Packard HP 4195A}

This spectrum analyzer was one of the more important pieces of equipment used during the DTMF and MF tests. The unit is all keypad operated and was programmed to cover an effective audio bandwidth of about $4000 \mathrm{~Hz}$. This analyzer was used to measure the amplitudes of the high and low frequency components of the DTMF and MF signals, as well as to establish the frequency tolerances in the DTMF and MF signal tests described in this report. The applicable specifications are:

$$
\begin{aligned}
& \text { Frequency accuracy: } \pm 20 \mathrm{ppm} \\
& \text { Resolution bandwith accuracy: } \pm 10 \% \\
& \text { Amplitude measurement accuracy: } \pm 1 \mathrm{~dB}
\end{aligned}
$$

Additional details about the above equipment can be found in manufacturers' operating manuals and technical literature. 


\section{IMPEDANCE MATCHING AND SIGNAL SUMMING FIXTURE}

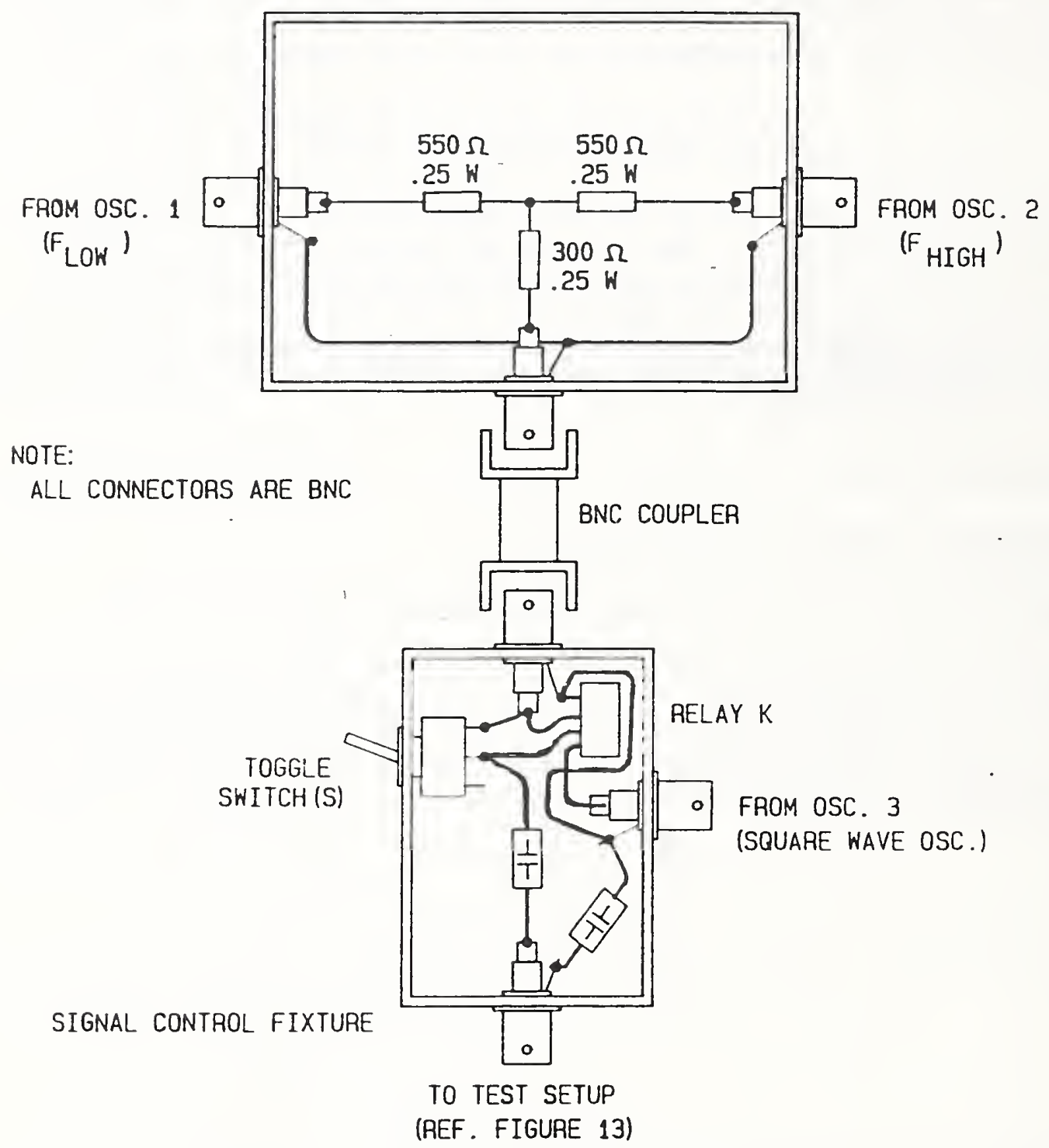

Figure 18. Test fixture used for DTMF and MF signal tests 


\begin{tabular}{|c|c|c|}
\hline \multirow[t]{3}{*}{$\begin{array}{l}\text { NIST-114A } \\
\text { (REV. 3-90) }\end{array}$} & \multirow{3}{*}{$\begin{array}{l}\text { U.S. DEPARTMENT OF COMMERCE } \\
\text { NATIONAL INSTITUTE OF STANDARDS AND TECHNOLOGY } \\
\text { BIBLIOGRAPHIC DATA SHEET }\end{array}$} & $\begin{array}{l}\text { 1. PUBLCATION OR REPOAT NUMBEA } \\
\text { NISTIR } 4700\end{array}$ \\
\hline & & 2 PERFORMINO ORQANIZATION REPORT NUMBER \\
\hline & & $\begin{array}{l}\text { 3. PUBUCATION DATE } \\
\text { OCTOBER } 1991\end{array}$ \\
\hline
\end{tabular}

4. TITLE AND SUBTITLE

Performance Evaluation of Dialed Number Recorders

5. AUTMOR(S)

Arnold G. Perrey and Barry A. Bell

6. PERFORMING ORGANIZATION (IF JOINT OA OTHER THAN MIST, SEE INSTRUCTIONS

U.S. DEPARTMENT OF COMMERCE

MATIONAL INSTITUTE OF STANDARDS AND TECHNOLOQY

CAITHERSBURG, MD 20890

7. CONTRACT/ORANT NUMBER

8. TYPE OF REPORT AND PERIOO COVERED

9. SPONSORINO ORGANIZATION MAME AND COMPLETE ADDRESS (STREET, CITY, STATE, ZIP)

10. SUPPLEMENTARY NOTES

11. ABSTRACT (A 200-WORD OA LESS FACTUAL SUMMAAY OF MOST SIONIFICANT INFORMATION. IF DOCUMENT INCLUDES A SIGNIFICANT BIBUOGAAPHY OA ITSERATURE SURVEY, MENTION IT MERE)

Dialed Number Recorders (DNRs) are used by local law enforcement agencies and by various federal agencies in order to prevent communication fraud as well as other violations of federal, state, and regional laws. This report describes methods and procedures used for testing the performance of DNRs with ordinary laboratory-type test equipment, i.e., without using sophisticated telephone-type test equipment. Five such DNRs were tested in order to measure their operational characteristics, which are given in this report.

12. KEY WORDS (6 TO 12 ENTAIES; ALPHABETICAL OADER; CAPITALZE ONLY PAOPER MAMES; AND SEPARATE KEY WOADS BY SEMICOLONS)

communication; detection; dialed number recorder; recording; interception;

pen register; signaling; secrity; monitoring

13.

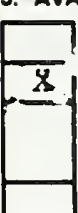

LNUMTTED

rOR OFFICLAL DISTRIBUTION. DO NOT RELEASE TO MATIONAL TECHNICAL INFORMATION SERVICE (NTIS).

ORDER FROM SUPERINTENDENT OF DOCUMENTS, U.S. COVERNMENT PRINTING OFFICE,

WASHINGTON, DC 20402.

ORDER FROM MATIONAL TECHMICAL IMFORMATION SERVICE (NTIS), SPRINGFIELD, VA 22161.

14. MUMBER OF PRINTED PAGES

79

15. PRICE 


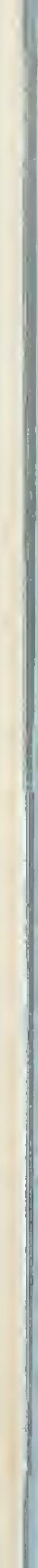



